\title{
UICN
}

Directrices relativas a la biodiversidad para la evaluación de oportunidades de restauración de paisajes forestales

Craig R. Beatty, Neil A. Cox y Mirjam E. Kuzee 



\section{Directrices relativas a la biodiversidad para la evaluación de oportunidades de restauración de paisajes forestales}

Craig R. Beatty, Neil A. Cox y Mirjam E. Kuzee

Primera edición 
La designación de entidades geográficas expuesta en este informe y la presentación del material no implican la expresión de opinión alguna por parte de la UICN con respecto al estatuto jurídico de cualquier país, territorio o zona, o de sus autoridades, ni en lo referente a la delimitación de sus fronteras o límites.

Los puntos de vista expresados en esta publicación no reflejan necesariamente los de la UICN.

Esta publicación ha sido posible gracias al programa KNOWFOR, financiado a través de una ayuda del Gobierno del Reino Unido, y al Ministerio del Clima y el Medio Ambiente de Noruega.

La UICN y las organizaciones participantes declinan cualquier error u omisión en la traducción de este documento de la versión original en ingles al español. En caso de discrepancia, remítase, por favor, a la edición original. Título de la edición original: Biodiversity guidelines for forest landscape restoration opportunities assessments. First edition. (2018). Publicado por: UICN, Gland, Suiza.

Publicado por: $\quad$ UICN, Gland, Suiza.

Copyright: $\quad$ C 2018 UICN, Unión Internacional para la Conservación de la Naturaleza y de los Recursos Naturales.

Se autoriza la reproducción de esta publicación con fines educativos u otros de carácter no comercial sin necesidad de obtener el consentimiento previo por escrito del titular de los derechos de autor siempre que se cite íntegramente la fuente.

Se prohíbe la reproducción de esta publicación para su venta u otros fines comerciales si no se obtiene el consentimiento previo por escrito del titular de los derechos de autor.

El informe debe

citarse como sigue: Beatty, C.R., Cox, N. A., y M. E. Kuzee (2018). Directrices relativas a la biodiversidad para la evaluación de oportunidades de restauración de paisajes forestales. Primera edición. Gland, Suiza: UICN. v + 43 pp.

ISBN:

978-2-8317-1928-3 (PDF)

DOI:

https://doi.org/10.2305/IUCN.CH.2018.10.es

Foto de portada: $\quad$ Los soliga son un pueblo tribal indígena de las colinas de Biligiri Rangana, en el sur de la India. Es posible que se encontraran entre los primeros seres humanos que se asentaron en lo que hoy es la India. Los soliga son un pueblo que depende de los bosques. Las plantas silvestres son un elemento fundamental en su dieta, especialmente un plato elaborado a base de kaddisoppu (Jasminum trichotomum), una planta endémica de los bosques deciduos secos (no se muestra en la foto). Foto utilizada por cortesía de Oxlaey

Layout:

www.chadiabi.com

Traducción : $\quad$ Prime Production Ltd., Londres, Reino Unido

Disponible a través de:

UICN (Unión Internacional para la Conservación de la Naturaleza), Programa Global de Bosques y Cambio Climático

Rue Mauverney 28

1196 Gland, Suiza

Tel.: +41229990000

Fax: +41229990002

Craig.Beatty@iucn.org

www.iucn.org/resources/publications 
Agradecimientos

Resumen ejecutivo

\section{- Primera parte}

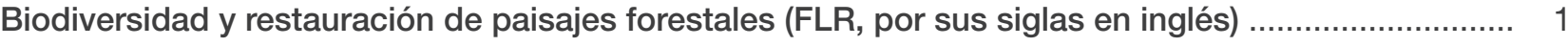

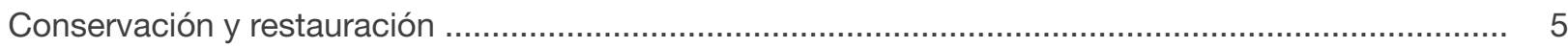

Biodiversidad genética para la restauración de paisajes forestales .......................................... 5

Biodiversidad de las especies y restauración de paisajes forestales ................................................ 5

La restauración de paisajes forestales y los ecosistemas ........................................................... 7

- Segunda parte

La biodiversidad en la planificación de evaluaciones de la restauración de paisajes forestales .......... 11

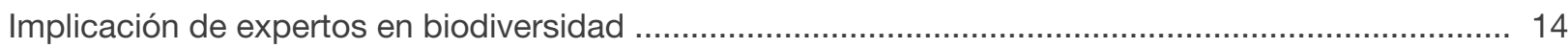

Seguimiento de los efectos de la FLR sobre la biodiversidad y las comunidades ..............................15

Información sobre la biodiversidad de cara al proceso de evaluación .............................................. 17

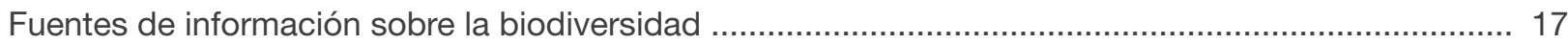

- Datos y contactos existentes en materia de biodiversidad a nivel nacional .............................. 17

- Algunos conjuntos de datos nacionales clave sobre la biodiversidad ................................... 17

Estrategias nacionales sobre la biodiversidad y planes de acción (ENBPA) .................................... 18

- Cómo extraer información pertinente sobre la biodiversidad de las ENBPA ................................ 18

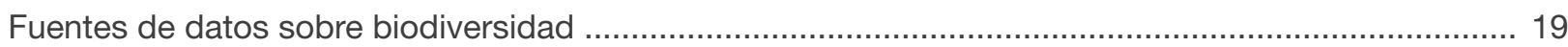

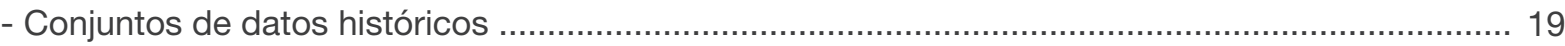

- Especies y lugares importantes desde el punto de vista cultural ..............................................20

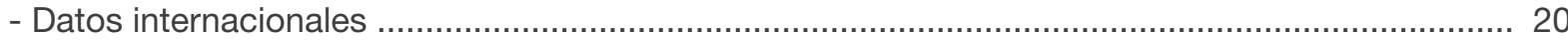

Información normativa e institucional referente a la biodiversidad .............................................. 22

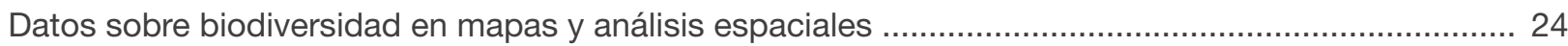

Identificación de carencias en materia de biodiversidad ............................................................ 27

Consideración de la biodiversidad en las evaluaciones y la planificación de la FLR ..........................27

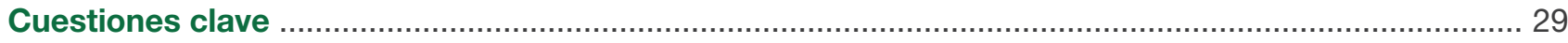

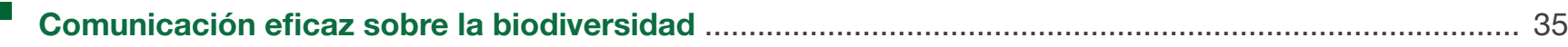

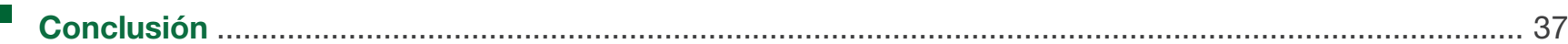

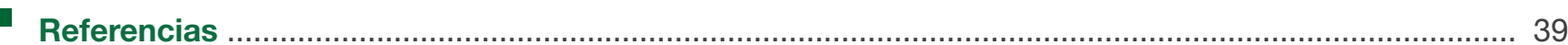

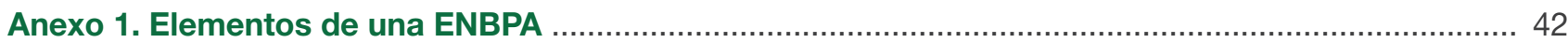




\section{Agradecimientos}

Esta publicación sienta las bases para alentar a un mayor reconocimiento del valor de incluir información sobre la biodiversidad en las evaluaciones de las oportunidades de restauración de paisajes forestales y en la ejecución de las acciones de restauración. Este trabajo no habría sido posible sin el generoso apoyo del Departamento de Desarrollo Internacional del Reino Unido en el marco del Programa de Conocimiento sobre los Bosques (Knowledge on Forests).

Swati Hingorani proporcionó orientaciones y un apoyo excepcionales en las fases de concepción y redacción de las presentes directrices. Queremos expresar asimismo nuestro profundo agradecimiento a Chetan
Kumar, Salome Begeladze, James McBreen, Adriana Vidal y Carole Saint-Laurent por sus constructivas recomendaciones a medida que avanzaba la publicación.

Los autores aprecian el aliento de Jean-Christophe Vié (ex miembro del Programa Global de Especies y Áreas Clave para la Biodiversidad de la UICN) y Frank Hawkins (de la oficina de la UICN en Washington, D.C.), sobre todo durante la fase de diseño del proyecto.

Asimismo, deseamos agradecer los esfuerzos de dos revisores externos que contribuyeron a mejorar notablemente estas directrices. 


\section{Resumen ejecutivo}

La biodiversidad es inherente a la restauración de paisajes forestales. Las iniciativas mundiales, como el Desafío de Bonn o la Declaración de Nueva York sobre los Bosques, inspiran a las naciones a tratar de fomentar unos paisajes y un crecimiento económico sostenibles; sobre el terreno, la biodiversidad vincula a los pueblos y la naturaleza con su futuro compartido. La restauración con visión prospectiva, con el fin de hacer frente a los desafíos paisajísticos presentes y futuros, requiere enfoques novedosos y soluciones basadas en la naturaleza. La restauración puede generar una rentabilidad económica enorme y mitigar muchos de los efectos del cambio climático inducidos por el hombre. Sin embargo, la función nuclear de la restauración debería ser apoyar la biodiversidad y las especies, los genes y los ecosistemas de los que se compone, y que prestan servicios a la humanidad, ya sea de manera directa o indirecta.

\section{Estas Directrices relativas a la biodiversidad para la evaluación de oportunidades de restauración de paisajes forestales pretenden ofrecer un mayor contexto, más recursos y perspectivas innovadoras a la interacción global en curso entre la conservación de la biodiversidad y la restauración de paisajes forestales. $Y$ todo ello en el contexto de una metodología utilizada por docenas de países y jurisdicciones, con el objetivo de ayudar a los profesionales que trabajan en la identificación y el logro de sus objetivos en el ámbito de la restauración de paisajes. De hecho, las directrices que se ofrecen en este documento deberían considerarse complementarias a la Metodología de Evaluación de Oportunidades de Restauración (ROAM).}

Entre el Desafío de Bonn, el Convenio sobre la Diversidad Biológica, los Objetivos de Desarrollo Sostenible y las puntuaciones que proporcionan otras iniciativas internacionales, regionales y nacionales, la conservación y restauración de la biodiversidad sigue siendo un precursor claro y constante de la prosperidad económica y social a largo plazo. Hasta fechas muy recientes, la biodiversidad y las iniciativas de restauración se han desarrollado en paralelo persiguiendo, en buena medida, idénticos objetivos. Las directrices siguientes ayudarán a aquellas personas que tienen un mandato o interés relacionado con la biodiversidad o con la restauración a armonizar su vocabulario y su trabajo.
En la sección 1 se definen el contexto y los principios de la restauración de paisajes forestales, y se explican brevemente las conexiones que existen entre la conservación de la biodiversidad y la restauración de paisajes. A continuación, profundiza en los componentes genéticos, de especies y ecosistémicos de la biodiversidad y su relación con la restauración de paisajes forestales; incluye una exposición sobre los puntos de partida para la medición de la biodiversidad y la visión paisajística requerida para la restauración a escalas cada vez más amplias. Un aspecto importante es que esta sección proporciona una base necesaria para quienes puedan considerar la restauración de paisajes forestales como un ejercicio de plantación de árboles, y demuestra que merece la pena adoptar un enfoque integral que busque un equilibrio entre las necesidades de la población y la naturaleza.

La sección 2 propone varios métodos para introducir la biodiversidad en el proceso de evaluación de la restauración de paisajes forestales. Incluye fuentes de información y de datos sobre la biodiversidad, cómo encontrar información sobre la biodiversidad cuando parece inexistente, una serie de ideas iniciales sobre cómo identificar la biodiversidad, así como la importancia de no considerar la biodiversidad únicamente desde la perspectiva biológica, sino en términos de políticas, leyes y misiones institucionales. En esta sección, los lectores encontrarán gran cantidad de recursos y contactos que les permitirán garantizar que la falta de disponibilidad de información no sea el motivo por el que no se incluya la biodiversidad en sus evaluaciones.

Por último, estas directrices buscan ayudar a los profesionales a traducir y comunicar la importancia de su trabajo en un contexto de biodiversidad, así como contribuir a integrar la cuestión de la biodiversidad en otros sectores. El resultado debería ser un proceso de evaluación que identifique de manera explícita diferentes opciones para la elección de especies y la interacción entre ellas en un paisaje con objeto de generar los beneficios biológicos, sociales y ecológicos que constituyen el propósito de la restauración. Las estrategias paisajísticas que resulten de esta inclusión explícita de conocimientos científicos y tradicionales en materia de biodiversidad garantizarán en gran medida que las importantes sumas invertidas en la restauración de paisajes forestales puedan ofrecer una rentabilidad que respalde la increíble diversidad de la vida y la cultura. 

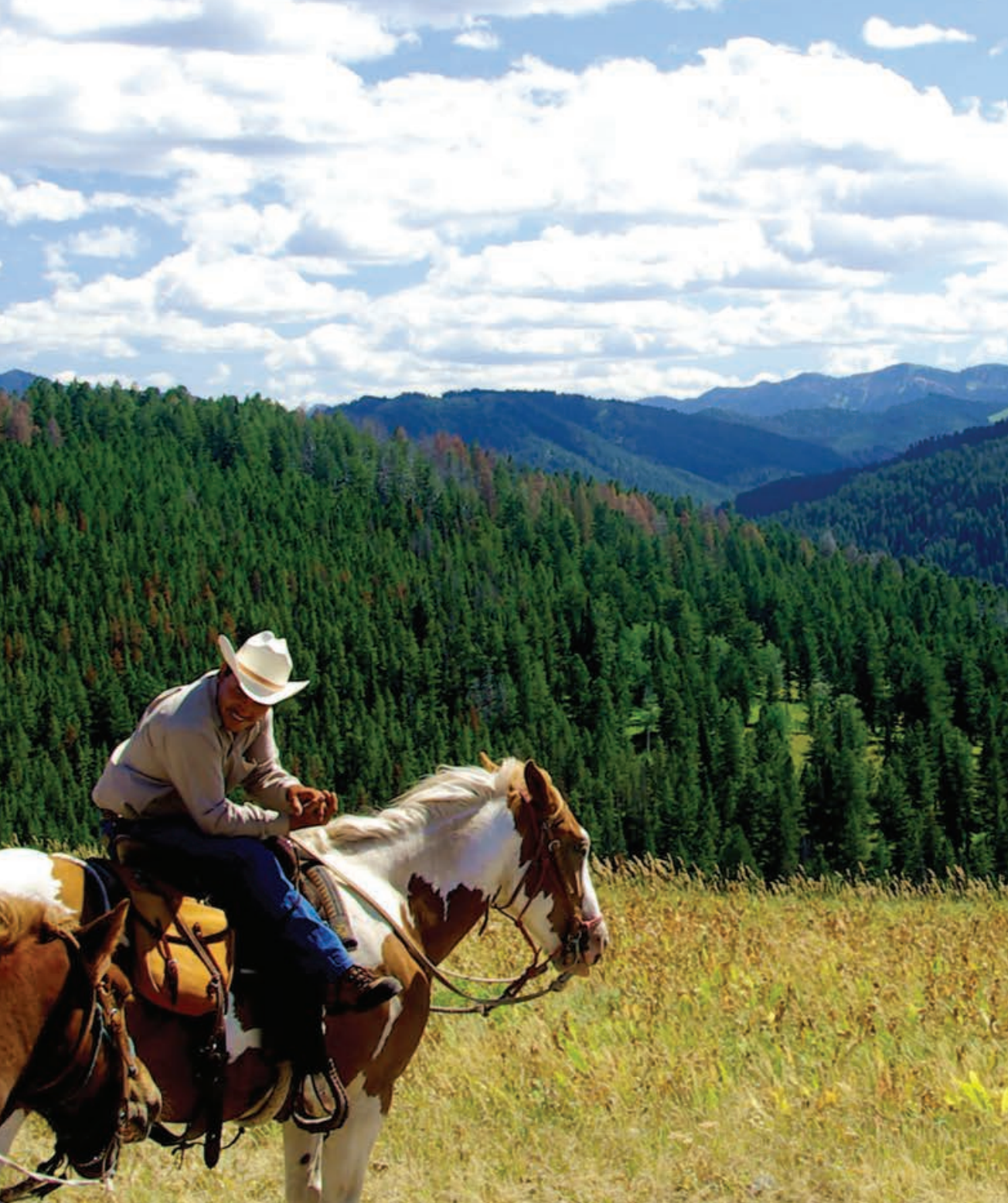

\section{Primera parte}

\section{Biodiversidad y restauración de paisajes forestales}


La restauración de paisajes forestales (FLR) es el proceso a largo plazo consistente en recuperar las funciones ecológicas y mejorar el bienestar humano en los paisajes deforestados y degradados; todavía hoy, continúa siendo una iniciativa clave para mantener o restaurar la biodiversidad. La FLR se ejecuta mediante un enfoque paisajístico que combina la gestión de recursos humanos y las consideraciones relativas a las oportunidades de restauración y a los medios de vida a través de los límites o fronteras entre jurisdicciones, con el objetivo de restaurar todo un mosaico de usos del suelo, incluidos los bosques, las zonas arboladas, los pastos, las tierras de cultivo, etc. A escala del paisaje, la restauración da respuesta a las necesidades sociales y posibilita la consideración de los múltiples beneficios que ofrecen los servicios ecosistémicos desde el punto de vista de la alimentación, la nutrición y la seguridad hídrica; fomenta la justicia social y la actividad empresarial en el ámbito local; respalda el desarrollo rural y las economías nacionales; y genera resiliencia frente a los desastres y al cambio climático. La restauración de los paisajes degradados y deforestados proporciona servicios ecosistémicos de aprovisionamiento que resultan fundamentales (como alimentos, leña y recursos genéticos), así como servicios reguladores (regulación del clima, ciclo de nutrientes y reconstrucción del suelo, regulación y purificación del agua, polinización) y culturales (espirituales, religiosos, recreativos, educativos y otros que contribuyen a crear un sentimiento de pertenencia); además, pueden proporcionar un hábitat muy necesario para las especies amenazadas, ya que un elevado porcentaje de las especies incluidas en la Lista Roja de Especies Amenazadas de la UICN se ven amenazadas por la pérdida o degradación de sus hábitats (Mace et al., 2005; UICN, 2018). Por lo general, estos importantes servicios se sustentan en la riqueza biológica de los paisajes; cada vez existen más pruebas que demuestran que el aumento de la biodiversidad es

La restauración de paisajes forestales (FLR) es el proceso a largo plazo consistente en recuperar las funciones ecológicas y mejorar el bienestar humano en las tierras deforestadas y degradadas. En última instancia, persigue restaurar "los bienes, servicios y procesos ecológicos que los bosques pueden proporcionar a nivel paisajístico, frente a la mera promoción del incremento de la cobertura arbórea en un determinado emplazamiento" (Maginnis y Jackson, 2002).

La restauración de paisajes forestales se apoya en varios principios rectores:

- Restaurar la funcionalidad: recuperar las funciones del paisaje, mejorando su capacidad para ofrecer un hábitat rico, prevenir la erosión y las inundaciones y resistir los efectos del cambio climático y otras perturbaciones.

- Se centra en los paisajes: se analiza la posibilidad de restaurar paisajes enteros, no emplazamientos individuales. Por lo general, esto implica la búsqueda de un equilibrio entre todo un mosaico de usos del suelo interdependientes, que incluyen, con carácter no limitativo, los siguientes: agricultura, zonas protegidas, sistemas agrosilvícolas, plantaciones forestales adecuadamente gestionadas, corredores ecológicos, plantaciones ribereñas y áreas reservadas para la regeneración natural.

- Posibilitar el logro de múltiples beneficios: el objetivo es generar un conjunto de bienes y servicios ecosistémicos mediante una introducción inteligente y adecuado de árboles y otras plantas leñosas en el paisaje. Esto puede conllevar la plantación de árboles en terrenos agrícolas con objeto de mejorar la producción de alimentos, reducir la erosión, proporcionar sombra y producir leña; también se pueden plantar árboles para crear un bosque con dosel cerrado que absorba grandes cantidades de carbono, proteja el suministro de agua corriente abajo y proporcione un hábitat con abundante fauna y flora silvestres.

- Emplear diversos tipos de estrategias: se deberá estudiar la posibilidad de utilizar diversas clases de estrategias técnicas posibles para restaurar los árboles del paisaje, desde la regeneración natural hasta la plantación.

- Involucrar a las partes interesadas: tratar de que las partes interesadas locales participen activamente en las decisiones relacionadas con los objetivos de restauración, los métodos de implementación y el equilibrio entre unos objetivos y otros. Los procesos de restauración deben respetar los derechos de estos agentes sobre la tierra y los recursos, estar en consonancia con sus prácticas de gestión del suelo y proporcionarles beneficios.

- Adaptar las estrategias a las condiciones locales: adaptar las estrategias de restauración de manera que respondan adecuadamente a los contextos sociales, económicos y ecológicos locales; no existe una solución universalmente válida para todo tipo de entornos.

- Evitar una reducción mayor de la cubierta forestal natural o de otros ecosistemas naturales: combatir la pérdida constante y evitar una mayor conversión de bosques naturales primarios y secundarios, así como de otros ecosistemas.

- Adaptar los modelos de gestión: es necesario prepararse para adaptar la estrategia de restauración a lo largo del tiempo, conforme cambien las condiciones medioambientales, el conocimiento y los valores sociales. Deberá llevarse a cabo un seguimiento y aprendizaje continuados e introducir los ajustes necesarios a medida que avance el proceso de restauración. 


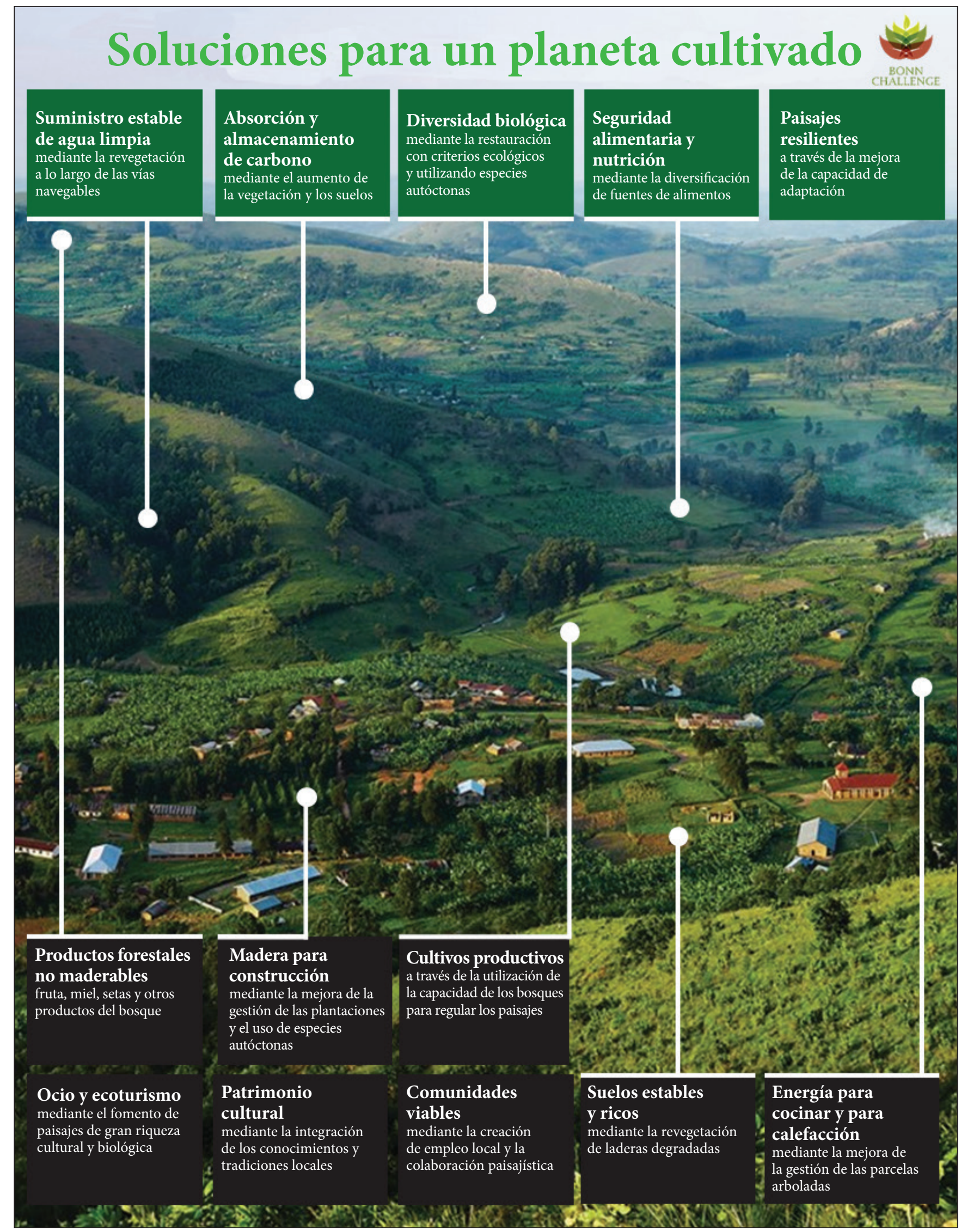


directamente proporcional tanto a la cantidad (funciones) y la "estabilidad" general" (resiliencia ambiental) de los servicios ecosistémicos prestados a la población (Hooper et al., 2005; Hooper et al., 2012; Cardinale et al., 2012; Larsen et al., 2012; Oliver et al., 2015a; Oliver et al., 2015b; Walker y Salt, 2006).

En la mayoría de los paisajes se puede llevar a cabo la FLR para la conservación y restauración de la biodiversidad. A escala mundial, los bosques albergan más del $75 \%$ de la biodiversidad terrestre (FAO, 2016) y siguen constituyendo una fuente muy importante para el hallazgo de numerosas especies todavía desconocidas y no descritas. Muchos animales y plantas son especies forestales autóctonas que no existen fuera de esos hábitats. Hasta el momento, la Lista Roja de Especies Amenazadas de la UICN clasifica como "en peligro de extinción" alrededor del $29 \%$ de las especies forestales evaluadas (UICN, 2018). La restauración de los paisajes deforestados y degradados puede detener y revertir la extinción de especies de diversas maneras. Además, el aumento del número de árboles y especies en las tierras de cultivo o en los sistemas silvopastorales puede reconstruir el suelo y mejorar la disponibilidad de agua para los cultivos en áreas de secano; esto permite adoptar estrategias de subsistencia diversificadas cuyo objetivo es recuperar y conservar los árboles y, al mismo tiempo, aumentar la producción agrícola y ganadera.
Pese a que los beneficios que ofrece la restauración para la biodiversidad pueden ser implícitos y son importantes, la restauración de los paisajes dirigida a mejorar el bienestar humano también generará beneficios sociales explícitos y cuantificables cuando la conservación y la restauración de la biodiversidad se convierta en un componente explícito del diseño, la planificación y la evaluación del potencial de restauración de paisajes forestales (la "evaluación de oportunidades de restauración").

El objetivo de esta publicación es ofrecer a los profesionales que trabajan en el ámbito de la FLR, la planificación de la restauración de paisajes y los responsables de la adopción de decisiones una serie de directrices sobre cómo integrar mejor el conocimiento y los datos disponibles sobre la biodiversidad en las oportunidades para la FLR y sus evaluaciones, y justificar por qué este enfoque tiene sentido. La intención de los autores es ofrecer orientaciones a los profesionales para cumplir un mandato de (o satisfacer un interés en) incluir los conocimientos y la información sobre la biodiversidad en el proceso de evaluación y planificación de la FLR. El documento describe por qué debe incluirse la biodiversidad en la FLR, algunas fuentes habituales de información y datos relativos a la biodiversidad, el proceso de comunicación de la información sobre la biodiversidad en el marco de las

\section{Una nota importante sobre los niveles iniciales de referencia}

Quedan pocos lugares en el mundo en los que las especies no se hayan visto afectadas por la actividad humana. Teniendo esto presente, la diversidad y abundancia de especies suelen evaluarse desde una visión actual (Antropoceno) de las bases iniciales de referencia que se consideran como un nivel aceptable de abundancia de especies y cambio de la composición comunitaria, o del estado de conservación de los hábitats y especies.

Sin embargo, de los aproximadamente 2 millones de especies descritas, la UICN tan solo ha evaluado el estado de conservación de 87.000, y continúan existiendo importantes lagunas taxonómicas en la evaluación del estado de conservación de las especies a escala mundial. Poco o nada se sabe sobre la diversidad y la abundancia de la mayoría de las especies de invertebrados, pese a que muchas de ellas son la base en la que se sustentan todos los ecosistemas. A pesar de esta falta de conocimiento, las drásticas reducciones que sufre la biodiversidad obligan a los profesionales a utilizar la escasa información que existe para detener este proceso.

En los últimos 250 años han desaparecido numerosas especies en hábitats salvajes, y en los últimos 50 se han producido pérdidas significativas de especies y hábitats. Lo que hoy parece abundante puede estar muy por debajo de los niveles de población históricos de una determinada especie. El resultado es una cantidad cada vez mayor de personas que dependen de un conjunto cada vez menor de especies para recibir los servicios en los que se apoyan las culturas, sociedades y economías humanas, y de los que todavía dependen en gran medida. Es fundamental establecer referencias iniciales para la comparación y, cuando sea posible, estas deberán estar basadas en un análisis de tendencias de las poblaciones de las especies o de la dimensión de los hábitats y ecosistemas adecuados para ellas, sobre todo de aquellos que puedan verse afectados por el cambio climático.

1. Existe un amplio reconocimiento en torno al hecho de que los ecosistemas no son sistemas estáticos, sino dinámicos. Por lo tanto, aunque por lo general no es correcto utilizar el término "estabilidad" para referirse a los ecosistemas, en este documento se utilizará de manera genérica con el fin de guiar a los lectores con menor especialización técnica. 
evaluaciones de la FLR y cómo se pueden constituir asociaciones para la ejecución de proyectos con el fin de atender mejor a la conservación y la restauración de la biodiversidad. Se recomienda vivamente utilizar estas directrices junto con la Metodología de Evaluación de Oportunidades de Restauración (ROAM), publicada por la UICN en colaboración con WRI (2014); dicha metodología proporciona un marco más amplio para el proceso de evaluación de la FLR y un conjunto de productos analíticos típicos.

\section{Conservación y restauración}

Existe un amplio corpus científico y bibliográfico dedicado a la conservación de las especies y ecosistemas establecidos. Sin embargo, la restauración de la biodiversidad en los lugares en los que ha experimentado una reducción o en los que prácticamente ha desaparecido no recibe tanta atención. La restauración de la biodiversidad no consiste simplemente en introducir especies y ecosistemas, sino también en la restauración o conservación de los procesos que generan biodiversidad. Consiste en procesos ecológicos capaces de crear biodiversidad y conservarla, y, para que tenga éxito, la restauración debe tener en cuenta y apoyar los patrones de la biodiversidad y sus procesos (Pressey et al., 2007). La literatura disponible sobre la restauración ecológica es cada vez más amplia, y por lo general esta joven disciplina pone el foco en la restauración de sistemas ecológicos degradados para crear un ecosistema o una trayectoria de sucesión de referencia (Young, 2000). Esto conlleva apoyar la reintroducción de especies y procesos ecológicos que, con el tiempo, interactuarán para crear ecosistemas restaurados u orientarán las interacciones entre las especies y los conjuntos de estas hacia las fases de sucesión deseadas. La restauración en pos de un ecosistema de referencia puede resultar más adecuada en el caso de determinados paisajes y para lograr ciertos objetivos de restauración (como la reintroducción o conservación de especies), sobre todo cuando lo que se pretende es restaurar zonas degradadas y deforestadas para devolverlas a su estado anterior. Para estos objetivos, la restauración ecológica constituye un enfoque valioso y necesario. En el marco de la FLR, la restauración ecológica representa un importante componente del conjunto de estrategias de restauración de las que disponen los profesionales dedicados a esta materia. La FLR utiliza numerosas actuaciones de restauración adicionales en los paisajes, con objeto de asegurar que la intervención se centre en integrar numerosos objetivos y tipos de uso del suelo sostenibles a fin de abordar los impulsores y los factores de presión que condujeron en primera instancia a la degradación.

La restauración de paisajes forestales implica la recuperación a largo plazo de la productividad ecológica, que está basada en una trayectoria ecológica sostenible y diversa desde el punto de vista biológico. Esta trayectoria se desarrolla a partir de las interacciones entre los tres principales componentes de la biodiversidad: genes, especies y ecosistemas. Sin embargo, en la práctica, a menudo se conceptualiza fuera de una perspectiva ecológica. En consecuencia, la diversidad genética, ecosistémica y de las especies en las evaluaciones y la planificación de la restauración de paisajes forestales se integran a menudo en el debate sobre la productividad agrícola, la resiliencia del paisaje o la capacidad de adaptación al cambio climático. Si bien cada uno de estos aspectos representa nobles interpretaciones, en su nivel más fundamental cada una de ellas depende de los bienes y servicios que prestan las especies y de sus redes de interacción en el seno de los ecosistemas. Las secciones que siguen se centran en analizar cómo pueden los profesionales traducir estos conceptos.

\section{Biodiversidad genética para la restauración de paisajes forestales}

La diversidad genética de las especies es una de las consideraciones más importantes en lo que atañe a la restauración de paisajes. Esta afirmación es cierta tanto para las especies agrícolas (por ejemplo: especies agrosilvícolas, tipos de cultivos y razas de ganado) como para las especies autóctonas utilizadas en las actividades de restauración. La diversidad genética confiere una mayor protección frente a las enfermedades y ayuda a garantizar que los servicios ecosistémicos presentes en el paisajes sean resilientes al cambio climático. La diversidad genética es la primera línea de defensa en la creación de paisajes y economías agrícolas resilientes, y es la moneda que utilizan las especies para mejorar su capacidad para adaptarse y sobrevivir al cambio climático.

Una consideración muy importante en el diseño de estrategias de restauración debería ser garantizar que la diversidad genética intraespecífica de la biomasa de restauración dentro del paisaje degradado que se vaya a restaurar sea lo más variada posible (dentro de los límites de los recursos disponibles). Si se utilizan monocultivos de individuos prácticamente idénticos desde el punto de vista genético, o clonados, para las iniciativas de restauración, estarán por lo general más expuestos a sufrir daños o pérdidas como consecuencia de sucesos estocásticos, como las enfermedades o la endogamia. Un paisaje o hábitat que presente una mayor diversidad genética tiene normalmente una probabilidad mucho mayor de contener individuos con resistencia parcial o total a un suceso amenazante (véase, por ejemplo, Reusch et al., 2005).

A la hora de buscar individuos o especies para llevar a cabo una intervención de restauración (sobre todo si se trata de semillas o plántulas), resulta útil tratar de obtener material cuya procedencia sea la misma o similar a la de las poblaciones existentes (o que existieron anteriormente) en el paisaje que se vaya a restaurar. Por lo general, esos individuos se encuentran genéticamente mejor adaptados a las condiciones ambientales (como los patrones meteorológicos locales, por ejemplo) del paisaje en cuestión que otros ejemplares obtenidos de poblaciones externas o más distantes. Si la restauración consiste en una 
intervención agrosilvícola, será útil estudiar asimismo la posibilidad de utilizar o fomentar variedades de cultivo locales (árboles incluidos) porque, como ocurre con las plantas autóctonas de procedencia local, esas variedades locales suelen estar mejor adaptadas a las condiciones ambientales locales y pueden tener una mayor capacidad de adaptación al cambio climático.

\section{Biodiversidad de las especies y restauración de paisajes forestales}

Las especies representan la unidad ecológica fundamental, por lo que constituyen el medio a través del que se propaga la diversidad genética y ecosistémica. Los procedimientos de evaluación y ejecución de la restauración de paisajes se nutren de las diferentes oportunidades para expresar la elección de las especies que se utilizarán en las actividades de restauración. La oportunidad de escoger especies para la restauración surge cuando los profesionales identifican una acción de restauración deseada, evalúan con detalle de qué modo dicha acción puede detener o ralentizar la degradación del paisaje, estiman cómo puede la restauración generar productividad ecológica y determinan el momento en que los planes de restauración cosecharán sus primeros frutos sobre el terreno.

En paisajes dominados por la agricultura, la elección de diferentes especies para utilizarlas en la restauración del paisaje dependerá de numerosos factores, entre los que cabe citar los tipos de cultivos, la rotación de estos y los problemas agrícolas concretos que se puedan abordar a través de la FLR. La selección de especies también puede utilizarse para incrementar los servicios de los agentes polinizadores, para aumentar la biodiversidad y la fertilidad del suelo o para aumentar la sombra y el forraje; estos aspectos constituyen decisiones que los profesionales toman basándose en sus propios conocimientos. Además, las especies agrosilvícolas se escogen, generalmente, en función de su disponibilidad, de la afinidad de las partes interesadas y de su utilidad económica; sin embargo, dichas especies también pueden tener consecuencias ecológicas que el equipo encargado de la FLR debe identificar, ponderar y abordar en consulta con los grupos de interés. En los casos en que exista una falta de diversidad genética o en que una especie agrosilvícola pueda convertirse en invasora, será necesario llevar a cabo un proceso de evaluación, consulta y planificación cuidadosas para determinar un nivel aceptable de riesgo ecológico, cuando exista dicho riesgo en las circunstancias descritas.

\begin{abstract}
Durante el proceso de restauración de paisajes forestales, con independencia del objetivo político o social que persiga, existe un potencial significativo para tomar decisiones relativas a la restauración que ejerzan efectos positivos sobre la biodiversidad autóctona, en algunos casos incluso mediante la utilización de especies exóticas. La diversidad de enfoques de restauración de paisajes forestales que pueden adoptarse dentro de un determinado paisaje garantiza que ningún tipo de restauración domine los paisajes degradados, sino que las soluciones se apoyen en el uso de diferentes especies y métodos para la restauración. Algunas de esas especies pueden no ser autóctonas pero sí importantes para la subsistencia y el bienestar humanos o para la restauración de los servicios ecosistémicos. Pese a esta realidad, cada paisaje y cada proceso de restauración debería incluir, con carácter preferente, la restauración y/o reintroducción de especies autóctonas en algún momento del cronograma del proyecto y en algún lugar del paisaje.
\end{abstract}

Aparte de las razones generales para llevar a cabo una evaluación de las especies que se utilizarán para la restauración, existen algunos beneficios prácticos y

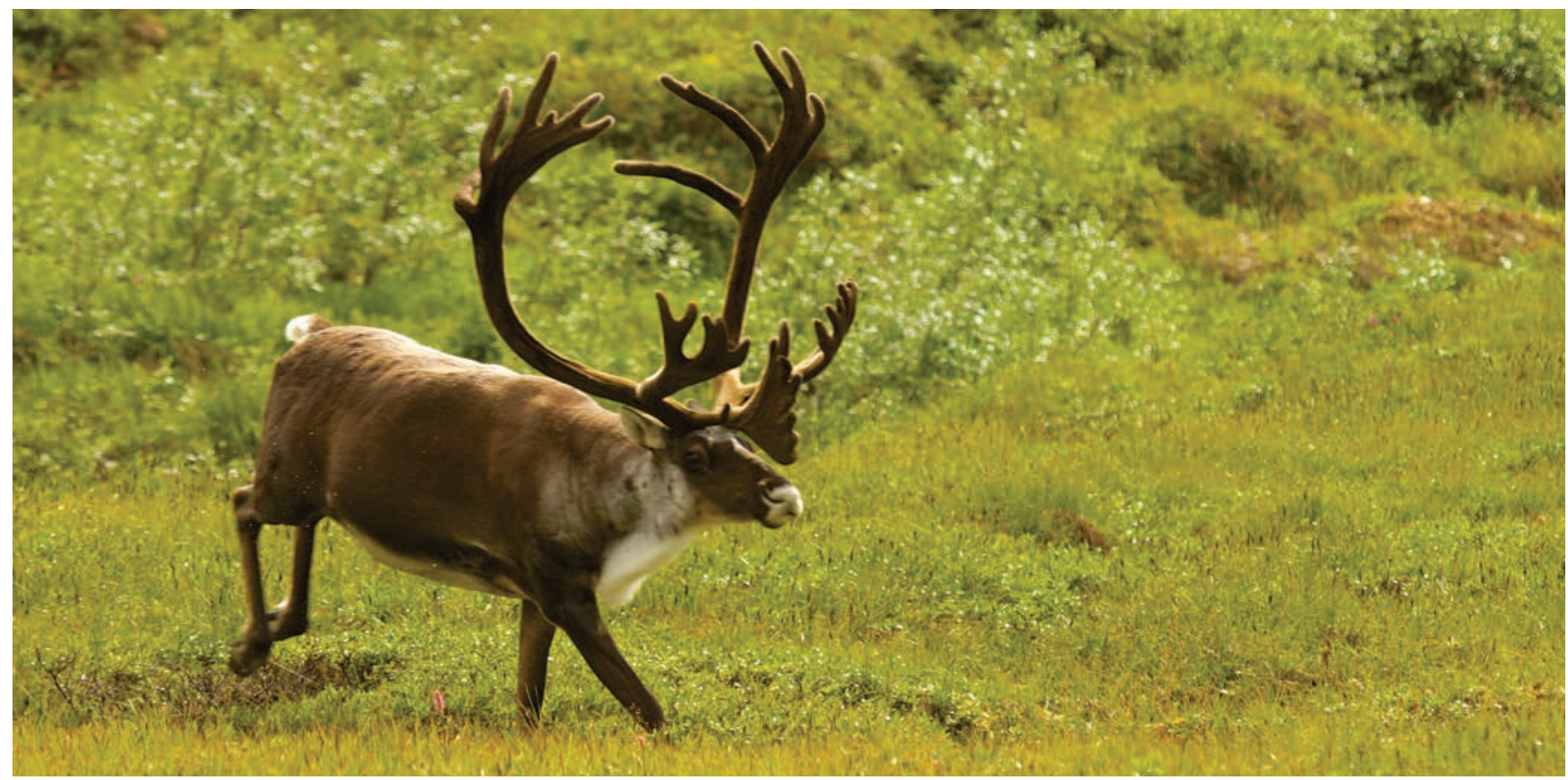

Entre las mayores iniciativas de recuperación de especies concretas del mundo, el gobierno canadiense tiene la misión de aplicar la estrategia para la recuperación del reno (Rangifer tarandus). Esto puede conllevar la realización de numerosas evaluaciones de las oportunidades de restauración del paisaje en apoyo a la ejecución de la iniciativa a nivel nacional, provincial y territorial. Fotografía utilizada por cortesía de Bill Bumgarner. 
bien conocidos derivados del hecho de garantizar que se tengan en cuenta la conservación o restauración de especies en entornos degradados durante todo el proceso de planificación de la restauración del paisaje. Muchos de estos beneficios están asociados al hecho de garantizar que las relaciones entre las especies dentro de las áreas restauradas mejoren la función ecológica del paisaje. Esto incluye la recuperación de diversas especies polinizadoras clave (como las abejas autóctonas y los murciélagos) y de agentes dispersores de semillas (como ardillas, casuarios o tucanes) que interactúan con las especies de árboles que se haya elegido plantar en la zona sometida a restauración. En las selvas tropicales, de manera especial, la polinización y la dispersión de semillas a cargo de animales resultan cruciales para mantener y aumentar la diversidad de la flora en el conjunto del paisaje.

No obstante, los hábitats son complejos e incluyen numerosas relaciones menos evidentes entre las especies en el seno de los emplazamientos sometidos a restauración, así como especies que es necesario tener en cuenta en el proceso de planificación para mejorar la funcionalidad. Un análisis de la comunidad ecológica que existía (o se supone que existía) en el lugar antes de que se produjera la degradación debería ofrecer algún tipo de orientación sobre las especies adecuadas en cada nivel trófico que se puedan considerar para su reintroducción o repoblación en la zona en la que se ejecute el proyecto. Sin embargo, es fundamental que los ecosistemas de referencia no sean la única base en la que se apoye la planificación de la restauración. La FLR no solo busca fomentar el bienestar humano además de mejorar la productividad ecológica, pero estas trayectorias de restauración pueden verse complicadas por el cambio climático, que en la actualidad está alterando la variedad de las especies y los modelos de aptitud de los hábitats. En consecuencia, las comunidades y poblaciones animales y vegetales están respondiendo a las cambiantes condiciones climáticas, y seguirán haciéndolo en el futuro. Aquello que una vez existió en un paisaje puede proporcionar orientación sobre las especies que se podrían restaurar, pero un enfoque centrado en las características funcionales y en los escenarios climáticos puede ofrecer predicciones más precisas a lo largo de los decenios venideros. Al estudiar la posibilidad de recuperar especies o planificar dicha recuperación, es importante tener siempre en cuenta los efectos (tanto positivos como negativos) que pueden tener sobre la población local residente en el lugar en que se desarrolle el proyecto y en las zonas adyacentes. Por ejemplo, puede no resultar práctico incluir grandes predadores (como los lobos) en una zona en la que haya ganado que pueda convertirse en presa habitual de estos. La UICN ha desarrollado unas directrices claras que pueden ser muy útiles a la hora de planificar la reintroducción y la translocación de especies (UICN/CSE, 2013).

Por último, la idoneidad de las especies que se vayan a (o se haya previsto) utilizar en intervenciones de restauración debería determinarse entre los diferentes sectores y partes interesadas a través de un proceso participativo. Un proceso de este tipo no solo puede aumentar la probabilidad de que las especies ofrezcan los beneficios funcionales a escala paisajística que desean obtener los diferentes interesados y sectores, sino que además contribuirá a incrementar la probabilidad de que las especies utilizadas en la restauración también satisfagan las necesidades de subsistencia de los habitantes de la zona, que en última instancia dependen de la productividad del paisaje.

\section{La restauración de paisajes forestales y los ecosistemas}

La FLR debe llevarse a cabo en paisajes enteros y abarcar todos los usos del suelo asociados a estos. Esta visión integral y las interacciones entre los

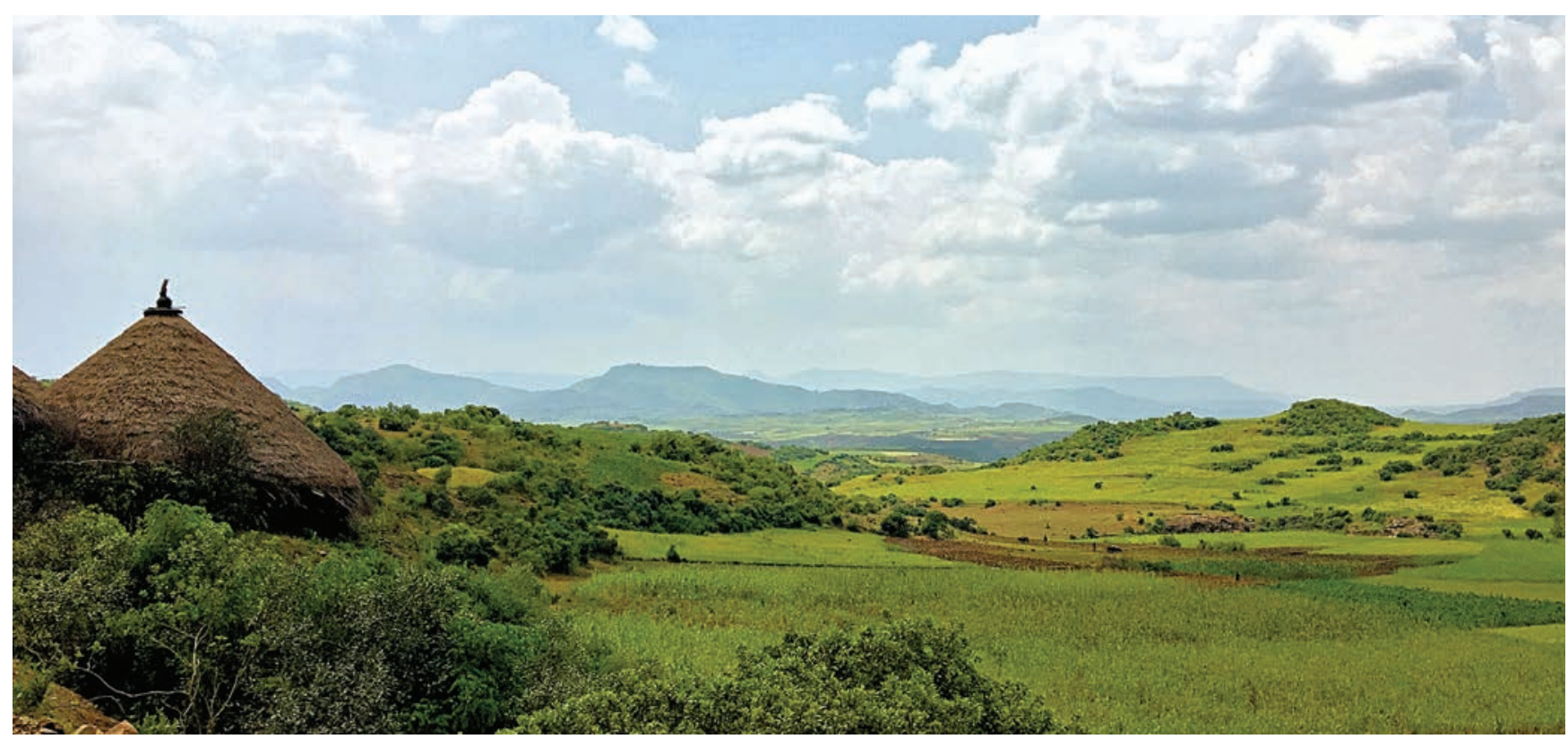

Etiopía se ha comprometido a restaurar 15 millones de hectáreas de suelo degradado o deforestado en apoyo al Desafío de Bonn. Buena parte de este trabajo se desarrollará en paisajes como este, en la región de Ahmara. Fotografía utilizada por cortesía de Adriana Vidal/UICN. 
paisajes y sus ecosistemas, no solo el lugar o unidad ecosistémica específico, impulsan las aspiraciones a gran escala de la FLR. La elección de especies y las interacciones previstas entre ellas deberían orientarse hacia la maximización de los múltiples beneficios que aportan los paisajes restaurados, tanto para las personas como para los propios paisajes. En última instancia, la elección de especies en el marco de la restauración de paisajes forestales debe adoptar una perspectiva más amplia y utilizar las capacidades de las especies para restaurar los paisajes a través de su contribución a uno o múltiples servicios. Además, se debería abordar un enfoque centrado en la evaluación de las características paisajísticas (como, por ejemplo, la diversidad geomórfica y los ecotonos de los hábitats) y en el resto de catalizadores espaciales de la biodiversidad, así como en los procesos que generan diversidad (Pressey et al., 2007; Anderson y Ferree, 2010). Estos pueden incluir la mejora de la capacidad de retención de agua, la prevención de la pérdida o filtración del suelo, la reconstrucción activa de suelos, el aumento de la dispersión y obtención de semillas, etc., proporcionando al mismo tiempo a la población beneficios económicos y formas de ganarse la vida a través de productos como frutas y cereales, forraje, una mayor la producción de alimentos, la producción de electricidad y la seguridad de su suministro, entre otros. La productividad ecológica que se trata de restaurar a través de la FLR se puede medir, por tanto, en términos económicos y sociales. A medida que se restauren los paisajes, la creciente diversidad taxonómica y funcional de estos conducirá hacia paisajes y ecosistemas más resilientes.

El aumento de la biodiversidad del suelo y de la heterogeneidad de los sustratos desde la base es una consideración muy importante y a menudo infravalorada en la restauración de paisajes forestales. Lo ideal es que la elección de especies de cara a las intervenciones de FLR incluya aquellas que sean cruciales desde el punto de vista del ciclo de nutrientes, y que modifiquen el paisaje de maneras favorables a la productividad ecológica y apoyen el ciclo del agua (a través de una mayor evapotranspiración, por ejemplo), por nombrar solo algunas.

No es frecuente que una sola especie genere servicios ecosistémicos de manera independiente; por lo tanto, cualquier planteamiento centrado en una especie en lo referente a la FLR o la restauración de ecosistemas adolecería de cortas miras. El origen de los servicios ecosistémicos de los que depende la población está en las relaciones biofísicas o tróficas entre las especies. En consecuencia, las estrategias de restauración de los paisajes deberían utilizar un conjunto variado de acciones de restauración y adoptar un enfoque ecosistémico en lo relativo a la elección de las especies que contribuirán a mejorar las condiciones ecológicas para el conjunto del paisaje.

Pese a que, con frecuencia, ya no resulta apropiado o práctico restaurar paisajes degradados o deforestados hacia niveles de referencia anteriores, los profesionales que se dedican a la restauración pueden incluir componentes de dichos ecosistemas y niveles de referencia previos para orientar la toma de decisiones sobre intervenciones adecuadas de restauración de paisajes forestales. En muchas partes del mundo, la degradación es lo suficientemente grave como para que haya especies que desaparezcan de determinadas regiones o incluso se extingan, y los ecosistemas subyacentes han sufrido importantes alteraciones o directamente han quedado destruidos. En esos casos extremos, y también en otros menos severos, se hace necesario proceder a la restauración a un nuevo estado adaptado. La restauración de los ecosistemas a nivel del paisaje mediante la restauración de la diversidad de las especies es una de las mejores oportunidades para la restauración paisajística en esas zonas gravemente degradadas, y puede generar los beneficios polivalentes que la población desea obtener de los ecosistemas de paisajes restaurados.

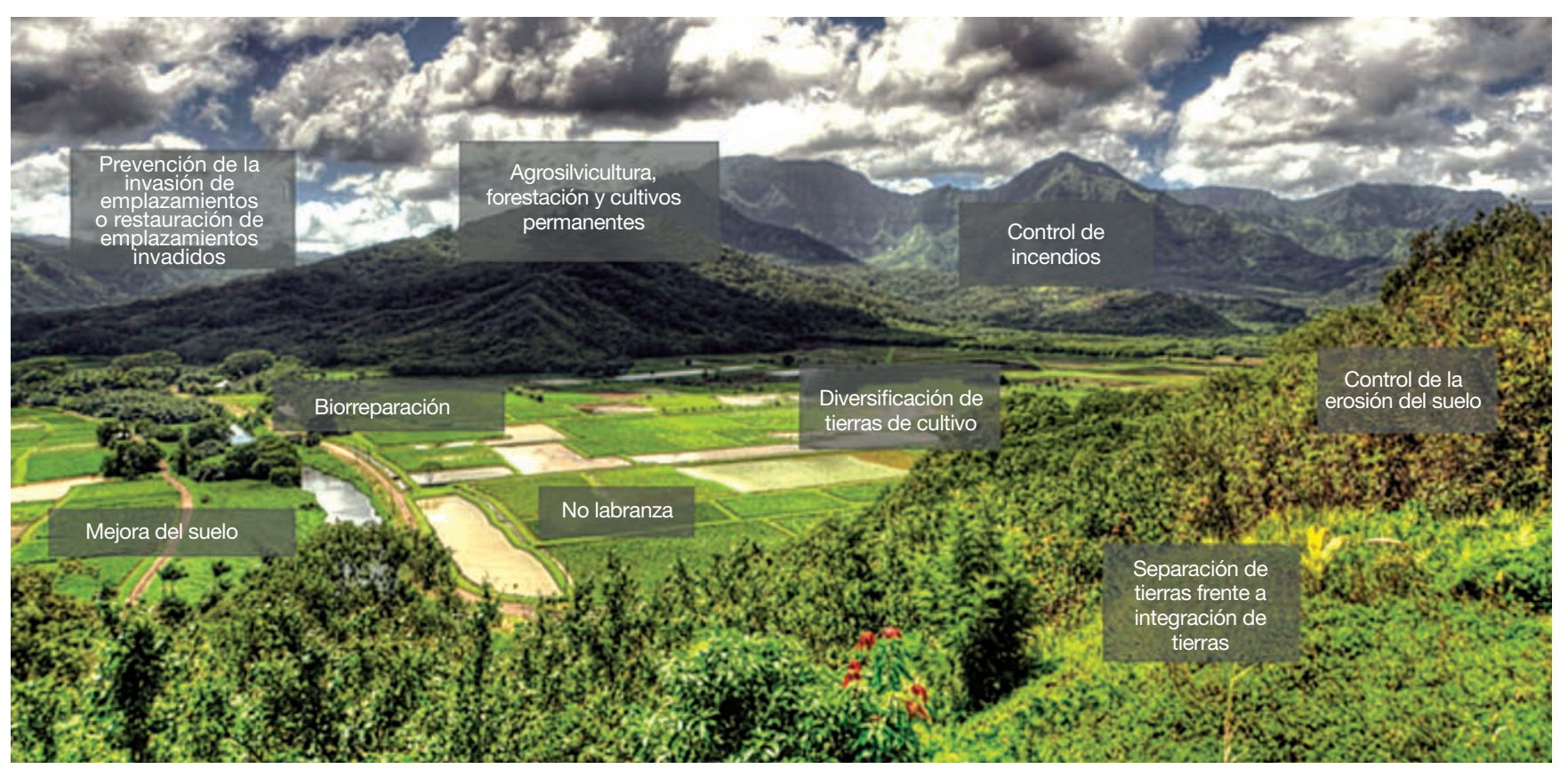

Figura 1. Enfoque paisajístico sobre la restauración de paisajes forestales, tomado del Atlas Global de Biodiversidad del Suelo (Orgiazzi et al., 2016). 
Dado que no existe una definición ni una clasificación armonizadas a escala mundial de los ecosistemas, sigue siendo problemático llevar a cabo una evaluación cuantitativa de la diversidad presente en un ecosistema, hábitat o comunidad (Centro Mundial de Vigilancia de la Conservación, 1992). No obstante, la UICN y sus socios están desarrollando una clasificación armonizada de los ecosistemas a través de la Lista Roja de Ecosistemas (https://iucnrle.org/).

La resiliencia de los paisajes se mide a través de la capacidad de estos para resistir a las perturbaciones y recuperarse de ellas. Todos los ecosistemas -y las especies que los componen- son dinámicos, aunque este dinamismo presenta escalas temporales y geográficas diferentes. Con frecuencia se define un paisaje sobre la base de las interacciones entre los ecosistemas, y la respuesta de las comunidades y los conjuntos de especies presentes en un ecosistema a los cambios medioambientales determinará la resiliencia de ese ecosistema.
Los individuos presentes dentro de un ecosistema viven y se reproducen, y la persistencia de las especies es la primera condición para mantener la resiliencia ecológica. Dado que la degradación reduce la cantidad de especies en un paisaje mediante la extirpación física como consecuencia del desbroce, la deforestación, la sobreexplotación agrícola y otras actividades que reducen o eliminan las especies del paisaje, la resiliencia de los ecosistemas y, por extensión, la del paisaje, se verá perjudicada. Por lo general, cuanto menor sea el número de especies que conformen un ecosistema, menos resiliente es este. La restauración de paisajes forestales, por definición, se produce en zonas en las que se han perdido especies nativas y las funciones que desempeñaban estas; se pretende recuperar la función ecológica de una zona degradada a partir de la expansión, el establecimiento o la reintroducción de especies que llenen esos vacíos funcionales en los paisajes degradados. El modo de colmar esos vacíos funcionales depende de muchos

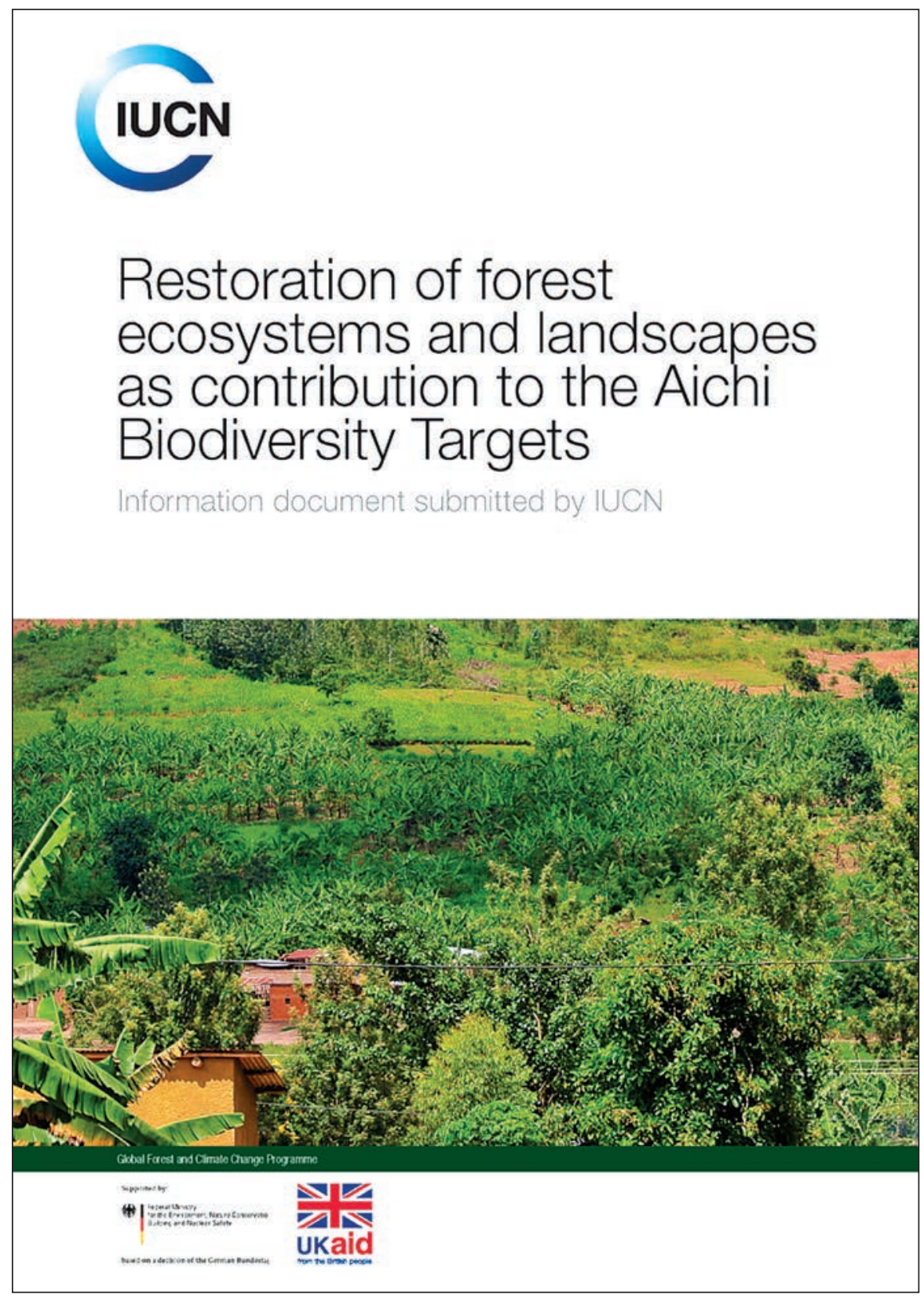

La figura 2 se incluyó como documento de información oficial para la 13. ${ }^{a}$ Conferencia de las Partes en el Convenio sobre la Diversidad Biológica en 2016. Esta publicación proporciona información sobre la forma en que la restauración de paisajes forestales (FLR) a nivel nacional y jurisdiccional puede ofrecer a los países un medio para recuperar bosques degradados y restaurar funciones ecosistémicas clave, de modo que aumenten los niveles de biodiversidad en un paisaje y se puedan conseguir varias de las metas de biodiversidad de Aichi. 
factores, pero está claro que un enfoque que utilice especies diversas dará lugar a ecosistemas y paisajes más resilientes que otro que no lo haga. Uno de los pasos más importantes que se pueden dar en el ámbito de la restauración de paisajes forestales es el estudio de las especies que, desde el punto de vista ecológico, resulta adecuado introducir.

Un punto de partida evidente para comenzar a analizar las especies que se utilizarán en la restauración son las especies terrestres y vegetales. Buena parte de la degradación que asola los paisajes comienza con el deterioro de la calidad del suelo o la erosión de su capa superficial y la filtración de sus nutrientes. La restauración del suelo para dotarlo de unas condiciones propicias para el crecimiento vegetal es fundamental, sobre todo la reintroducción de especies de plantas que sustituyan a las anteriores, a menudo en combinación con intervenciones de restauración paisajística, como la agrosilvicultura, las parcelas arboladas y los sistemas de agricultura sostenible.

Como mínimo, la restauración de paisajes forestales debería incluir algún componente de un enfoque ecosistémico integrado en relación con la restauración. Esto exigirá que los profesionales encargados de la restauración conozcan los tipos de ecosistemas existentes en su zona geográfica, así como de las especies notables o destacadas. Cualquier evaluación de la restauración debería dar como resultado un enfoque basado en diversas especies con el fin de mejorar la biodiversidad autóctona y aumentar la conexión entre diferentes paisajes, ecosistemas y hábitats fragmentados. De forma alternativa, en los casos en que la degradación haya extirpado numerosas especies, este enfoque puede ayudar a crear ecosistemas con especies autóctonas basados en rasgos funcionales deseables, como la fijación de nitrógeno, la disuasión de predadores o herbívoros, o hábitats esenciales para otras especies que susciten preocupación o que sea necesario cuidar.

Los beneficios ecológicos -y los beneficios integración de la restauración y la conservación de la biodiversidad en la planificación de la FLR, junto con los conceptos de diversidad genética, ecosistémica y de las especies, se pueden utilizar para medir el progreso que pueden realizar los países de cara al cumplimiento de los compromisos internacionales, como el Convenio sobre la Diversidad Biológica (CDB) y los Objetivos de Desarrollo Sostenible de las Naciones Unidas [en particular los Objetivos 15 (Vida de ecosistemas terrestres) y 13 (Acción por el clima)]. El artículo 6 del CDB merece una mención especial, pues pide a los países que elaboren Estrategias nacionales sobre la biodiversidad y planes de acción (ENBPA) para el fomento de la biodiversidad, que revisten una importancia particular de cara a la aplicación del CDB a nivel nacional. Mediante una planificación e intervención de FLR a gran escala, las jurisdicciones pueden respaldar el logro de objetivos específicos de conservación de la biodiversidad a nivel nacional e internacional, restaurando al mismo tiempo la productividad ecológica de los paisajes de los que depende la población. En la segunda parte de estas directrices se describe el modo en que los profesionales pueden traducir a la práctica un interés o mandato de incluir explícitamente la biodiversidad en la planificación de la FLR. Además, se sugiere una serie de fuentes de información y metodologías clave para garantizar que la planificación paisajística de la FLR también incluya los conocimientos disponibles sobre la biodiversidad, de manera que estos puedan guiar la planificación de la restauración hacia el éxito de estas intervenciones a largo plazo.

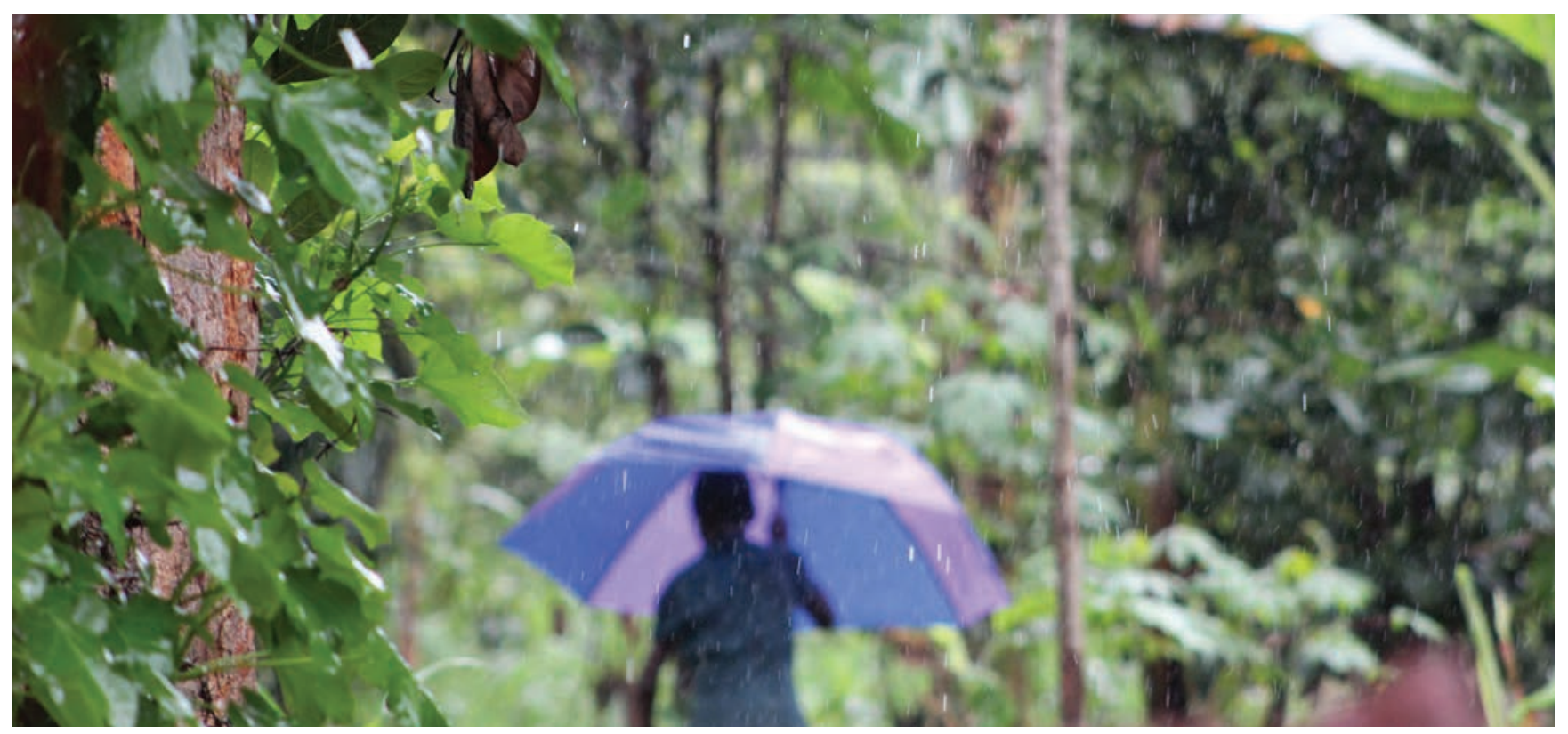

Aunque Uganda concluyó su evaluación nacional de oportunidades de restauración de paisajes forestales en 2016, la implementación y una serie de evaluaciones adicionales a nivel subnacional todavía se encuentran en curso. Las actuaciones incluyen intervenciones centradas en la gestión sostenible del suelo en los distritos agrícolas con las asociaciones de campesinos, así como la implicación de grupos de jóvenes en los paisajes en los que se está trabajando, como en este del distrito de Mukono. Fotografía utilizada por cortesía de Craig Beatty/UICN. 


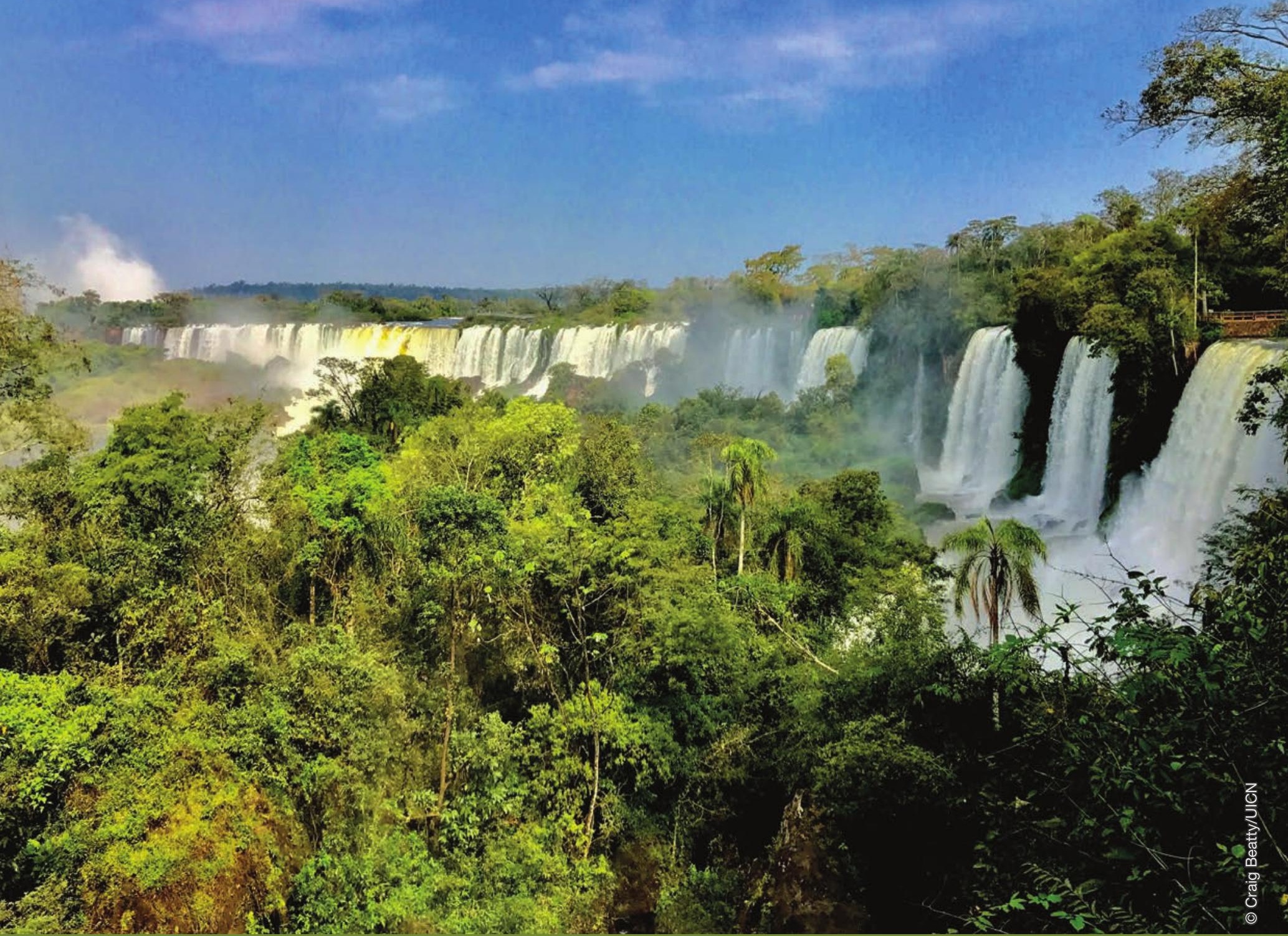

\section{Segunda parte}

\section{La biodiversidad en la planificación de evaluaciones de la restauración de paisajes forestales}


Algunas de las metodologías existentes (véase, por ejemplo, UICN y WRI, 2014) justifican con argumentos diversos y muy claros el valor que ofrecen las actividades de FLR correctamente planificadas para el mantenimiento o la restauración de la biodiversidad y sus beneficios. En esta sección se proporcionan a los profesionales dedicados a la restauración orientaciones adicionales sobre cómo adoptar un enfoque más integral y práctico con respecto a la biodiversidad en las evaluaciones de la restauración de paisajes forestales.

En la evaluación de las oportunidades de restauración, las partes interesadas identificarán en primer lugar sus objetivos de restauración del paisaje forestal. Este proceso dará lugar a diferentes tipos de acciones de restauración que, cuando se ejecuten, deberían mitigar los impulsores subyacentes de la degradación del paisaje. Cada una de esas soluciones implicará intervenciones de restauración que precipitarán las transiciones físicas de los paisajes degradados a otros restaurados y más productivos.

Esas transiciones se apoyan en procesos biológicos que favorecen un aumento de las poblaciones o de la diversidad de una o varias especies. De hecho, si no mejora la diversidad vegetal, animal, fúngica y microbiana, es improbable que la restauración consiga a largo plazo aumentar la productividad y garantizar la sostenibilidad de esta. En su nivel más fundamental, la restauración de paisajes forestales pretende crear o apoyar ecologías resilientes, centradas en la interconexión de relaciones entre las especies y grupos tróficos funcionales y en sus beneficios inherentes para

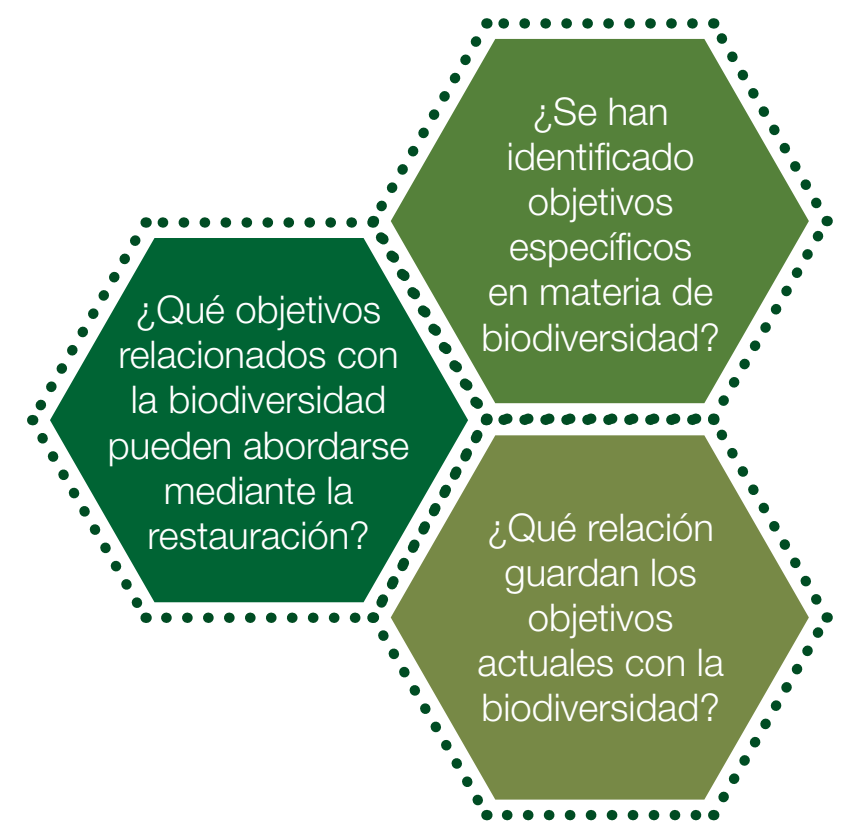

la subsistencia y el bienestar humanos (por ejemplo, el aumento de la biodiversidad del suelo se traduce en una mayor fertilidad de este) (Reitbergen-McCracken et al., 2007; Lamb, 2014).

Al examinar los objetivos de la FLR y los beneficios que aporta esta desde el punto de vista de la biodiversidad, es importante reconocer que el problema o los desafíos que deben abordarse en términos de biodiversidad y especies deben estar en consonancia con los objetivos de las políticas de

Cuadro 1. Alineación entre los objetivos habituales de la FLR y la biodiversidad

\section{Ejemplos \\ de objetivos \\ de la FLR}

Seguridad alimentaria

\section{Alineación con la biodiversidad}

La biodiversidad sustenta la agricultura (incluida la agrosilvicultura), especialmente a través de la resiliencia al cambio ambiental -mediante variedades y especies adaptadas al entorno local- y de un suministro de productos más diverso. En la actualidad, existe un reconocimiento amplio en torno al hecho de que los ecosistemas (y, de manera especial, los bosques) en buen estado representan una importante reserva de alimentos y recursos que desempeñan un papel crucial desde la perspectiva de la seguridad alimentaria (Sunderland, 2011).

\footnotetext{
Seguridad Los bosques son una fuente reconocida de protección natural corriente arriba del abastecimiento hídrica de agua. Existen múltiples ejemplos de degradación de cursos de agua corriente abajo (incluido el deterioro de la calidad del agua) cuando se produce deforestación en las tierras altas. A menudo se considera que los paisajes diversos son más eficaces en lo que respecta a la prestación de servicios ecosistémicos y más eficiente en la protección de las fuentes de agua (Secretaría del Convenio sobre la Diversidad Biológica, 2013; Herrera et al., 2018). Estos ecosistemas y paisajes forestales también son vitales para favorecer la recarga de los acuíferos y respaldar la conectividad hidrológica (Pringle, 2001; Hatton y Nulsen, 1999).

Producción La conservación y restauración de la biodiversidad en los paisajes gozan de reconocimiento sostenible a escala mundial como contribuyentes directas al desarrollo de sistemas de producción sostenibles, especialmente en sectores como la silvicultura, la agricultura, la pesca, la industria farmacéutica, la papelera, la cosmética, la horticultura, el turismo, la construcción y la biotecnología (meta 12 de los ODS).
} 


\begin{tabular}{|c|c|}
\hline $\begin{array}{l}\text { Ejemplos } \\
\text { de objetivos } \\
\text { de la FLR }\end{array}$ & Alineación con la biodiversidad \\
\hline $\begin{array}{l}\text { Absorción } \\
\text { de carbono }\end{array}$ & $\begin{array}{l}\text { La restauración futura de los paisajes degradados (especialmente en los trópicos) y el potencial } \\
\text { de absorción de carbono conexo es hoy en día una solución basada en la naturaleza bien } \\
\text { conocida para el problema de la mitigación del cambio climático (Griscom et al., 2017). Pese } \\
\text { a que todavía se sabe muy poco sobre los efectos de la pérdida de la biodiversidad sobre la } \\
\text { mitigación del cambio climático por parte de los bosques y los hábitats asociados a estos, } \\
\text { suele asumirse que las zonas con gran diversidad biológica son más eficientes desde el } \\
\text { punto de vista del almacenamiento de carbono (Nauman et al., 2014; Griscom et al., 2017); } \\
\text { la investigación de Vayreda et al. (2012) demuestra el impacto positivo que puede tener la } \\
\text { gestión de paisajes forestales, como intervención de FLR, sobre la absorción de carbono en } \\
\text { los bosques españoles. }\end{array}$ \\
\hline Resiliencia & $\begin{array}{l}\text { Los sistemas biodiversos desde el punto de vista genético son más resilientes a los cambios } \\
\text { ambientales (por ejemplo, al cambio climático) que los paisajes degradados. Si bien esto puede } \\
\text { no resultar evidente a corto plazo, la variación (desde las especies hasta los paisajes) puede } \\
\text { revestir una importancia crucial para la resiliencia a largo plazo de la función ecosistémica y de } \\
\text { los servicios que esta posibilita (Oliver et al., 2015a; Oliver et al., 2015b). }\end{array}$ \\
\hline $\begin{array}{l}\text { Reducción de } \\
\text { la pobreza }\end{array}$ & $\begin{array}{l}\text { Los recursos y ecosistemas biodiversos constituyen bienes públicos a menudo infravalorados. } \\
\text { Este problema adquiere especial relevancia a la hora de considerar la desproporcionada } \\
\text { dependencia que presenta la población pobre con respecto a la biodiversidad para satisfacer } \\
\text { sus necesidades vitales, en términos tanto de ingresos como de protección frente al riesgo y, } \\
\text { en ocasiones, como ruta para salir de la pobreza (Secretaría del Convenio sobre la Diversidad } \\
\text { Biológica, 2010). El vínculo que existe entre la biodiversidad y las perspectivas de las personas } \\
\text { pobres indica que la conservación de la biodiversidad (incluidas las iniciativas de restauración) } \\
\text { debería ser una prioridad en los esfuerzos internacionales dirigidos a lograr la reducción de la } \\
\text { pobreza (Secretaría del Convenio sobre la Diversidad Biológica, 2010). }\end{array}$ \\
\hline $\begin{array}{l}\text { Medios } \\
\text { de vida }\end{array}$ & $\begin{array}{l}\text { Las oportunidades que ofrecen los bosques y otros ecosistemas en buen estado para la extracción } \\
\text { sostenible (estrechamente vinculada con los componentes de dichos ecosistemas relacionados con } \\
\text { la biodiversidad) son evidentes. Es preciso señalar, no obstante, que los suministros procedentes de } \\
\text { los ecosistemas pueden ser inflexibles, y los bajos niveles de rentabilidad suelen limitar su función } \\
\text { como redes de seguridad y vías para salir de la pobreza (Wunder, 2014). El acceso a esos recursos } \\
\text { por parte de la población y a las fuentes diversificadas de productos forestales no maderables es } \\
\text { un aspecto muy importante que debe tenerse en cuenta a la hora de medir el valor que ofrecen los } \\
\text { ecosistemas a las comunidades y, en su caso, la conservación sostenida de esos hábitats. }\end{array}$ \\
\hline
\end{tabular}

desarrollo nacionales e internacionales asociadas a la restauración de paisajes forestales, y respaldar dichos objetivos. Los retos asociados al mantenimiento o la restauración de la biodiversidad a escala nacional se registran a menudo en documentos existentes, como las estrategias nacionales sobre la biodiversidad y planes de acción (ENBPA), que constituye el principal instrumento en el que se apoyan los países para cumplir los compromisos contraídos en virtud del Convenio sobre la Diversidad Biológica (CDB). Los objetivos recogidos en dichas estrategias nacionales y planes de acción, así como en otros documentos centrados en la biodiversidad, ponen el foco, en general, en la restauración de poblaciones de especies individuales o en el mantenimiento de zonas en las que existe una diversidad de especies reconocida y priorizada. Pese a que las estrategias nacionales sobre la biodiversidad y planes de acción y otros documentos similares resultan de especial ayuda para lograr los objetivos a nivel nacional, si las actividades de FLR se planifican a escala subnacional puede ser necesario examinar los desafíos desde un punto de vista más local (véase la sección siguiente relativa a las estrategias nacionales sobre la biodiversidad y planes de acción).
En algunos casos -y esto es algo que quizá suceda con más frecuencia a nivel subnacional-, puede que no se haya considerado explícitamente la inclusión de los objetivos de restauración o mantenimiento de la biodiversidad en el proceso de FLR. En esas circunstancias, los profesionales dedicados a la FLR deberán identificar y ponerse en contacto con los expertos adecuados a nivel local, nacional o internacional para obtener asesoramiento (consúltese la sección siguiente, titulada "Implicación de expertos en biodiversidad").

Durante el proceso de consideración de la inclusión de la biodiversidad en el cronograma de la evaluación de la restauración, siempre es importante que se articulen adecuadamente unos vínculos positivos entre el entorno restaurado, saludable y biodiverso con otros sectores de interés (especialmente los relacionados con el desarrollo humano); de ese modo los responsables de la adopción de decisiones dispondrán de una garantía de que la restauración de la biodiversidad ofrecerá una rentabilidad positiva de la inversión en el marco del proceso global de FLR (el cuadro 1 ofrece diversos ejemplos de relaciones entre la biodiversidad y muchos de los objetivos habituales de la FLR). 
Entre las principales partes interesadas cuya implicación se puede intentar obtener durante la fase de planificación del proyecto y las actividades de recogida de datos que revisten una importancia especial para adquirir información pertinente sobre la biodiversidad figuran los responsables gubernamentales de adoptar decisiones (incluidos los funcionarios medioambientales, ya sea a nivel ministerial o de departamento), representantes de ONG que trabajen en este ámbito (como sociedades de historia natural u organizaciones de conservación nacionales o locales), instituciones académicas, comunidades locales y grupos indígenas, personal técnico adecuado del gobierno, la sociedad civil o el sector privado (a menudo de los departamentos de silvicultura y vida silvestre), usuarios comerciales de productos para la fauna y la flora silvestres o de recursos naturales pertenecientes al ámbito de interés, así como personal técnico de apoyo (que posea, por ejemplo, aptitudes para la elaboración de modelos ambientales y socioeconómicos).

\section{Implicación de expertos en biodiversidad}

Además de una institución específica que se responsabilice de coordinar el proceso global de evaluación y planificación de la restauración (como se describe en UICN y WRI, 2014), es fundamental contar con personal técnico para garantizar que los profesionales adopten un enfoque equilibrado en relación con la FLR. También será crucial disponer de acceso a un/a ecologista que posea un conocimiento profundo de los ecosistemas autóctonos y de la fauna y flora asociadas que normalmente estarán presentes en la zona que se esté estudiando someter a actividades de restauración. El hecho de contar con su orientación ayudará a comprender tanto los diversos costes y beneficios ecológicos de la restauración planificada como el cronograma o calendario que deba establecerse para que el proyecto logre sus objetivos.

Igualmente importante es implicar a un naturalista $u$ otra persona que esté familiarizada con el conocimiento tradicional y los valores culturales de la biodiversidad en la(s) zona(s) de interés. La cooperación de un ecologista clásico y de otro profesional familiarizado con los aspectos tradicionales y culturales de la biodiversidad contribuirá a garantizar la inclusión de ambas perspectivas y su validación durante el proceso de evaluación.

Estas funciones consultivas clave ayudarán a asegurar que la inversión en restauración aborde eficazmente los desafíos y objetivos relacionados con el paisaje. El ecologista y el naturalista también podrán aconsejar sobre la mejor forma de llevar a cabo el seguimiento de los progresos de la restauración (incluida la elaboración de informes sobre los indicadores establecidos en lo referente a la biodiversidad; véase el apartado "Seguimiento de los efectos de la FLR sobre la biodiversidad y las comunidades". En algunos casos puede resultar difícil identificar un ecologista con las competencias necesarias para asesorar sobre la fauna y la flora autóctonas de un paisaje. En esos casos se podrá reclutar a un/a experto/a en botánica o en biología silvestre en lugar del ecologista; no obstante, el biólogo deberá conocer en profundidad los principios ecológicos y disponer de acceso a una red de zoólogos y botánicos expertos de apoyo (como la Comisión de Supervivencia de Especies de la UICN, https://www.iucn.org/ssc-groups).

Otra consideración clave para involucrar a socios en lo que atañe a la biodiversidad y la FLR es la alineación de perspectivas y expectativas. Si bien la inclusión de la información relativa a la biodiversidad en las evaluaciones de la restauración de paisajes forestales puede ofrecer beneficios sustanciales, la incorporación de partes interesadas centradas exclusivamente en la biodiversidad o la silvicultura, pese a ser necesaria, puede generar tensiones. La gestión de las expectativas en cuanto a los resultados de la FLR puede ser un proceso delicado; en última instancia, el objetivo de la restauración de paisajes forestales es restaurar la funcionalidad de los ecosistemas en beneficio de las personas y del planeta.

Si la conservación y la restauración de la biodiversidad no es el principal punto de partida para una evaluación de oportunidades de restauración del paisaje, no es arriesgado suponer que también se obtendrán algunos beneficios desde el punto de vista de la biodiversidad, y

Algunos ejemplos de posibles reflexiones sobre la biodiversidad en el marco de las evaluaciones de la FLR:

1. Incluir a (y comunicarse con) personas a las que les importe la biodiversidad y que la apoyen, incluidos los puntos focales nacionales del Convenio sobre la Diversidad Biológica, las instituciones académicas y las sociedades naturalistas.

2. Utilizar los conocimientos y la información pertinentes sobre las especies y la ecología en la recogida y el análisis de datos relativos a las oportunidades de FLR.

3. Proporcionar productos y recomendaciones adecuados que se puedan difundir a los diferentes sectores (desde las ONG dedicadas a la conservación hasta los ministerios de Agricultura, Finanzas, etc.). 
es importante cuantificarlos. En el caso de que el punto de partida para una evaluación de oportunidades de FLR es conseguir una conservación más sustancial de la biodiversidad y/o la restauración de zonas de alto valor desde la perspectiva de la biodiversidad, entonces los beneficios en términos de biodiversidad son el objetivo explícito de la restauración de paisajes forestales. En ambos casos se producirán beneficios de biodiversidad que merece la pena examinar en el proceso de evaluación, en los resultados y en el seguimiento de la FLR. Las partes a las que interese fundamentalmente la conservación de la biodiversidad deberán reconocer el potencial de obtener dichos beneficios incluso aunque el paisaje no se restaure necesariamente a su estado de referencia o a su ecosistema o vegetación original. Las partes interesadas en los múltiples objetivos que puede aportar la FLR siempre deben tener en consideración los beneficios de la conservación y restauración de la biodiversidad.

A lo largo de toda la fase de planificación y preparación resulta evidente la importancia de garantizar que las partes interesadas en el proceso de FLR sean conscientes de cualquier posible efecto (positivo o negativo) resultante de prestar una mayor atención a la biodiversidad, tanto dentro del área delimitada para su restauración como en las zonas adyacentes o asociadas. Los comentarios proporcionados durante la fase de planificación y preparación por las partes interesadas de la sociedad civil, incluidos los representantes de los gobiernos, organismos no gubernamentales y comunidades locales o indígenas aportarán una información muy valiosa para el proyecto, sobre todo en lo que respecta a cualquier tema o iniciativa que suscite controversia.

\section{Seguimiento de los efectos de la restauración de paisajes forestales}

El seguimiento del progreso hacia el logro de los objetivos de la FLR se adaptará, por lo general, a la disponibilidad de recursos u oportunidades locales, y normalmente se llevará a cabo una vez que las actuaciones de restauración se encuentren en marcha. El seguimiento tiene lugar durante y después del proceso físico de restauración, y también es una consideración muy importante en el cronograma de la recogida de datos y la evaluación. No obstante, es crucial que los marcos e indicadores de seguimiento se sometan a debate entre las partes interesadas durante el proceso de evaluación. De ese modo se sentarán las bases necesarias para el seguimiento, con independencia de si este se efectúa finalmente o no. Buena parte de los datos de entrada para la evaluación servirán también como posibles indicadores de progreso de la FLR; además, durante la fase de evaluación se establecerán y medirán los niveles iniciales de referencia, un aspecto fundamental para el seguimiento.

Aunque algunos indicadores relativos a la biodiversidad serán comunes (como, por ejemplo, la cobertura del hábitat, la diversidad de especies, la superficie protegida), los métodos concretos variarán en función de los hábitats y ecosistemas. A modo de ejemplo, el seguimiento de las poblaciones o comunidades de especies puede requerir diferentes enfoques en los terrenos arbolados de la sabana que en las pluviselvas tropicales de las tierras bajas o en los desiertos altos, y también dependerá de la implicación y la continuidad de las partes interesadas. Sin embargo, existen diversas herramientas y protocolos de seguimiento normalizados que se pueden utilizar o adaptar según sea necesario para la mayoría de los principales grupos de animales y plantas. Los avances tecnológicos han mejorado la accesibilidad y asequibilidad de determinadas herramientas, como la teledetección basada en drones o satélites, los sensores in situ, como las cámaras trampa o los dispositivos de grabación de sonidos y el seguimiento del ADN medioambiental; todos ellos tienen un importante papel que desempeñar en algunos paisajes sometidos a restauración. Siempre que resulte posible, los datos recopilados deberán aportar información no solo a los sistemas de elaboración de informes a nivel nacional y de paisaje, sino también a los procesos de investigación, seguimiento y evaluación en los que se apoyan las bases de datos mundiales, como la Lista Roja de Especies Amenazadas de la UICN, Protected Planet o el Îndice Planeta Vivo. Esto es particularmente importante, puesto que la información que se incluye en dichas bases de datos se utiliza para medir los avances hacia el logro de los objetivos medioambientales mundiales (como las metas de Aichi o los Objetivos de Desarrollo Sostenible). La UICN agradece cualquier aportación a la Lista Roja de Especies Amenazadas relativa a la distribución de las especies, su historia natural, las amenazas a las que se enfrentan y su estado de conservación. Si desea enviar nueva información a la UICN, puede escribir a la siguiente dirección de correo electrónico: redlist@iucn.org. Además, el Grupo de Especialistas en Seguimiento de la Comisión de Supervivencia de Especies de la UICN es un recurso clave a la hora de diseñar o aplicar estrategias de FLR.

La UICN también ha elaborado un conjunto de indicadores sobre la biodiversidad en la Lista Roja de Ecosistemas, que continuará desarrollando a lo largo de los próximos años. La colaboración con los profesionales de la Lista Roja de Ecosistemas y la Comisión de Gestión de Ecosistemas de la UICN garantizará que el seguimiento de la biodiversidad y los ecosistemas en las evaluaciones de la FLR también respalde estos criterios internacionales sobre el estado de conservación de los ecosistemas.

La cooperación con las comunidades locales y otras partes interesadas dentro del paisaje sometido a restauración de cara al seguimiento de los avances de la restauración es una forma práctica de facilitar tanto la apropiación local del proceso de FLR como de establecer un medio para llevar a cabo un seguimiento periódico y eficiente de los cambios que experimenta la biodiversidad. Se deberá trabajar para identificar un ecologista clave especializado en restauración (nacional o internacional) que pueda trabajar con los expertos locales en los ecosistemas que se haya previsto restaurar. Dicho experto podrá orientar a las 
partes interesadas locales (por ejemplo, estudiantes universitarios locales o grupos de amantes de la fauna y la flora silvestres) en el proceso de seguimiento, explicándoles cómo determinar si las iniciativas de restauración están resultando eficaces o si es preciso un esfuerzo adicional para lograr los objetivos paisajísticos. A modo de ejemplo de oportunidades de seguimiento cabe citar el registro de avistamientos de una especie amenazada que se haya fijado como objetivo en las zonas sometidas a restauración; el recuento del número de individuos de una especie de árbol autóctona que se esté regenerando a partir del banco de semillas existente; o la mejora de un servicio ecosistémico en las tierras agrícolas circundantes (por ejemplo, el aumento de los frutos asociado a la abundancia de poblaciones de agentes polinizadores autóctonos). Estas oportunidades que brinda la ciencia cívica pueden mejorar la recogida de datos, incrementar la sostenibilidad de los programas de seguimiento y potenciar el compromiso de los promotores de la FLR y las comunidades locales con las acciones de restauración. En ausencia de implicación y aportaciones locales, resultará difícil llevar a cabo un seguimiento de los distintos tipos de afectación de la FLR sobre los servicios ecosistémicos y de los beneficios o costes sociales derivados de las actividades de restauración.

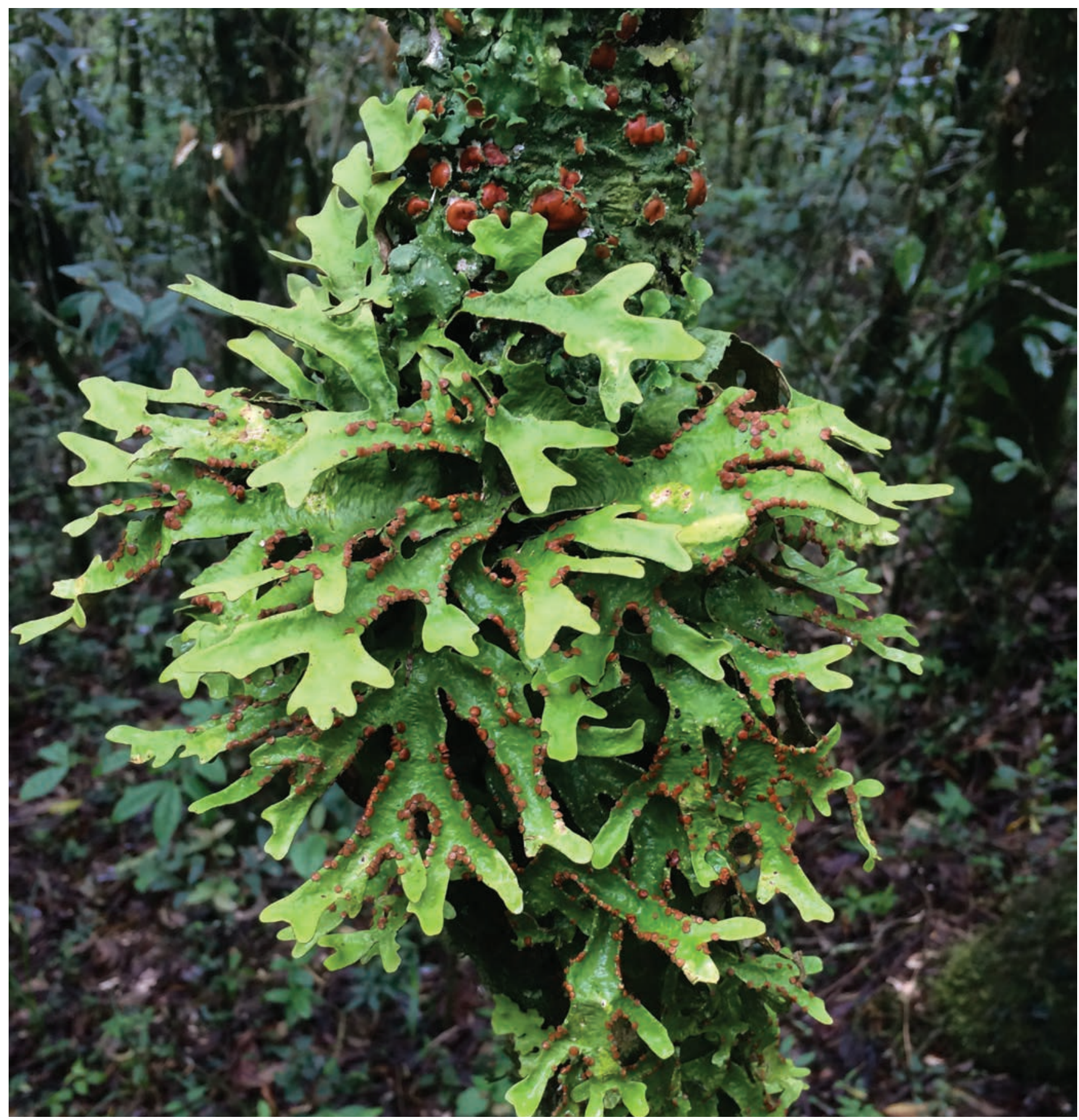

Liquen Sticta angstroemii (Lobariaceae, Ascomycota) fotografiado en un bosque fragmentado de zonas nubosas en Campos do Jordão, São Paulo, Brasil. Los líquenes de la familia Lobariaceae pueden utilizarse como indicadores biológicos a efectos de conservación, ya que sirven para detectar fragmentos residuales de bosques, en este caso del Bosque Atlántico. Fotografía utilizada por cortesía de Manuela Dal Forno. 


\section{Información sobre la biodiversidad de cara al proceso de evaluación}

Tras asegurar la implicación de las partes interesadas clave en el sector de la biodiversidad y el establecimiento de un proceso de evaluación de la restauración de paisajes forestales, como la Metodología de Evaluación de Oportunidades de Restauración (ROAM), la atención se centrará en la recogida y el análisis de datos e información sobre la FLR. A menudo esta tarea se dividirá entre diferentes grupos de trabajo, que tratarán temas como la identificación de partes interesadas, análisis de datos espaciales, modelización de servicios ecosistémicos, análisis de género, análisis coste-beneficio, identificación de empresas, análisis de políticas y evaluación de la preparación institucional. Aunque la mayor parte de los datos relativos a la biodiversidad tiende a ser de carácter geográfico y taxonómico, la información sobre biodiversidad debería ser un componente que cualquier grupo de trabajo acoja con agrado y normalmente ya está incluida de un modo u otro.

\section{Fuentes de información sobre biodiversidad}

Una vez examinados y acordados los resultados generales y el alcance de la FLR, la atención se dirigirá hacia los recursos y los datos existentes disponibles que pueden aportar información de cara a la evaluación. Generalmente, los resultados y el alcance de la FLR se acuerdan durante la fase inicial de determinación del interés nacional o subnacional en la FLR como solución basada en la naturaleza a un número cualquiera de desafíos sociales y ecológicos. Con frecuencia, los resultados y el alcance de la intervención se recogen en un documento de planificación y/o definición del alcance de la restauración; este documento se elabora con la participación de los titulares de derechos de gestión del suelo en la zona que se vaya a evaluar. Este proceso debería garantizar la integración de los mejores conocimientos disponibles en materia de biodiversidad en la evaluación, utilizando una combinación de la mejor información y conocimientos científicos sobre la biodiversidad y de los conocimientos más pertinentes relativos a la biodiversidad regional, nacional y local.

\section{Datos y contactos existentes en materia de biodiversidad a nivel nacional \\ La mayoría de los países cuenta con un valioso historial de recopilación y mantenimiento de información sobre su entorno natural. Además de otra información de carácter más general sobre la fauna y la flora del país, también existen conjuntos de datos asociados a la evolución histórica del uso del suelo (incluida la conversión de tierras forestales) a las prácticas de uso del suelo empleadas en el país. Además, es posible que se disponga de datos sobre el uso comercial de especies que se puedan utilizar para guiar el proceso de restauración de plantas y animales (incluidas variedades agrícolas y variedades silvestres de los cultivos) que se hayan visto extirpadas o sean poco frecuentes en la zona evaluada.}

El primer paso en la recopilación de recursos de información para respaldar una inclusión sustancial de la información sobre la biodiversidad en el proceso de evaluación de la FLR debería ser el establecimiento de una estructura de gestión de la evaluación de la FLR (por ejemplo, un comité técnico de FLR, un comité ejecutivo de FLR, una institución responsable, etc.) que trabaje con el profesional experto en biodiversidad para identificar expertos locales o nacionales en silvicultura y vida silvestre que estén dispuestos a prestar asesoramiento en el proceso de evaluación y planificación de la restauración. Esto incluirá la elaboración de una lista inicial de contactos en los departamentos del gobierno, las organizaciones de la sociedad civil, las instituciones académicas y las comunidades locales que probablemente posean conocimientos especializados adecuados. Al contactar con esos agentes clave, resulta útil pedir datos de contacto de otros expertos adicionales con el fin de garantizar que no se olvide a nadie en la búsqueda inicial. La creación de una red desde el inicio será muy importante para desarrollar la apropiación (desde el nivel local al nacional) del proceso global de restauración.

\section{Algunos conjuntos de datos nacionales clave sobre la biodiversidad}

Muchos países han publicado listas o libros nacionales en los que se identifican y documentan especies prioritarias a nivel nacional desde el punto de vista de la conservación. El contenido de estas publicaciones varía de manera sustancial según los países; algunas de ellas son de carácter general, mientras que otras ofrecen información extremadamente detallada. Muchas se centran únicamente en los vertebrados (a menudo en los grandes mamíferos), si bien cada vez es más habitual encontrar información sobre múltiples grupos taxonómicos, incluidos invertebrados y plantas (como las especies de árboles amenazadas). El equipo responsable del proyecto deberá examinar estos documentos a fin de comprobar si las especies recogidas en ellos se pueden integrar en el proceso de evaluación y planificación de la restauración, y qué valor aportará su inclusión. En el caso de que no estén disponibles públicamente, con frecuencia estos datos se pueden adquirir a través del punto focal nacional del Convenio sobre la Diversidad Biológica o bien consultando las estrategias nacionales sobre la biodiversidad y planes de acción. 


\section{Estrategias nacionales sobre la biodiversidad y planes de acción (ENBPA)}

Se han elaborado estrategias nacionales sobre la biodiversidad y planes de acción para 189 Estados partes en el Convenio sobre la Diversidad Biológica. Esto significa que prácticamente todos los países han llevado a cabo recientemente una evaluación de su biodiversidad nacional y han formulado una estrategia nacional y un plan de acción para su conservación. Como es natural, el grado de detalle y profundidad de estos documentos varía en función de la capacidad de los países para llevar a cabo y ejecutar estas actividades. No obstante, pese a esta variedad, todas las estrategias nacionales sobre la biodiversidad y planes de acción ofrecen información sobre el estado de la biodiversidad nacional, las amenazas a las que se enfrenta, sus tendencias, prioridades y las acciones estratégicas llevadas a cabo.
Varias estrategias nacionales sobre la biodiversidad y planes de acción reconocen el papel de la restauración en el apoyo a las metas nacionales e internacionales de fomento de la biodiversidad, y para los países o regiones que lleven a cabo evaluaciones de la restauración de paisajes forestales estos documentos pueden ser una importante fuente de información específica sobre las especies existentes y un punto de partida para despertar el interés en la FLR entre las partes interesadas involucradas en el proceso de diseño de la estrategias nacionales sobre la biodiversidad y planes de acción (véase la sección Fuentes de datos sobre biodiversidad).

\section{Cómo extraer información pertinente sobre} la biodiversidad de las estrategias nacionales sobre la biodiversidad y planes de acción Al tratarse de un mandato internacional, la elaboración de estrategias nacionales sobre la biodiversidad y planes de acción y su contenido están relativamente armonizados y normalmente incluyen fuentes de información general sobre la biodiversidad. De manera similar a lo que ocurre en el caso de las evaluaciones de la restauración de

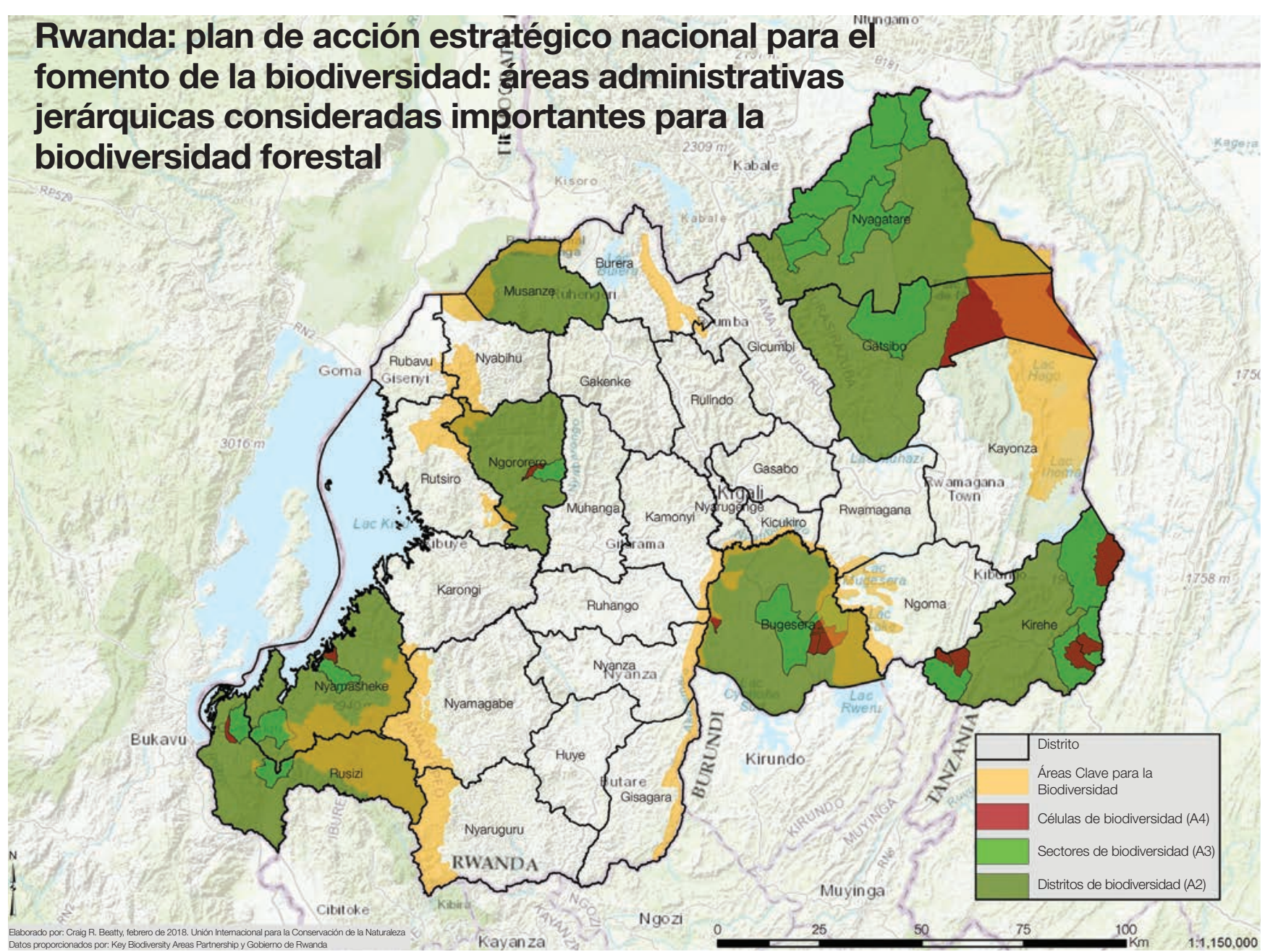

La figura 3 muestra los datos extraídos de la estrategia nacional sobre la biodiversidad y plan de acción de Rwanda, que no contenían mapas. Rwanda se divide administrativamente en distritos, sectores y células. Dentro de la estrategia nacional sobre la biodiversidad y plan de acción, se mencionan varios distritos como zonas prioritarias desde el punto de vista de la biodiversidad, y dentro de cada distrito se identifican hábitats cruciales que hacen referencia explícitamente a subdistritos (sectores) y/o a células dentro de estos (tres niveles administrativos). También se observaron situaciones en las que se mencionaban bosques concretos sin indicar la división administrativa en la que se ubicaban. Una sencilla búsqueda a través de Internet proporcionó la información necesaria para confirmar las áreas administrativas en cuestión. A partir de esta información textual y de datos espaciales correspondientes a las áreas administrativas, un analista del SIG puede crear mapas nacionales de las zonas prioritarias desde el punto de vista de la biodiversidad con base en jerarquías administrativas, y esos datos se pueden utilizar durante el análisis espacial de las oportunidades y prioridades de FLR. Además, este proceso analítico también se puede completar utilizando las cuencas hidrográficas, que pueden describir con mayor precisión los límites entre los diferentes ecosistemas. 
paisajes forestales, en las estrategias nacionales sobre la biodiversidad y planes de acción se identifican partes interesadas, zonas geográficas y acciones, muchas de las cuales coinciden con las de las evaluaciones de la FLR. Con frecuencia, los resultados del análisis normativo e institucional elaborado en el marco de una estrategia nacional sobre la biodiversidad o plan de acción estarán alineados con el mismo proceso de la evaluación de la FLR, y en la práctica podrán incluir varias de las mismas partes interesadas clave dentro de una jurisdicción. En consecuencia, sería recomendable iniciar la evaluación de la FLR con una auditoría de las políticas y leyes mencionadas en la estrategia nacional sobre la biodiversidad o plan de acción y de su relación con la FLR. Las políticas sectoriales relacionadas con la conservación de la biodiversidad suelen estar vinculadas a (o, de hecho, ser) políticas relativas a los bosques y paisajes, si bien a menudo se abordan en secciones diferentes de dichas políticas.

Las estrategias nacionales sobre la biodiversidad y planes de acción también están repletas de información geográfica sobre el estado y las tendencias de la biodiversidad. A menudo esta información es de naturaleza contextual y se refiere a zonas o características geográficas en las que la conservación de la biodiversidad reviste una importancia especial. Si bien la mayoría de las estrategias nacionales sobre la biodiversidad y planes de acción no contienen datos geoespaciales complementarios, la extracción de esta información a partir del texto de la estrategia nacional sobre la biodiversidad y plan de acción resulta relativamente sencilla y ofrece orientaciones adicionales para identificar e integrar las zonas importantes desde el punto de vista de la biodiversidad en las evaluaciones de la FLR. Es posible que el punto focal nacional del CDB para la zona objeto de evaluación también pueda ayudar a obtener esta información.
Por último, dado que se trata de un proceso reconocido internacionalmente que casi todos los países llevan a cabo, las estrategias nacionales sobre la biodiversidad y planes de acción recibieron un apoyo muy importante para su creación. En cada país se organizaron talleres que contribuyeron a reunir a los expertos y la información necesarios para formular las estrategias y las actuaciones indicadas en los planes. En muchos casos, estos procesos son tan recientes que las plataformas institucionales y el personal no han experimentado prácticamente variaciones. Las listas de grupos de trabajo y de partes interesadas están disponibles para su seguimiento por parte de los profesionales encargados de la FLR y por lo general constituyen anexos a los documentos de las estrategias nacionales sobre la biodiversidad y planes de acción. El personal gubernamental que se encarga actualmente de las evaluaciones de la FLR suele tener colegas dentro de sus propios departamentos o ministerios que trabajaron en la elaboración de la estrategia nacional sobre la biodiversidad o plan de acción. La identificación de (y la comunicación con) esas personas sobre la evaluación de la FLR en curso ofrecerá la oportunidad de integrar tanto la biodiversidad como la restauración de paisajes forestales.

\section{Fuentes de datos sobre biodiversidad}

\section{Conjuntos de datos históricos}

Para algunos países y regiones, la cobertura terrestre y el uso del suelo (incluidos los bosques y los hábitats asociados a estos), así como la distribución de las especies, han sido objeto de seguimiento o registro durante décadas. En muchos casos, estos registros se han centrado principalmente en los recursos naturales vivos con un claro valor comercial. Dichos registros pueden resultar útiles para determinar el alcance anterior de los ecosistemas autóctonos, incluida la

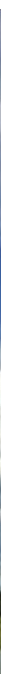


distribución previa de especies importantes (como los árboles madereros), que pueden constituir una parte de las futuras intervenciones de restauración. Los registros históricos de la distribución de especies animales pueden resultar valiosos para el proceso de planificación, sobre todo si uno de los objetivos del proceso de FLR es restablecer los paisajes que dan cobijo a esas especies. El retorno natural de especies extirpadas a un paisajes restaurado se podría utilizar como un indicio general de éxito de la restauración.

\section{Especies y lugares importantes desde el punto de vista cultural \\ Como parte de una estrategia general de restauración del paisaje y de su componente de biodiversidad, resulta útil -tanto desde el punto de vista del proceso técnico de restauración como de la interacción con las comunidades locales- tener en cuenta en el proceso de planificación las especies y lugares que revistan importancia desde el punto de vista cultural. Puede tratarse de especies o lugares importantes por razones religiosas o espirituales, que tengan algún uso económico a nivel local (por ejemplo, para la obtención de medicamentos o alimentos de subsistencia), o bien zonas o especies que ofrezcan un especial disfrute por su belleza, su valor intrínseco u otro tipo de motivo relevante para las comunidades locales. La información sobre las especies y lugares importantes (como los bosques sagrados) suele estar disponible únicamente a escala local, y por lo general lo más adecuado es obtenerla mediante la interacción temprana con los naturalistas y las comunidades presentes en las zonas en las que se haya propuesto ejecutar el proyecto.}

\section{Datos internacionales}

Además de los numerosos recursos nacionales que ofrecen datos e información sobre la biodiversidad, existe una amplia variedad de datos normalizados relativos a la biodiversidad generados por las organizaciones internacionales dedicadas a la conservación; buena parte de ellos resultan de utilidad durante las evaluaciones de la FLR. A continuación se facilita una relación parcial de algunos de los principales datos disponibles que los profesionales encargados de la FLR pueden estudiar utilizar:

La Lista Roja de Especies Amenazadas de la UICN. La Lista Roja de la UICN es la principal fuente de datos a escala mundial sobre especies amenazadas y no amenazadas (en ella se documentan más de 87.000 especies). Con frecuencia, la Lista Roja proporciona información detallada sobre la distribución mundial de una especie (incluidos datos espaciales sobre una variedad), tendencias poblacionales, requisitos ecológicos y de los hábitats, amenazas a las que está expuesta la especie en cuestión, uso y comercio y necesidades de conservación. A continuación, la información de la Lista Roja se utiliza para determinar el estado de conservación global de cada especie; la escala de estados va desde "En peligro crítico de extinción" (especies prioritarias para la conservación a nivel mundial) hasta "Preocupación menor" (aquellas especies que suscitan una menor preocupación inmediata desde el punto de vista de la conservación). Los datos están disponibles públicamente para su uso no comercial, y se puede acceder a ellos en la dirección siguiente: http://www.iucnredlist.org

Áreas Clave para la Biodiversidad. Se trata de lugares identificados a nivel nacional sobre los que existe el reconocimiento de que contribuyen al mantenimiento de la biodiversidad. Se ha desarrollado un conjunto de criterios y umbrales armonizados a nivel mundial (divididos en cinco categorías: biodiversidad amenazada, biodiversidad geográficamente restringida, integridad ecológica, procesos biológicos y carácter irreemplazable) para guiar la identificación de zonas prioritarias desde el punto de vista de la conservación con límites definidos. Las Áreas Clave para la Biodiversidad se utilizan cada vez más para apoyar la planificación

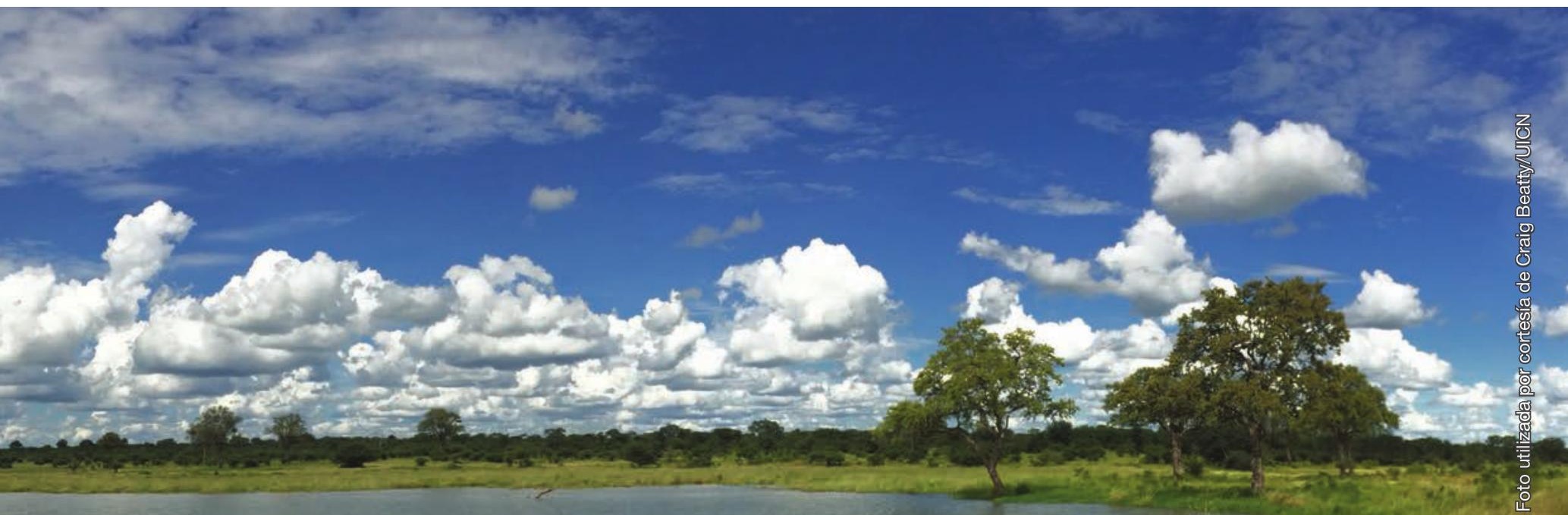


de la conservación y el desarrollo sostenible a nivel nacional y regional. En la actualidad incluyen las Áreas Importantes para las Aves y la Biodiversidad y las zonas de la Alianza para Cero Extinción, que se detallan más adelante. Puede accederse a la Base de Datos Mundial de las Áreas Clave para la Biodiversidad en la dirección siguiente: http://www. keybiodiversityareas.org/home

Áreas Importantes para las Aves y la Biodiversidad. Desarrolladas por BirdLife International, se trata de zonas que han sido identificadas como significativas para la conservación de especies de aves. Estas áreas se han catalogado mediante un conjunto de criterios armonizados a nivel internacional; se han definido en total más de 12.000 Áreas Importantes para las Aves y la Biodiversidad en más de 200 países y territorios. Estos lugares también están reconocidos como Áreas Clave para la Biodiversidad de las aves. Puede obtenerse información más detallada sobre las Áreas Importantes para las Aves y la Biodiversidad y su valor en la dirección siguiente: http:// www.birdlife.org/ worldwide/programme-additional- info/important-birdand-biodiversity-areas-ibas

Lugares de la Alianza para Cero Extinción. La Alianza para Cero Extinción es unaasociación de organizaciones no gubernamentales dedicadas a la conservación de la biodiversidad que trabaja para evitar la extinción de las especies mediante la identificación y protección de los lugares en los que hay especies en peligro de extinción o en peligro crítico de extinción restringidas a un único emplazamiento. Los grupos de especies terrestres evaluados según los criterios de la Alianza para Cero Extinción incluyen mamíferos, aves, anfibios, coníferas y algunos reptiles, aunque también se están realizando progresos con otras especies. Puede consultarse información adicional sobre los lugares de la Alianza para Cero Extinción en el siguiente sitio web (que incluye un mapamundi): http://www.zeroextinction.org

La Lista Roja de Ecosistemas de la UICN. La Lista Roja de Ecosistemas de la UICN reviste interés para los profesionales dedicados a la restauración, sobre todo porque pretende ofrecer una evaluación global del estado de conservación de los ecosistemas del mundo para 2025, basada en la aplicación de una serie de categorías y criterios normalizados recientemente desarrollados. Este objetivo central se ha establecido con el propósito de respaldar la conservación en las decisiones sobre la gestión y el uso de los recursos mediante la identificación de los ecosistemas expuestos a un mayor riesgo de destrucción. Puede encontrarse información adicional sobre la Lista Roja de Ecosistemas de la UICN y su cobertura geográfica actual en: https://iucnrle.org

Base de Datos Mundial de Especies Invasoras. El mantenimiento de esta base de datos corre a cargo del Grupo de Especialistas en Especies Invasoras de la Comisión de Supervivencia de Especies de la UICN. Contiene información (y una función de búsqueda) sobre especies exóticas e invasoras que influyen negativamente en la biodiversidad y las áreas naturales autóctonas, incluida una lista de las "100 especies exóticas más invasoras del mundo". Aunque, como es natural, no puede abarcar la enorme variedad de especies potencialmente invasoras, la Base de Datos Mundial de Especies Invasoras representa una herramienta extremadamente útil para planificar un proyecto de FLR, sobre todo a la hora de llevar a cabo el estudio inicial de especies no nativas

Cómo evitar durante la planificación de la FLR los daños duraderos que pueden ocasionar las especies invasoras

Si bien se recomienda utilizar en la medida de lo posible las especies amenazadas, en muchos casos una intervención específica de FLR requerirá el uso de especies no autóctonas (por ejemplo, en situaciones en las que se necesiten árboles de crecimiento rápido y no existan alternativas autóctonas, o en las que haya emergido la agrosilvicultura como solución basada en la naturaleza al problema de la degradación del paisaje). En los casos en que se haya previsto recurrir a especies no autóctonas, debe prestarse la máxima atención para identificar especies que no dañen el ecosistema local por convertirse en (o albergar) especies exóticas invasoras.

Las especies invasoras constituyen una de las amenazas más habituales para la biodiversidad autóctona. Además de los problemas que ocasionan a las especies autóctonas (por ejemplo a través de la predación, la competencia o los cambios en el suelo o la estructura del sustrato), las especies invasoras pueden afectar a las comunidades locales, al invadir y dañar los terrenos de cultivo y otros lugares económicamente viables. El coste asociado a la eliminación de especies invasoras puede ser extremadamente elevado y, en muchos casos, puede resultar imposible erradicar por completo las especies exóticas invasoras, de modo que la única opción de gestión posible es su control constante por parte de la población, algo que resulta muy oneroso.

Si bien es necesario extremar la cautela a la hora de elegir los tipos de vegetación (como árboles exóticos que puedan convertirse en especies invasoras), también es importante tomar decisiones inteligentes a la hora de introducir especies animales. Toda la información detallada que recopile el ecologista del proyecto debe ser analizada antes de estudiar cualquier opción para su introducción. Como ocurre con la vegetación, la introducción de especies animales invasoras puede ser difícil de revertir y provocar un daño continuado, no solo en la zona en la que se ejecute el proyecto, sino también en el paisaje, incluidas las zonas y ecosistemas circundantes. 
asociadas al paisaje en el que se va a desarrollar el proyecto. También es importante señalar que no todas las especies exóticas introducidas son invasoras. El Convenio sobre la Diversidad Biológica define las "especies exóticas invasoras" como "plantas, animales, agentes patógenos y otros organismos que no son nativas de un ecosistema, y que pueden causar daño económico o medioambiental o afectar negativamente a la salud humana". La Base de Datos Mundial de Especies Invasoras puede encontrarse en la siguiente dirección: http://www.iucngisd. org/gisd

Base de Datos Mundial sobre Zonas Protegidas. El acceso a esta base de datos públicamente disponible, que constituye un proyecto conjunto del Programa de las Naciones Unidas para el Medio Ambiente (PNUMA), el Centro Mundial de Vigilancia de la Conservación y la UICN, se proporciona a través de la plataforma en línea "Protected Planet". Esta plataforma permite descargar datos espaciales, que incluyen humedales importantes recogidos en el Convenio de Ramsar. Además, contiene la información más detallada a escala mundial sobre cobertura de zonas terrestres y marinas protegidas. Puede accederse a las estadísticas conexas y a información adicional relativa a la Base de Datos Mundial sobre Zonas Protegidas y a la plataforma Protected Planet en la dirección siguiente: https://protectedplanet.net

Herramientalntegrada de Evaluación dela Biodiversidad. Pese a no ser uno de los principales recursos para la obtención de datos sobre la biodiversidad, representa una herramienta valiosa que reúne diversas capas de datos mundiales y nacionales que resultan útiles para la planificación de la FLR, como los límites de las zonas protegidas (a partir de la Base de Datos Mundial sobre Zonas Protegidas), información biológica sobre índices de diversidad de hábitats y especies (proporcionada a través de la Lista Roja de la UICN) y Areas Clave para la Biodiversidad (incluidas las Áreas Importantes para las Aves y la Biodiversidad y los lugares de la Alianza para Cero Extinción anteriormente expuestos), que resultan de utilidad tanto con fines de investigación como de planificación de la conservación y para guiar el desarrollo sostenible (especialmente a la hora de gestionar el riesgo y las oportunidades comerciales). Estos datos están disponibles en dos sitios web: el de la Herramienta Integrada de Evaluación de la Biodiversidad para la Investigación y la Planificación de la Conservación (https://www.ibat-alliance.org/ibatconservation), que proporciona acceso a información disponible de manera gratuita, y la Herramienta Integrada de Evaluación de la Biodiversidad para Empresas (https://www.ibatforbusiness.org), que exige el pago de una tasa para poder utilizar los amplios datos relativos a la biodiversidad con fines comerciales.

\section{Información normativa e institucional referente a la biodiversidad}

Una de las actividades más importantes que deben llevarse a cabo durante una evaluación de la FLR es un análisis del grado en que las políticas, leyes, códigos e instituciones existentes favorecen o desincentivan la restauración de paisajes forestales. Las políticas y leyes nacionales específicamente relacionadas con

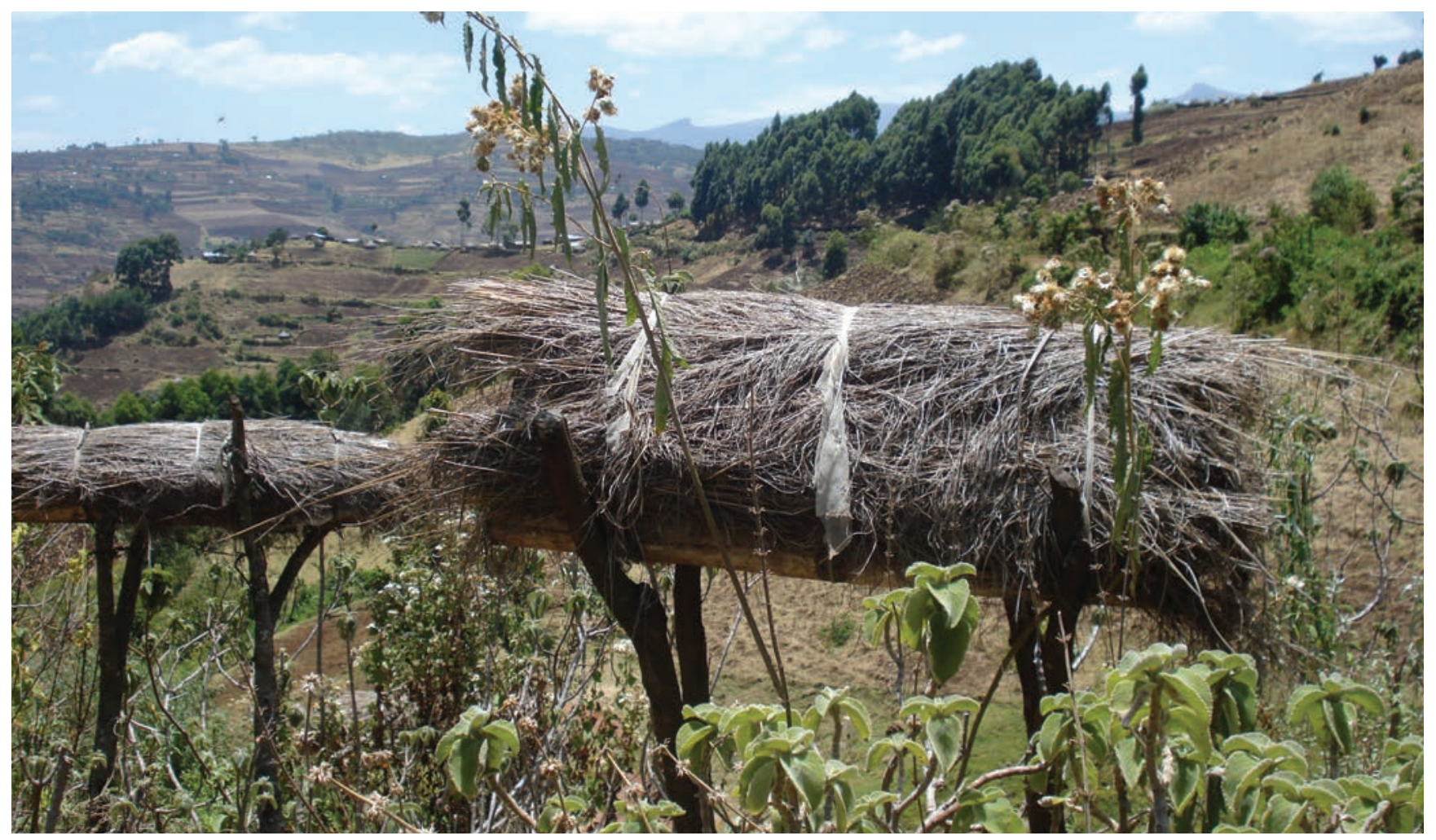

Las colmenas producen miel que pueden ser un producto básico no maderable y no agrícola de gran valor, al tiempo que potencian la polinización. Aquí, en las faldas del monte Elgon, en el distrito de Bukwo (Uganda), tanto las comunidades como las abejas dependen de la biodiversidad del paisaje. Fotografía utilizada por cortesía de Craig Beatty/UICN. 
la biodiversidad suelen resumirse en la estrategias nacionales sobre la biodiversidad y planes de acción. Como resultado de ello, es posible que los tipos de leyes y políticas que se describen en estas estrategias nacionales y planes de acción reflejen con más frecuencia las políticas relacionadas específicamente con las especies amenazadas, el comercio y las zonas protegidas para su conservación, sin adoptar una visión más amplia sobre las implicaciones sociales o la dependencia respecto de la biodiversidad. Otras políticas, planes y estrategias identificadas durante el proceso de evaluación que resultan pertinentes para la FLR guardan relación con el uso de los recursos naturales, los regímenes de tenencia de la tierra y las cuestiones relacionadas con los conflictos, la jurisdicción y la tenencia. Dado que muchas de estas políticas pueden contemplar de manera inherente o específica el acceso a los recursos naturales, existe un componente inherente relacionado con la biodiversidad en cada una de ellas, y la mayoría proporciona información adicional sobre la dependencia social respecto de los recursos naturales y el capital ecológico.

La restauración de paisajes forestales adopta una visión de la conservación de la biodiversidad que incluye especies y ecosistemas que puede que no se encuentren actualmente amenazados, pero que proporcionan las condiciones cruciales para la restauración de paisajes polivalentes. Cuando la biodiversidad se deteriora, las especies y los ecosistemas se ven expuestos a un riesgo cada vez mayor, lo que provoca una degradación a gran escala del paisaje. Para comprender mejor el entorno propicio para la FLR que puede maximizar también los resultados desde el punto de vista de la biodiversidad, es necesario entender también mejor las políticas y los planes que afectan al conjunto del paisaje.
El análisis de las estrategias, leyes, políticas y planes de FLR que afectan a la zona evaluada proporcionará orientaciones esenciales para superar los obstáculos que dificultan la correcta ejecución de la FLR. Este análisis puede incluir la identificación de políticas contradictorias o que afecten de manera desproporcionada a un sector a expensas de otro. Por lo general, este proceso corre a cargo de un grupo detrabajo sobre "políticaeinstituciones" dentro de la estructura de evaluación de la FLR, aunque el hecho de contar con un profesional especializado en biodiversidad que sepa traducir el efecto que tendrán dichas políticas (como, por ejemplo, la agrícola o la comercial) sobre la biodiversidad permitirá mejorar drásticamente el reconocimiento y la incorporación de este aspecto en la FLR. Un análisis del entorno favorable a la FLR puede ofrecer un panorama claro de los (des) incentivos a la restauración y conservación para las partes interesadas presentes en el entorno; este análisis puede asimismo proporcionar recomendaciones de cara a la adopción de un enfoque holístico y cohesivo con respecto a la biodiversidad y la FLR.

Una de las dificultades a las que puede enfrentarse el profesional son los diferentes límites jurídicos y jurisdicciones establecidos en las diversas leyes y políticas relacionadas con la FLR y en las estrategias nacionales sobre la biodiversidad y planes de acción, por ejemplo. La inmensa mayoría de las estrategias nacionales sobre la biodiversidad y planes de acción se basan en zonas protegidas, mientras que muchos de los otros instrumentos jurídicos en torno a la FLR consideran jurisdicciones como provincias, distritos o comunidades. En la actualidad sigue resultando complicado extraer e interpretar esta información necesaria al nivel administrativo o político correcto para la evaluación de la FLR. A esta dificultad puede sumarse la falta de consideración general de la biodiversidad en las políticas y planes económicos, de desarrollo, sobre la FLR o sobre el uso del

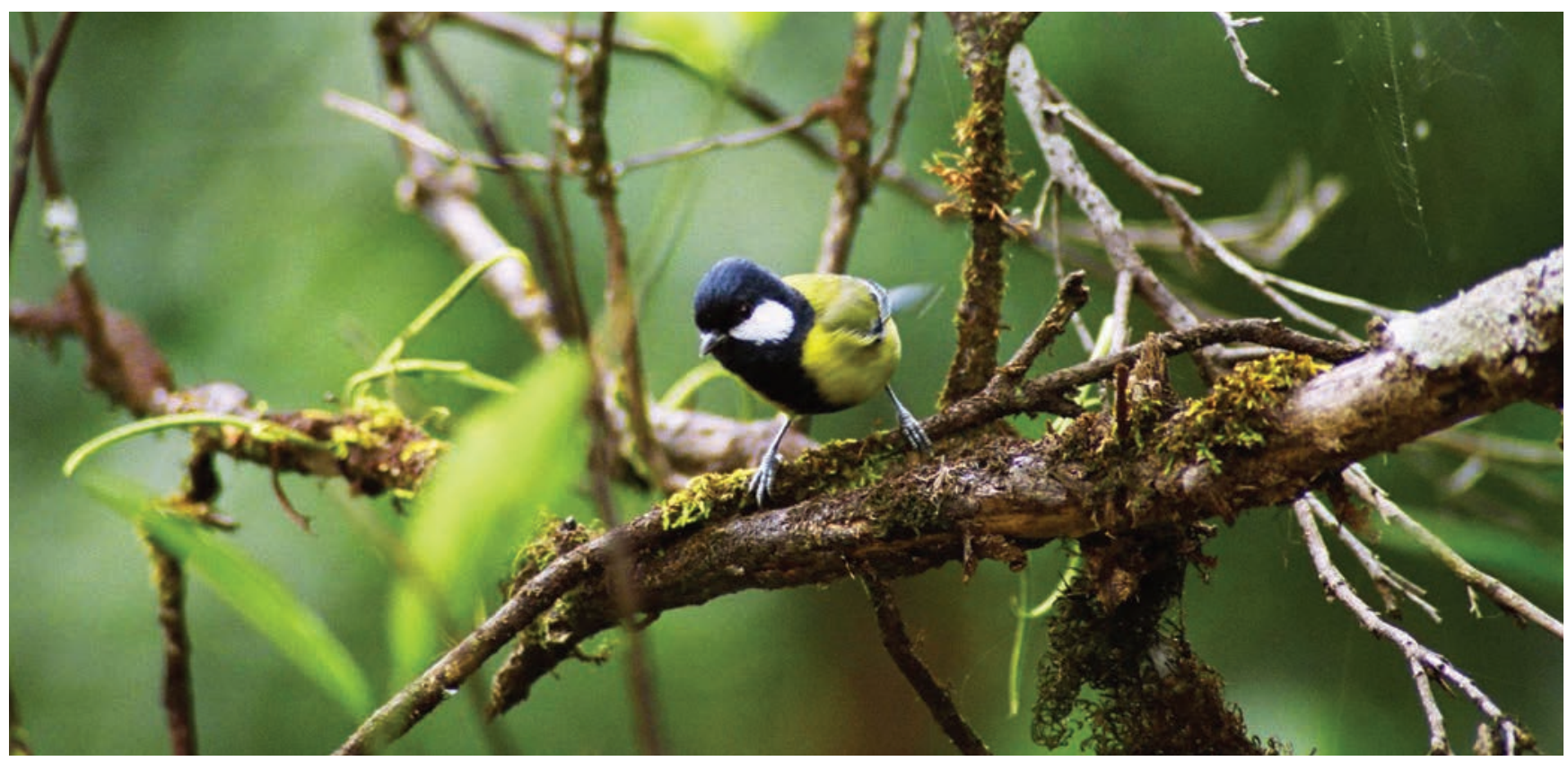

La presencia de especies de aves puede ser un importante indicio de éxito de la restauración. Muchas especies presentan estrictos requisitos en cuanto al hábitat en el que pueden vivir, pero la presencia continuada de especies generalistas también señala que es posible que los paisajes hayan dejado de degradarse. Asimismo, los cantos de las aves y los avistamientos de estas constituyen una forma relativamente sencilla de llevar a cabo un seguimiento de, al menos, un componente de la biodiversidad. Carbonero dorsiverde (Parus monticolus), Sikkim, India. Fotografía utilizada por cortesía de Akshay Vishwanath. 
suelo actualmente existentes. Como resultado de ello, puede que se ignore la biodiversidad cuya conservación no figure entre los objetivos prioritarios (de la estrategia nacional sobre la biodiversidad o plan de acción) y que no esté catalogada en el resto de políticas y planes, incluso en términos de valor de exportación de recursos naturales específicos. Dado que la biodiversidad y los servicios ecosistémicos constituyen bienes públicos que tienden a infravalorarse, las políticas y leyes que apoyan la función de la biodiversidad en la restauración de paisajes funcionales han ido generalmente rezagadas con respecto a los objetivos de las políticas diseñadas para impulsar el crecimiento económico (Arrow et al., 1995; Kumar et al., 2013). A su vez, esta infravaloración de la biodiversidad y de los servicios ecosistémicos ha conducido a bajas inversiones en la restauración del paisaje, a pesar de los numerosos y diversos beneficios que ofrece esta.

Además, cada uno de los objetivos habituales de la FLR cuenta con una amplia base de leyes e instituciones que lo respalda, sobre todo si se tiene en cuenta que dichos objetivos apoyan a su vez otros que guardan un vínculo más directo con el bienestar social. La voluntad política y el movimiento en favor de temas como la salud pública y el alivio de la pobreza están relativamente consolidados y adecuadamente financiados, y está claro que ambos objetivos están íntimamente relacionados con unos paisajes en buen estado (Herrera et al., 2018). La restauración, el mantenimiento y la conservación de la biodiversidad del paisaje -con independencia de su valor de conservación, pero reconociendo también este- son cruciales para lograr un avance significativo y sostenible en pos de estos objetivos.

Un aspecto especialmente útil de la elaboración de una estrategia nacional sobre la biodiversidad y plan de acción es la identificación, desarrollo y perfeccionamiento de políticas públicas de fomento de la conservación de la biodiversidad. Por extensión, muchas de las políticas desarrolladas para la conservación de la biodiversidad también influyen en la restauración de los paisajes degradados. En algunos casos se puede exigir que las intervenciones de restauración incluyan la utilización de un determinado umbral de especies de plantas autóctonas en el proceso de restauración. En otros, puede que los tipos de restauración que se pueden llevar a cabo estén definidos en las leyes aprobadas para apoyar la conservación de la biodiversidad o para limitar la propagación de especies invasoras. El análisis de las políticas públicas y de las leyes elaboradas en el marco del proceso de formulación de la estrategia nacional sobre la biodiversidad y plan de acción, y de su conexión con otras políticas y leyes similares relativas a la FLR, puede permitir detectar los puntos en común entre ambos tipos de políticas y posibles lagunas normativas.

Los profesionales encargados de la FLR deberán tratar de modificar las políticas públicas que socaven las iniciativas de restauración de paisajes forestales, a fin de garantizar que cualquier actuación restauradora que se lleve a cabo en tierras degradadas cuente con respaldo político e institucional. Pese a que a menudo representa una tarea considerable, en muchos países se han modificado leyes nacionales o subnacionales para apoyar la restauración de paisajes forestales y/o la conservación de la biodiversidad, generando resultados positivos tanto para la población como para la naturaleza. La revisión y modificación de políticas públicas ayuda a garantizar que las soluciones derivadas del proceso de evaluación de la FLR impulsado por las partes interesadas y las estrategias resultantes sienten unas bases para la implementación que puedan resistir los ciclos políticos y beneficiarse de la visión a largo plazo de una restauración de paisajes sostenible y eficaz.

\section{Datos sobre biodiversidad en mapas y análisis espaciales}

Un aspecto clave en lo que concierne a la alineación entre la información sobre la biodiversidad y las evaluaciones de la FLR en apoyo a las iniciativas de conservación y restauración del paisaje, como REDD+ o el Desafío de Bonn, es la evaluación analítica de si existe algún tipo de interacción (y, en ese caso, cuál) entre la información sobre la restauración y la biodiversidad. Las evaluaciones de la conservación de la biodiversidad, que por lo general se llevan a cabo en el marco de las estrategias nacionales sobre la biodiversidad y planes de acción pero también se pueden realizar a través de otros programas e iniciativas de conservación, contienen gran cantidad de datos geográficos referentes a la biodiversidad, los hábitats y los paisajes. De manera similar, las evaluaciones de la FLR también recopilan y analizan datos espaciales para identificar los impulsores de la degradación del paisaje y las zonas que ofrecen oportunidades para la restauración paisajística para los numerosos y diferentes usos del suelo. Uno de los principales objetivos de este documento de orientación es facilitar la cooperación y el intercambio de información y conocimientos entre estos procesos complementarios.

Entre las diferentes fuentes nacionales, regionales y mundiales de información sobre la biodiversidad, existen numerosas fuentes de información especial bien documentadas y respetadas que ofrecen datos sobre las especies, los hábitats y los ecosistemas. A nivel mundial, la Lista Roja de Especies Amenazadas de la UICN exige que todos los informes que se publiquen sobre especies amenazadas contengan rangos de distribución, y la mayor parte de los informes sobre especies incluyen esta información. Además, se han llevado a cabo varias evaluaciones a nivel mundial de ecosistemas y ecorregiones, incluidas las realizadas por el Servicio Geológico de los Estados Unidos² y por WWF/TNC ${ }^{3}$. La atención prestada a escala planetaria al seguimiento de la deforestación y a los cambios en el uso del suelo y la cubierta terrestre también han llevado a utilizar datos de teledetección por satélite, que pueden proporcionar información muy útil en tiempo real sobre la pérdida de superficie forestal y sobre los cambios de uso del suelo, que no se debe confundir con el seguimiento de la biodiversidad per se, pero no por ello deja de ser

2. https://rmgsc.cr.usgs.gov/ecosystems

3. https://www.worldwildlife.org/biome-categories/terrestrial-ecoregions 
información muy útil desde el punto de vista paisajístico. La medición y evaluación de la biodiversidad en el contexto de la FLR debería aprovechar estos conjuntos de datos mundiales y otros datos nacionales (o de nivel inferior) sobre la biodiversidad que se obtengan durante las fases iniciales de la evaluación.

Como resultado del proceso de evaluación de la FLR se deberían obtener mapas que muestren los lugares en los que se ha producido degradación de la tierra (y que a menudo incluirán análisis de la intensidad de esta degradación), de emplazamientos en los que sea posible llevar a cabo una intervención de restauración y de los sitios en los que podrían existir oportunidades para la restauración. En cada uno de estos productos se puede utilizar información sobre la biodiversidad para contribuir a definir, priorizar y delimitar con mayor precisión las zonas que muestren un elevado potencial para llevar a cabo actividades de restauración de paisajes forestales. Los lugares en los que la biodiversidad se encuentre amenazada pueden incluirse en el análisis espacial como un tipo de filtro de priorización que dé un mayor peso a los lugares sometidos a mayores presiones de degradación. El profesional encargado de la FLR debería ubicar las zonas degradadas en las que la ejecución de la FLR puede beneficiar al paisaje y a la población que habite en él, así como identificar los solapamientos entre esas zonas y aquellas que también sean prioritarias desde el punto de vista de la biodiversidad.

De manera alternativa, dado que la mayor parte de los datos referentes a la biodiversidad estarán relacionados con la presencia o ausencia de especies o con otros datos asociados a la biodiversidad, resulta relativamente sencillo integrar esos datos en las evaluaciones espaciales de las tierras degradadas, las zonas prioritarias y las oportunidades para la FLR. Normalmente, los datos de biodiversidad son datos de presencia geográfica; no es frecuente encontrar datos espaciales que abarquen la totalidad de una zona en la que se esté llevando a cabo una evaluación de la FLR y que también incluya características relacionadas con la biodiversidad, como índices de riqueza o variedad de especies (por ejemplo, el índice de Shannon o el índice de Simpson). A pesar de ello, se puede llevar a cabo la planificación de la conservación y la modelización de la idoneidad de los hábitats utilizando herramientas con las que los biólogos o ecologistas especializados en conservación están familiarizados como NatureServe Vista, Maxent, Marxan, Zonation, VORTEX, RAMAS, BIOMOD, etc.. Cuando se introduce en ellos un contexto adecuado para las especies, estos tipos de modelos pueden ayudar a ilustrar la respuesta de las especies a la restauración.

Con el fin de identificar eficazmente las prioridades desde el punto de vista de la biodiversidad utilizando los recursos de información descritos anteriormente, el analista especial debería ponerse en contacto con los proveedores de datos utilizando para ello la información de contacto que figura en las fuentes de datos sobre biodiversidad. Una vez adquiridos los datos, estos se pueden analizar por separado en forma de estudios de la biodiversidad o bien integrarse en la parte general de análisis de datos de la evaluación de la FLR. La decisión dependerá de los objetivos de la evaluación de la FLR y de las expectativas del grupo de trabajo encargado de ella, así como de las partes interesadas. Si la biodiversidad constituye una consideración clave incluida en forma de objetivo de la FLR, podría tener sentido efectuar un análisis independiente de la biodiversidad y posteriormente utilizar sus resultados para aportar información a otros análisis o para definir las prioridades

\section{Análisis multicriterio de la biodiversidad en evaluaciones de la FLR}

El análisis espacial de datos sobre la biodiversidad dentro de un marco analítico multicriterio resulta relativamente sencillo. El analista de datos espaciales deberá adquirir todos los tipos de capas de datos pertinentes, asegurarse de que se encuentren en formato de trama y trabajar con las partes interesadas para parametrizarlos a fin de incluir en el análisis los datos que sean de interés. La parametrización de los datos espaciales sobre la biodiversidad puede incluir la eliminación de variedades de especies que estén catalogadas como de "preocupación menor" o la selección de un taxón particular que revista interés para los profesionales encargados de la restauración o para las partes interesadas. Además, puede incluir la extracción de zonas que presenten un porcentaje mínimo específico de cubierta vegetal, o de ecorregiones con una prioridad o valor de conservación demostrados.

A continuación, el analista reclasifica estos datos en tramas binarias, en las que el valor 1 se iguala al parámetro de biodiversidad que el analista encuentra interesante y el 0 incluye todas las demás zonas incluidas en la trama. Existe la posibilidad de asignar diferentes ponderaciones a las capas de entrada durante la reclasificación, si bien es posible que esto provoque un debate prolongado entre los socios del proyecto y las partes interesadas sobre las ponderaciones adecuadas. En su lugar, es más sencillo debatir con las partes interesadas sobre los parámetros adecuados que deberían incluirse en cada capa.

Seguidamente, el analista pide al SIG que ejecute un cálculo algebraico aditivo de mapas utilizando las capas de entrada de la trama binaria que se acaban de parametrizar y reclasificar. La trama resultante mostrará los puntos en los que los criterios de biodiversidad se solapan, y en qué medida. En esta fase se deberá prestar atención para reducir el riesgo de que se produzcan solapamientos de datos que distorsionen el análisis. Un ejemplo frecuente de lo anterior en el análisis de la biodiversidad es el solapamiento entre las Áreas Clave para la Biodiversidad y las zonas protegidas. La utilización de ambas capas en un análisis multicriterio de la biodiversidad sin reconocer su autocorrelación dará lugar a una doble contabilidad de las zonas en cuestión. 
En la figura siguiente, se utilizaron cuatro criterios amplios para evaluar la posibilidad de incluir la biodiversidad en la Evaluación y estrategia nacional de restauración de paisajes forestales de Malawi. La cubierta arbórea "elevada" se determinó empleando como umbral mínimo un $40 \%$ de cobertura vegetal. Las partes interesadas también deseaban identificar las zonas legalmente protegidas situadas fuera de las Áreas Clave para la Biodiversidad actualmente identificadas y las Áreas Clave para la Biodiversidad ubicadas fuera de las zonas actualmente protegidas. Debido a la naturaleza de la evaluación, no se incluyeron en este análisis las zonas protegidas, tal como se explica en el documento de la evaluación nacional. Por último, se incluyeron como información de entrada las ecorregiones designadas como "en peligro" o "en peligro crítico". Al superponerlas, se obtiene el mapa de colores que muestra los lugares en los que coinciden los criterios de entrada.

En la evaluación nacional de la FLR de Malawi se determinó que si el país cumplía menos de un 10\% del compromiso contraído en el marco del Desafío de Bonn utilizando enfoques que priorizaran la restauración utilizando especies autóctonas y apoyando los ecosistemas naturales, el país podría restaurar todas sus tierras degradadas incluidas en sus Áreas Clave para la Biodiversidad. Esto podría ofrecer enormes beneficios para los compromisos asumidos por Malawi en virtud del Convenio sobre la Diversidad Biológica.

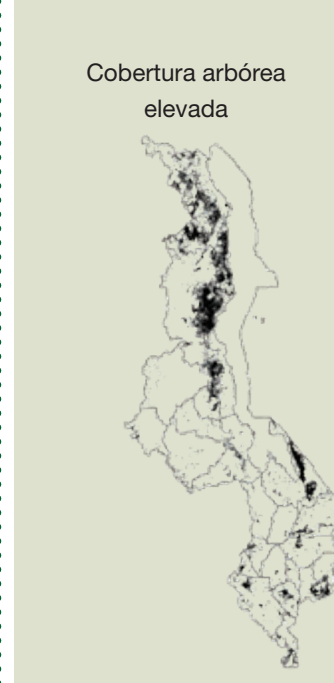

$$
\begin{aligned}
& \text { Zonas protegidas } \\
& \text { fuera de las Áreas } \\
& \text { Clave para la } \\
& \text { Biodiversidad }
\end{aligned}
$$
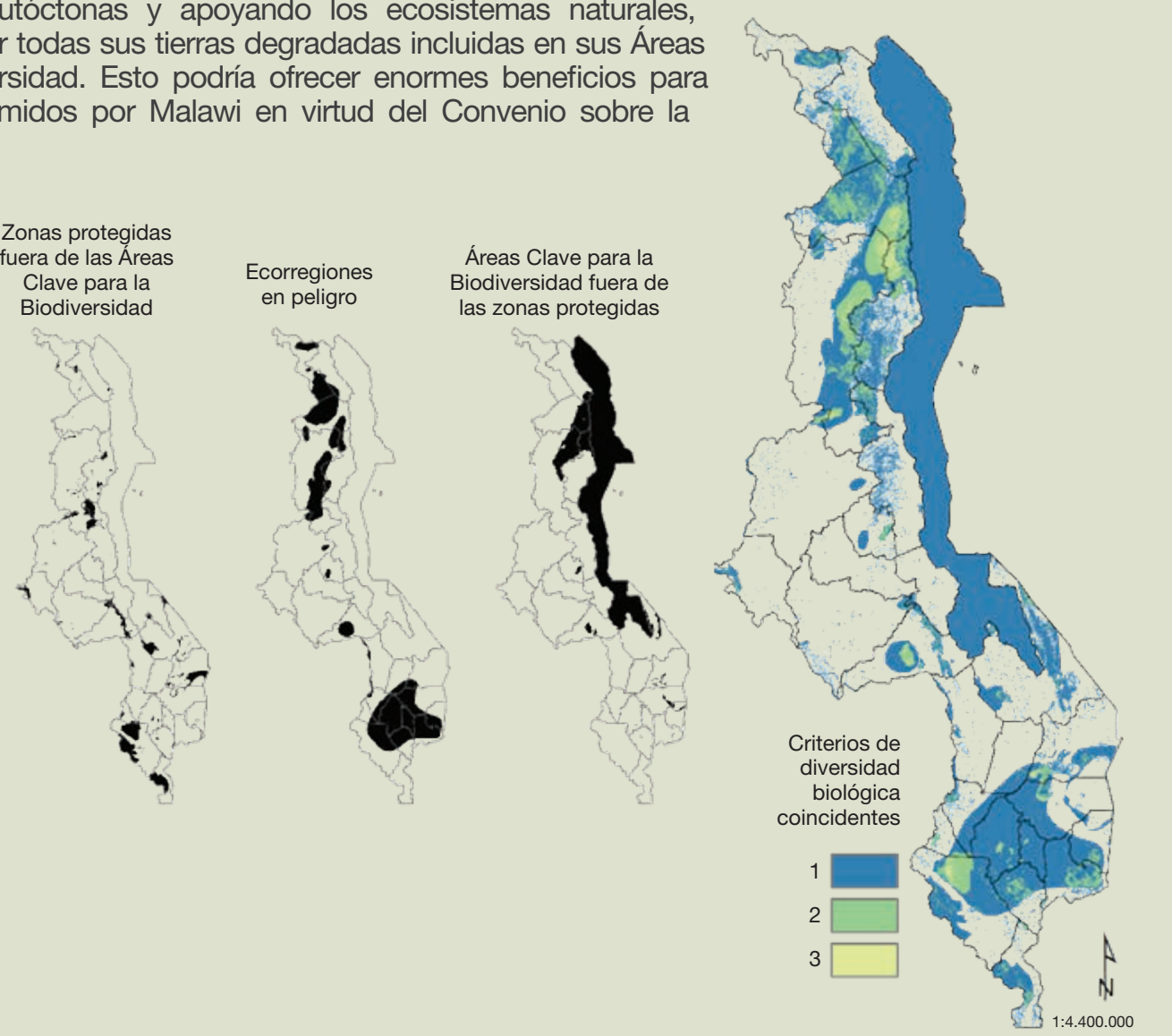

de estos (por ejemplo, análisis sobre la degradación, la seguridad alimentaria, la resiliencia, etc.). Sin embargo, en el caso de que la restauración de la biodiversidad no sea un objetivo explícito de la evaluación de la FLR, podría resultar útil incluir esos datos como componentes de la evaluación subyacente de la FLR. Esto implica incluir los datos sobre la biodiversidad como uno de los muchos criterios de los que consta un análisis multicriterio, o bien utilizar los datos sobre la biodiversidad como indicadores indirectos de otros procesos biofísicos o sociales que tengan interés para la evaluación de la FLR.

La última consideración que es preciso tener en cuenta en el análisis espacial es la dinámica y el flujo ecológicos en la evaluación de los datos referentes a la biodiversidad de cara a la FLR. Si bien los datos espaciales son estáticos, los ecosistemas, las especies y los genes son dinámicos, y la proximidad de las diferentes áreas importantes para la biodiversidad confiere un nivel adicional de consideración a la hora de establecer las prioridades de la FLR en lo que atañe a la biodiversidad; la configuración de los fragmentos residuales de hábitats, los cursos de agua o las poblaciones pueden aumentar el nivel de prioridad de esas zonas desde el punto de vista de la restauración de la biodiversidad. Si existen datos disponibles, se recomienda que los profesionales expertos en biodiversidad analicen las tendencias de las especies y las dinámicas de las poblaciones a lo largo de varias generaciones para su inclusión en el análisis de los datos espaciales de las evaluaciones de la FLR. Esto proporcionará asimismo una información más fiable sobre los datos iniciales y los valores de referencia que se utilizarán para llevar a cabo el seguimiento de los efectos de la FLR sobre la biodiversidad.

También puede ser pertinente analizar los cambios que pueden sufrir las diferentes variedades de especies como consecuencia de las variaciones climáticas o de los 
efectos derivados del cambio climático. Existe al menos un caso confirmado en la era moderna de extinción de un mamífero debida al cambio climático (Waller et al., 2017), y la influencia de las variaciones climáticas, incluidas las consecuencias del aumento del nivel de los mares sobre las especies, es real y está evolucionando (Thomas et al., 2004; Wetzel et al. 2013). Dichas consecuencias pueden incluir reducciones de las variedades o de la población, además de cambios más amplios en los ecosistemas asociados a la alteración de las relaciones entre las especies, los efectos de las especies exóticas invasoras o cascadas tróficas indeterminadas. Está claro que a la hora de considerar la FLR en el contexto del cambio climático, la inclusión de la biodiversidad no solo debería tener en cuenta las condiciones ecológicas actuales, sino también, siempre que sea posible, las condiciones ecológicas futuras previstas. Esto permite mejorar la resiliencia de las especies seleccionadas para la restauración ante los cambios en los patrones climáticos y meteorológicos. La utilización de diversos tipos de especies en las intervenciones de restauración ayuda asimismo a evitar que las grandes inversiones en el diseño, la planificación y la implementación se retiren como consecuencia de cambios ambientales imprevistos. Existen varias herramientas, como el Índice de Vulnerabilidad al Cambio Climático $^{4}$ desarrollado por NatureServe, que pueden ser muy importantes para modelizar los efectos que puede ejercer el cambio climático sobre las especies. Además, el Grupo de Especialistas en Cambio Climático de la Comisión de Supervivencia de Especies de la UICN (https://iucnccsg.org/) puede proporcionar recursos e información adicionales sobre la susceptibilidad de las especies al cambio climático, así como recomendaciones para mejorar la conservación de las especies en condiciones climáticas cambiantes.

\section{Identificación de carencias en materia de biodiversidad}

Pese al creciente volumen de información fiable sobre la biodiversidad que puede obtenerse a través de fuentes de datos nacionales e internacionales, es probable que en muchos lugares existan lagunas de conocimiento sustanciales acerca de las especies y comunidades ecológicas que existían en ellos antes de que experimentaran un proceso de degradación. En muchos casos, los registros sobre la composición de las especies en los paisajes anteriores serán escasos (sobre todo en lo que afecta a los invertebrados, los hongos y determinados grupos de plantas); no obstante, la falta de disponibilidad de información no debe disuadir los esfuerzos de restauración. En el caso de que durante la restauración del paisaje se obtenga información adicional sobre la presencia previa de una especie en el lugar, se podrá llevar a cabo una evaluación con objeto de determinar si las poblaciones de dicha especie deberían incluirse en los trabajos en curso o en los que se realicen en el futuro. Esto puede ocurrir especialmente con especies de árboles o de animales "emblemáticas" que ofrezcan unos beneficios ecológicos sustanciales y apoyen la supervivencia de numerosas especies adicionales dentro del paisaje en cuestión (a través, por ejemplo, de la dispersión de semillas de árboles).

Una de las carencias más notorias observada en las evaluaciones de la biodiversidad efectuadas en el marco de las evaluaciones de la FLR es la relativa escasez de reservas de semillas y plántulas autóctonas para las actividades de restauración (Jalonen et al., 2017). En todo el mundo, las iniciativas de FLR recomiendan a menudo que se planten y utilicen especies nativas en las actividades de restauración, y este tipo de actuación suele recibir un amplio apoyo. Sin embargo, en la mayoría de los lugares no es habitual cultivar especies autóctonas, por lo que existe un gran vacío entre las aspiraciones de restauración de la biodiversidad autóctona y las reservas físicas y genéticas necesarias para hacerlas realidad (Haase y Davis, 2017). Durante una evaluación de la FLR será necesario realizar una auditoría de las posibles fuentes de semillas y plántulas existentes en la zona evaluada, para lo cual generalmente se deberá contar con la ayuda de viveros y jardines botánicos, si existen. En algunos casos, la falta de semillas y plántulas autóctonas puede suponer un obstáculo para llevar a cabo intervenciones de FLR eficaces utilizando especies nativas. Sin embargo, en otros casos esa misma falta puede ofrecer una valiosa oportunidad comercial para la recolección y suministro de semillas y plántulas en las zonas rurales de cara a las intervenciones de restauración pendientes (así ha ocurrido en varios países; véase, por ejemplo, Urzedo, et al., 2017, De Vitis, et al., 2017).

\section{Consideración de la biodiversidad en las evaluaciones y la planificación de la FLR}

Dado que se ha asumido el compromiso de restaurar cientos de millones de hectáreas de tierras degradadas, cada vez es más importante que los profesionales encargados de la FLR cuenten con información y comprendan las numerosas perspectivas de los paisajes en los que trabajan. Los planes de las intervenciones de restauración deberán modificarse y ejecutarse en el contexto del paisaje, de manera que la restauración fomente una mejora del bienestar humano y el valor global de la biodiversidad no disminuya como consecuencia de las actividades de restauración.

Para ejecutar una intervención de FLR, el profesional utiliza un conjunto de estrategias de restauración, incluida la restauración ecológica tradicional. Es importante destacar que la FLR no propugna cambios de gran calado en el uso predominante del suelo, sino más bien en la restauración de los paisajes degradados y deforestados y la alineación del uso actual del suelo con los principios de la FLR. Al mismo tiempo, es preciso tener en consideración las diferentes compensaciones, que pueden llevar a modificar el uso del suelo. A modo de ejemplo, pese a que la agrosilvicultura puede ser una intervención de FLR importante, quizá no resulte adecuada como estrategia de intervención en zonas en las que exista biodiversidad de alto valor. Además,

4. http://www.natureserve.org/conservation-tools/climate-change-vulnerability-indexability-index 
la restauración ecológica en zonas en las que la biodiversidad presente un valor extremadamente bajo suele resultar prohibitiva en términos de coste y esfuerzo.

Uno de los resultados clave de cualquier evaluación de oportunidades de restauración del paisaje debería ser una estimación de la forma en que la restauración puede afectar a la biodiversidad autóctona. A través del análisis de la información espacial y no espacial sobre la biodiversidad en una zona sometida a evaluación, el profesional encargado de la FLR deberá adquirir una comprensión profunda de las prioridades de la biodiversidad de un paisaje, además de las evaluaciones de la degradación y sus impulsores. A la hora de adoptar medidas de protección de la biodiversidad, el objetivo es "no causar daño" cuando se ejecuten las acciones de restauración; por otro lado, la visión consiste en utilizar la restauración para mejorar los resultados desde el punto de vista de la biodiversidad. Esto se puede lograr llevando a cabo la restauración de una de las dos maneras que se exponen a continuación.

En primer lugar, la restauración de paisajes dirigida a mejorar la productividad y apoyar los medios de vida humanos puede reducir la presión a la que se ve sometida la biodiversidad. La restauración que mejora las condiciones del paisaje y la productividad agrícola, además de ofrecer otros beneficios sociales, puede reducir la presión sobre las zonas con biodiversidad elevada y reducir o evitar la sobreexplotación de los recursos naturales. En muchos lugares, los ecosistemas en buen estado brindan los servicios ecosistémicos y la red de seguridad social necesarios para la supervivencia de la población rural pobre. Además, la FLR puede aumentar la biodiversidad general de los paisajes a medida que proliferen las especies de árboles, plantas y cultivos en la zona evaluada cuando se ejecuten las estrategias de restauración.

En segundo lugar, las intervenciones de restauración adecuadas que se llevan a cabo en zonas degradadas y revisten una importancia específica desde el punto de vista de la biodiversidad tienen el potencial de ayudar a las especies a recuperarse y mejorar la biodiversidad en el conjunto del paisaje. Así sucede, en particular, en las zonas analizadas que se clasifican como degradadas pero forman parte de zonas protegidas o de Áreas Clave para la Biodiversidad. La restauración de esas zonas, sobre todo cuando se tiene en mente su restauración ecológica (o esta es uno de los componentes de la intervención), contribuye a mejorar y mantener la integridad y la conectividad de esos paisajes. Lo anterior se extiende también al efecto de la restauración del paisaje sobre la calidad del agua y las vías navegables, que a menudo representan zonas en las que no es físicamente posible llevar a cabo intervenciones de FLR pero que pueden mejorar de manera drástica como resultado de las actuaciones de restauración.

Entre otros recursos adicionales para garantizar que las actividades de restauración favorezcan la biodiversidad cabe citar Environmental and Social Safeguards (Chapter 6) del Banco Mundial, IFC Performance Standard 6: Biodiversity Conservation and Sustainable Management of Living. Natural Resources (PSS 6), The Society for Ecological Restoration's International Standards for the Practice of Ecological Restoration, así como Resource Box for Resilient Seed Systems de Biodiversity International, y las Guidelines on Business and KBAs, desarrolladas por The Key Biodiversity Areas Partnership.

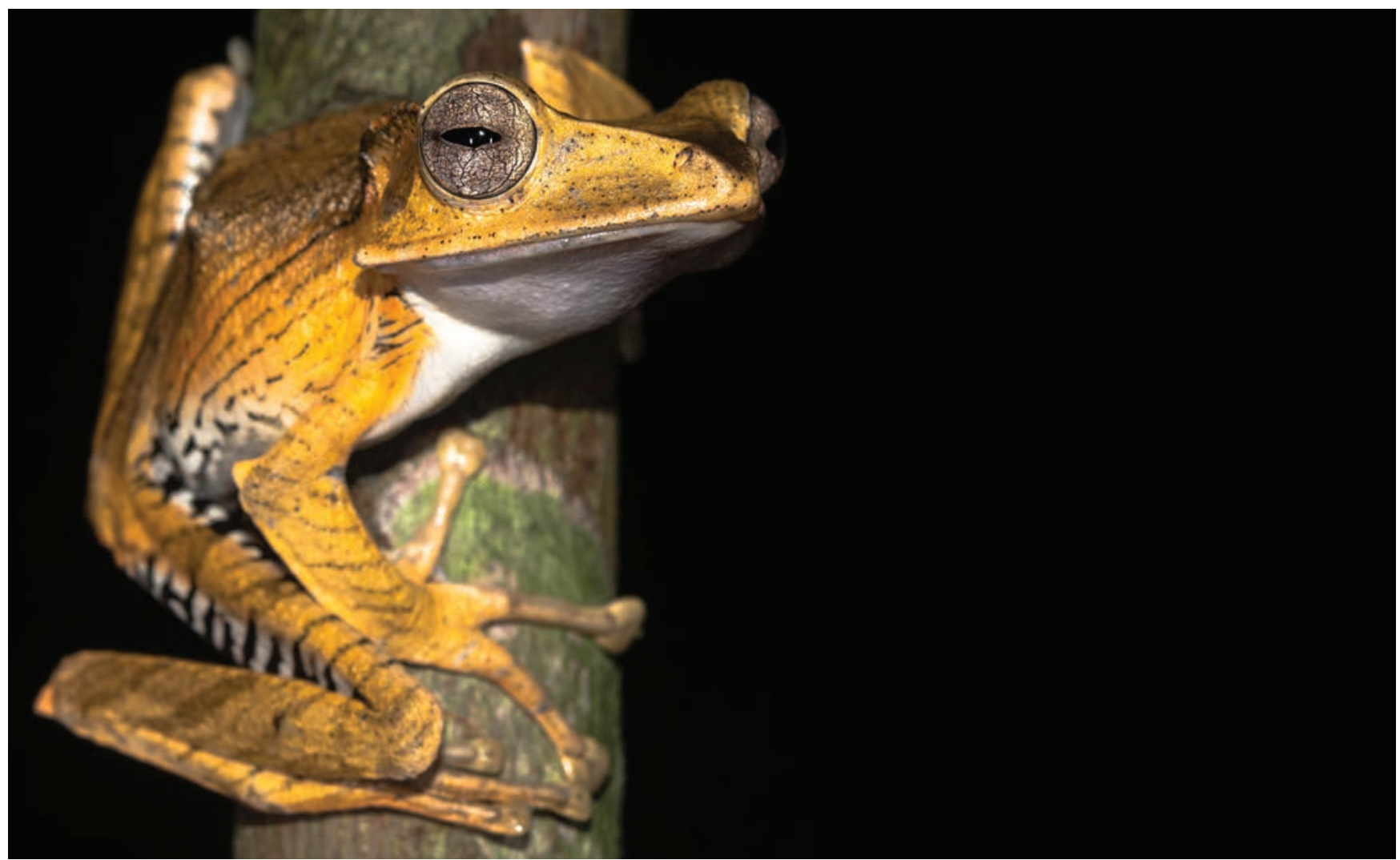

Ejemplar de Polypedates otophilus de la isla de Borneo. Fotografía utilizada por cortesía de Philip Bowles. 


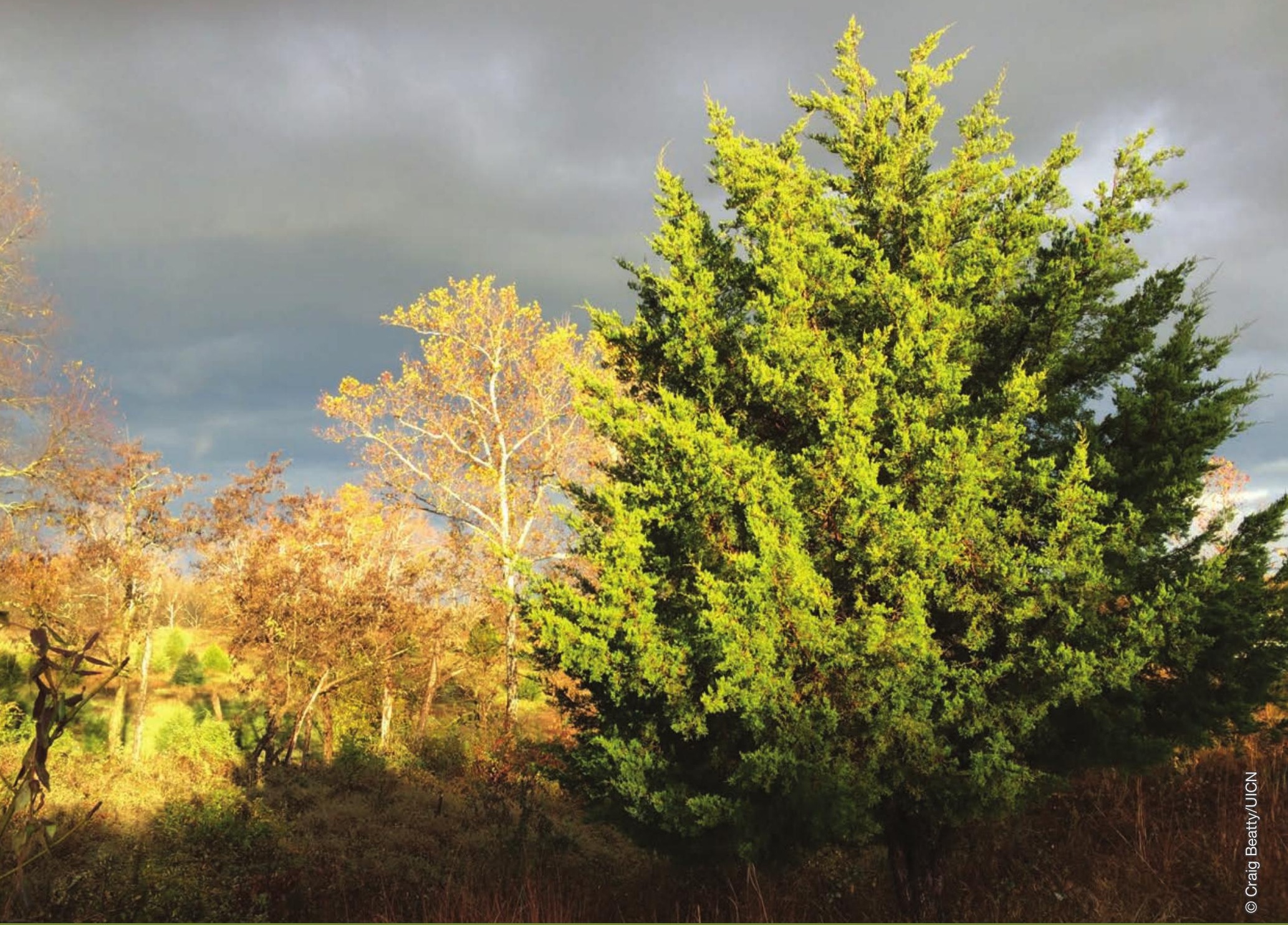




\section{¿Dónde, o de qué manera, se distribuye la biodiversidad en la} zona evaluada? ¿Existen datos disponibles o accesibles sobre la biodiversidad?

Los conjuntos de datos sobre la biodiversidad descritos anteriormente pueden permitir llevar a cabo un análisis inicial de las distribuciones de la biodiversidad (tanto de especies amenazadas como no amenazadas). Dichos datos incluyen información espacial públicamente disponible para un conjunto de especies cada vez más amplio. La superposición de los mapas de variedades de estas especies (o de las zonas prioritarias desde el punto de vista de la conservación) puede ofrecer una guía general de la posible distribución de las especies en la zona objeto de evaluación. Es importante incluir en el proceso de evaluación conjuntos de datos locales, si se dispone de ellos. Estos no solamente contendrán información sobre especies adicionales incluidas hasta la fecha en los conjuntos de datos regionales o mundiales, sino que además, en muchos casos, ofrecerán datos más específicos sobre los lugares en los que se hayan registrado especies prioritarias. Por otro lado, es importante señalar que, siempre que resulte posible, será importante contar con datos históricos sobre los cambios en el uso del suelo (sobre todo cuando se explique la distribución de la biodiversidad) de cara a planificar el trabajo de restauración.

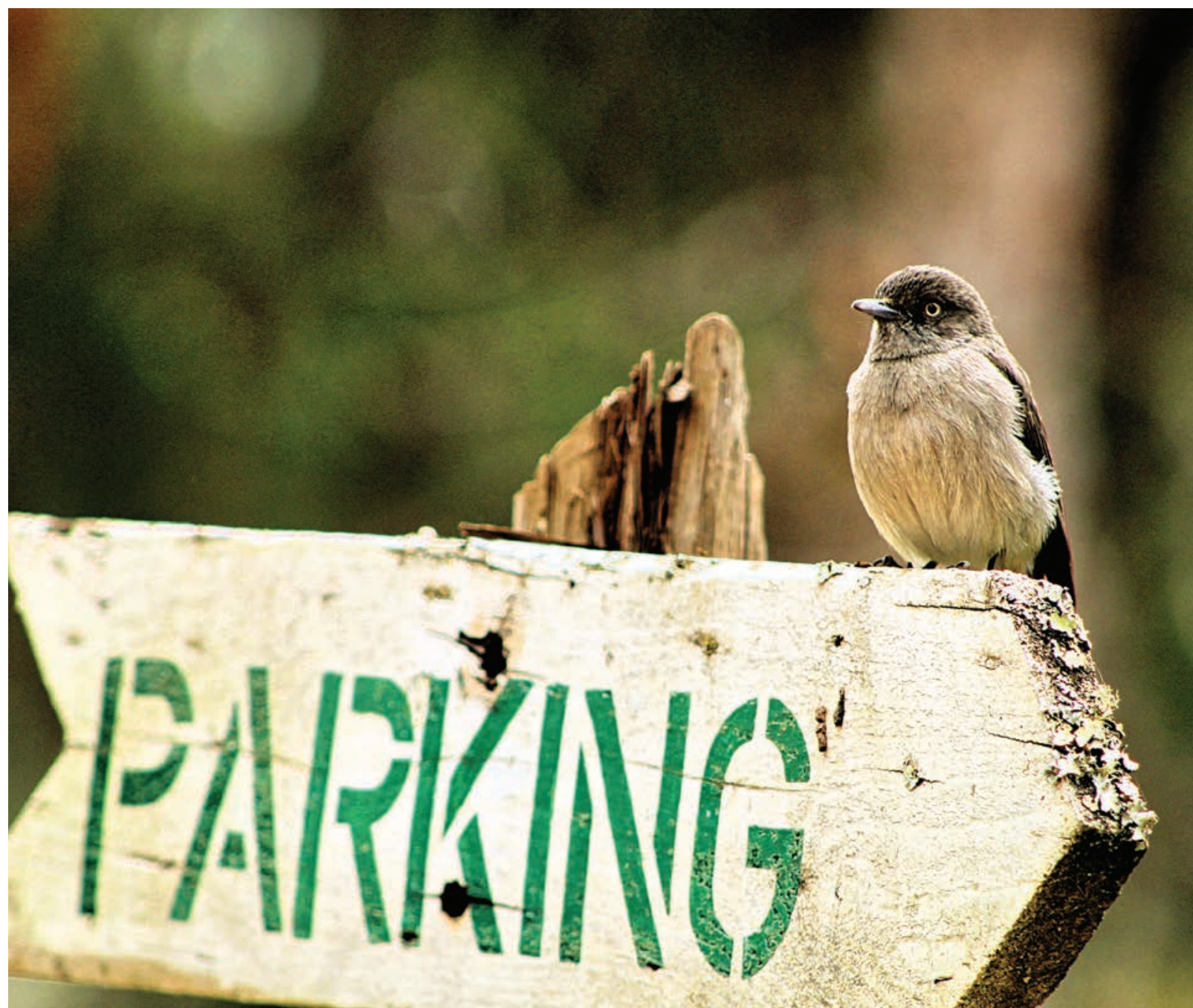

Un papamoscas chocolate (Melaenornis chocolatinus) posa con algunos líquenes en el bosque de Suba, en Oromia (Etiopía). Fotografía utilizada por cortesía de Craig Beatty/UICN. 


\section{¿Debería darse prioridad a la restauración de determinadas zonas geográficas por ofrecer claros beneficios tanto para la población como para la naturaleza?}

Al examinar las zonas de un paisaje susceptibles de ser objeto de actividades de restauración, habrá diversas opciones para la puesta en marcha de la intervención de FLR. Las zonas en las que anteriormente existiera vegetación autóctona y en la actualidad se encuentren gravemente degradadas y sean poco utilizadas son claramente zonas en las que, con carácter general, las intervenciones de FLR serán beneficiosas para la población y para la naturaleza. La identificación de las tierras degradadas cercanas a zonas en las que exista vegetación autóctona representa un primer paso acertado hacia una planificación más específica de actividades de FLR beneficiosas para la biodiversidad o que permitan estrategias de regeneración natural de los terrenos degradados adyacentes. La restauración de esas tierras debería permitir, en principio, la expansión de variedades de especies deseables que en la actualidad se encuentren confinadas en las zonas restantes del hábitat (si bien la recolonización de algunos taxones puede ser un proceso lento), además de prestar servicios ecosistémicos más amplios a las personas que dependan del paisaje sometido a restauración.

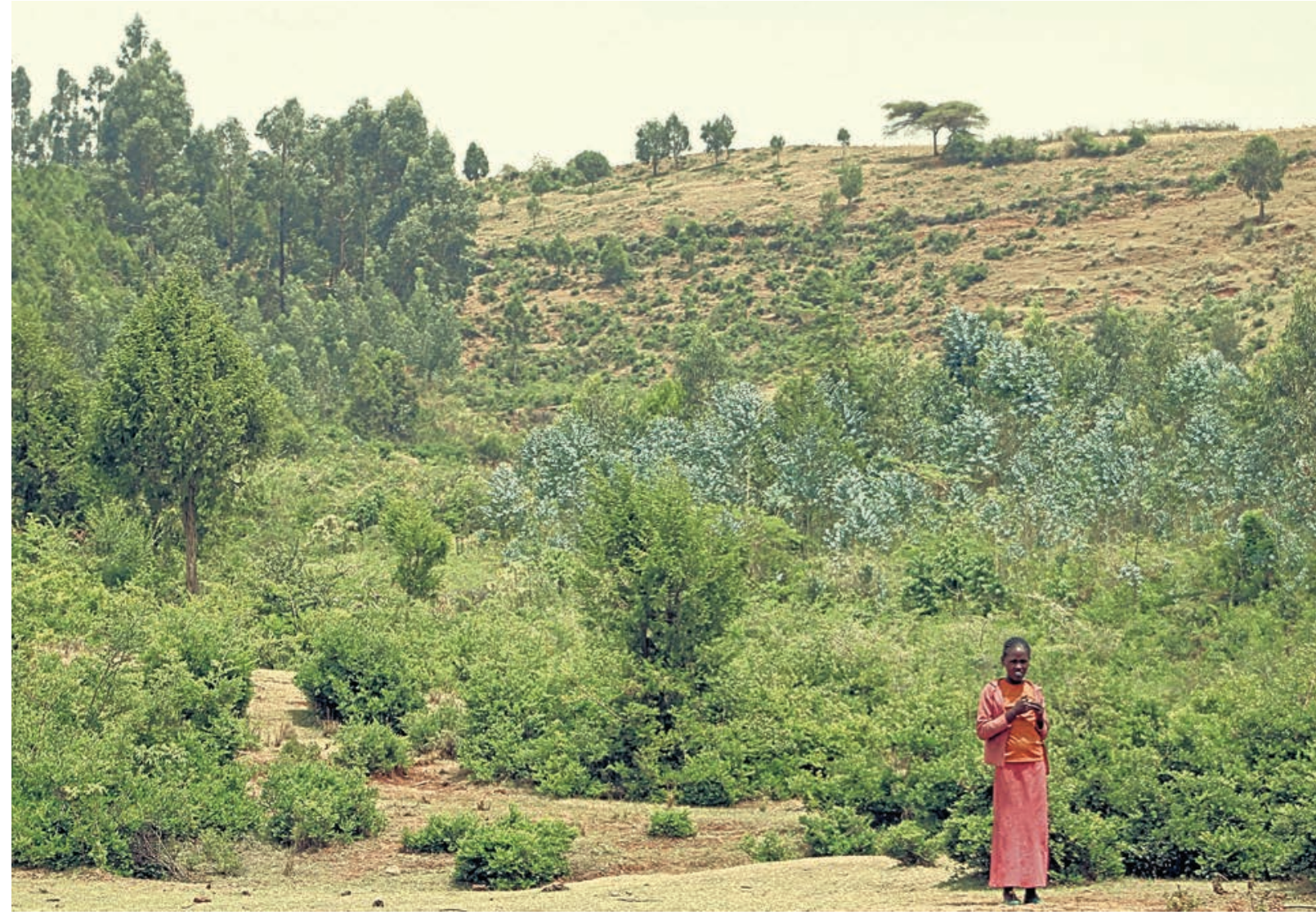

Zona de transición entre tierras agrícolas, plantaciones forestales de amortiguación y bosque de enebro autóctono en Oromia, Etiopía.

Fotografía utilizada por cortesía de Craig Beatty/UICN. 


\section{¿Cómo se pueden incluir en el proceso de restauración especies} autóctonas en el paisaje, en especial vegetales, y qué disponibilidad de plantas autóctonas existe actualmente? ¿Hay viveros de plantas o existe la oportunidad de desarrollar viveros de plantas autóctonas como parte del proceso de restauración?

En muchas intervenciones de FLR (pero no en todas) lo ideal puede ser concentrar los esfuerzos de restauración en especies vegetales autóctonas, puesto que se adaptarán mejor al entorno local y maximizarán los beneficios derivados de la conservación de la biodiversidad y la expansión de los servicios ecosistémicos para la población. Los funcionarios locales responsables de la silvicultura, los trabajadores de extensión y el ecologista principal del proyecto pueden prestar asistencia en la selección de especies vegetales; puede que dicha selección se centre en zonas mixtas de especies autóctonas, en lugar de en plantaciones de monocultivos autóctonos y la rotación con especies de árboles autóctonos en sistemas de agrosilvicultura o cortavientos, por ejemplo. La adquisición de especies autóctonas para la restauración también puede entrañar desafíos, puesto que quizá no sea tan sencillo acceder a plantones o plántulas autóctonos a través de los viveros locales. Será necesario examinar esta cuestión en una fase temprana del proceso general de planificación del proyecto, sobre todo si se tiene en cuenta que puede ofrecer oportunidades laborales a la comunidad local mediante el desarrollo de viveros en los que se cultiven las especies autóctonas requeridas para la FLR (algo que, en muchos casos, adquiere el carácter de compromiso a largo plazo). En el caso de que se necesite efectuar una plantación más inmediata en una zona determinada, existe la posibilidad de utilizar especies exóticas para estabilizar el terreno degradado mientras se cultivan plantas autóctonas. A continuación se podrá sustituir la vegetación exótica por especies autóctonas (lo antes posible), o bien integrarlas en un plan de sucesión (Tanveer et al., 2017).

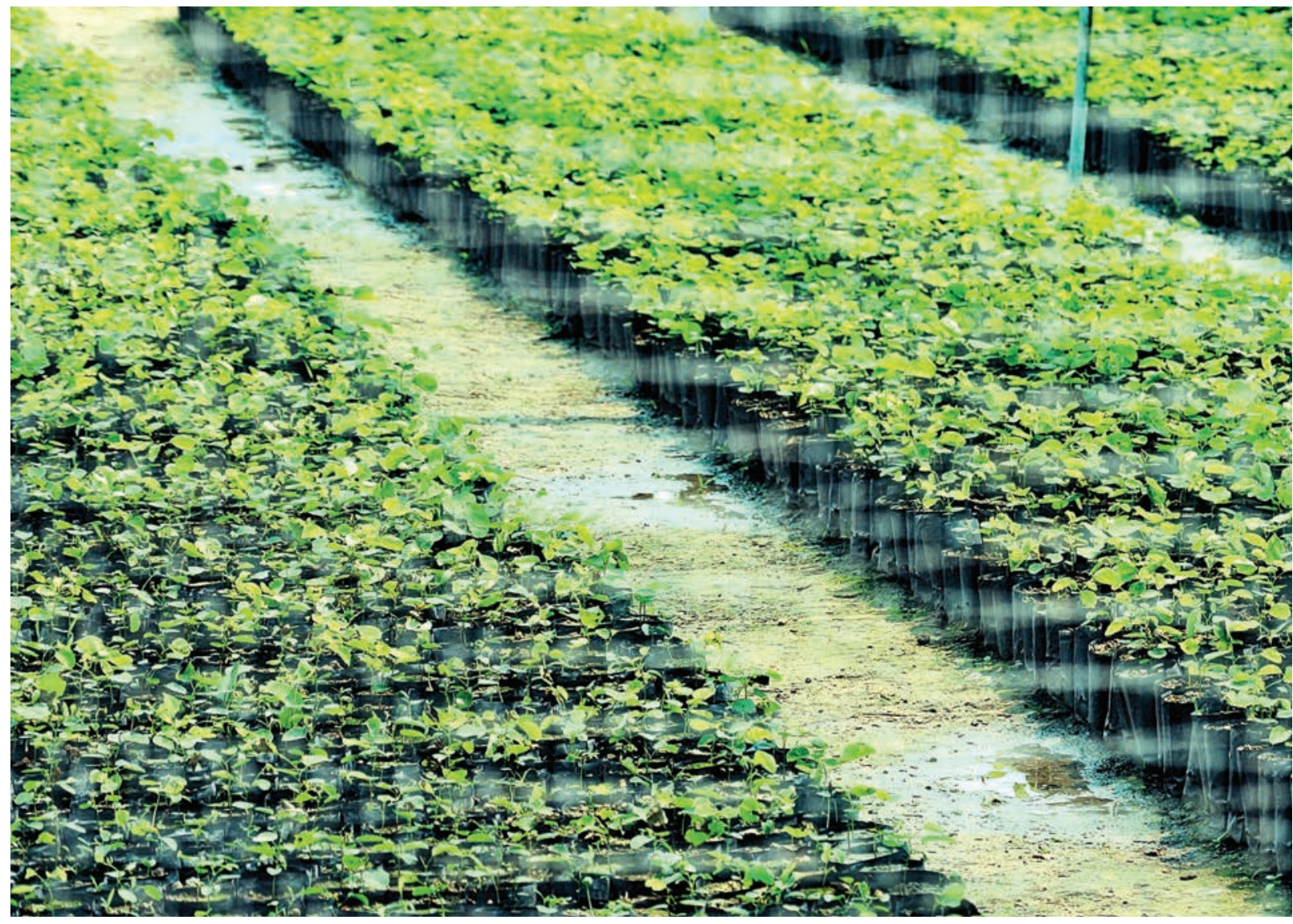

Vivero de palo de rosa siamés (Dalbergia cochinchinensis), en Siem Reap (Camboya). Este vivero de titularidad estatal proporciona semillas de forma gratuita a terratenientes y escuelas; además, quienes deseen poner en marcha una producción comercial de esta variedad también pueden adquirir semillas. El palo de rosa siamés es una especie de gran valor que puede ofrecer una inversión muy lucrativa a largo plazo para la restauración de paisajes forestales. Fotografía utilizada por cortesía de Craig Beatty/UICN. 


\section{¿Cómo afectará la restauración de una zona, bioma o ecosistema}

al valor de la biodiversidad de las zonas, biomas y ecosistemas (incluidos los marinos y de agua dulce) adyacentes al paisaje que se va a someter a restauración (o vinculados a él)?

Es prácticamente seguro que la restauración de los hábitats presentes en un lugar en el que se vaya a desarrollar un proyecto a gran escala tendrá algún tipo de efecto ecológico o ambiental sobre la riqueza (o el valor) de la biodiversidad de las zonas, biomas o ecosistemas circundantes. En los sistemas terrestres, un efecto inmediato será el restablecimiento o la expansión de un tipo de hábitat que anteriormente se hubiera perdido (o que hubiera experimentado una fuerte reducción) en la zona, a menudo como consecuencia de las presiones que ejercía la población sobre el suelo o los recursos. Aunque esto puede ser deseable desde la perspectiva de la restauración de la biodiversidad (como se ha expuesto de manera sintética a lo largo de estas directrices), es importante estudiar los hábitats existentes en el emplazamiento en el que se vaya a llevar a cabo el proyecto antes de poner en marcha cualquier actuación de restauración. En ausencia de estudios del paisaje adecuados y correctamente planificados, cabe la posibilidad de que se dañen hábitats locales importantes (como pastizales o humedales naturales) a través de medidas inapropiadas. Antes de que comience un proyecto, es recomendable cartografiar las zonas en cuestión y reflexionar en profundidad sobre los efectos que puede ejercer sobre ellas un trabajo de plantación o restauración de gran envergadura (por ejemplo, la modificación de los sistemas hidrológicos). Además de los efectos de la restauración (en gran medida terrestres), se producirán cambios en los sistemas marinos y de agua dulce locales, a menudo dentro de la cuenca hidrográfica del proyecto de restauración. Como ya se ha señalado, en ocasiones los sistemas hidrológicos pueden sufrir cambios complicados como consecuencia de la alteración de la vegetación circundante; por ejemplo, es probable que se produzca una reducción de la escorrentía de agua de la tierra a los lagos y riachuelos de agua dulce, y, en última instancia, a los sistemas marinos, así como una reducción de la erosión de sedimentos procedentes de los hábitats terrestres. En muchos casos esto puede tener un efecto medioambiental global positivo para el sistema hidrológico asociado (por ejemplo, una disminución de la turbidez), si bien durante la fase de planificación deberán tenerse en cuenta estos posibles cambios.

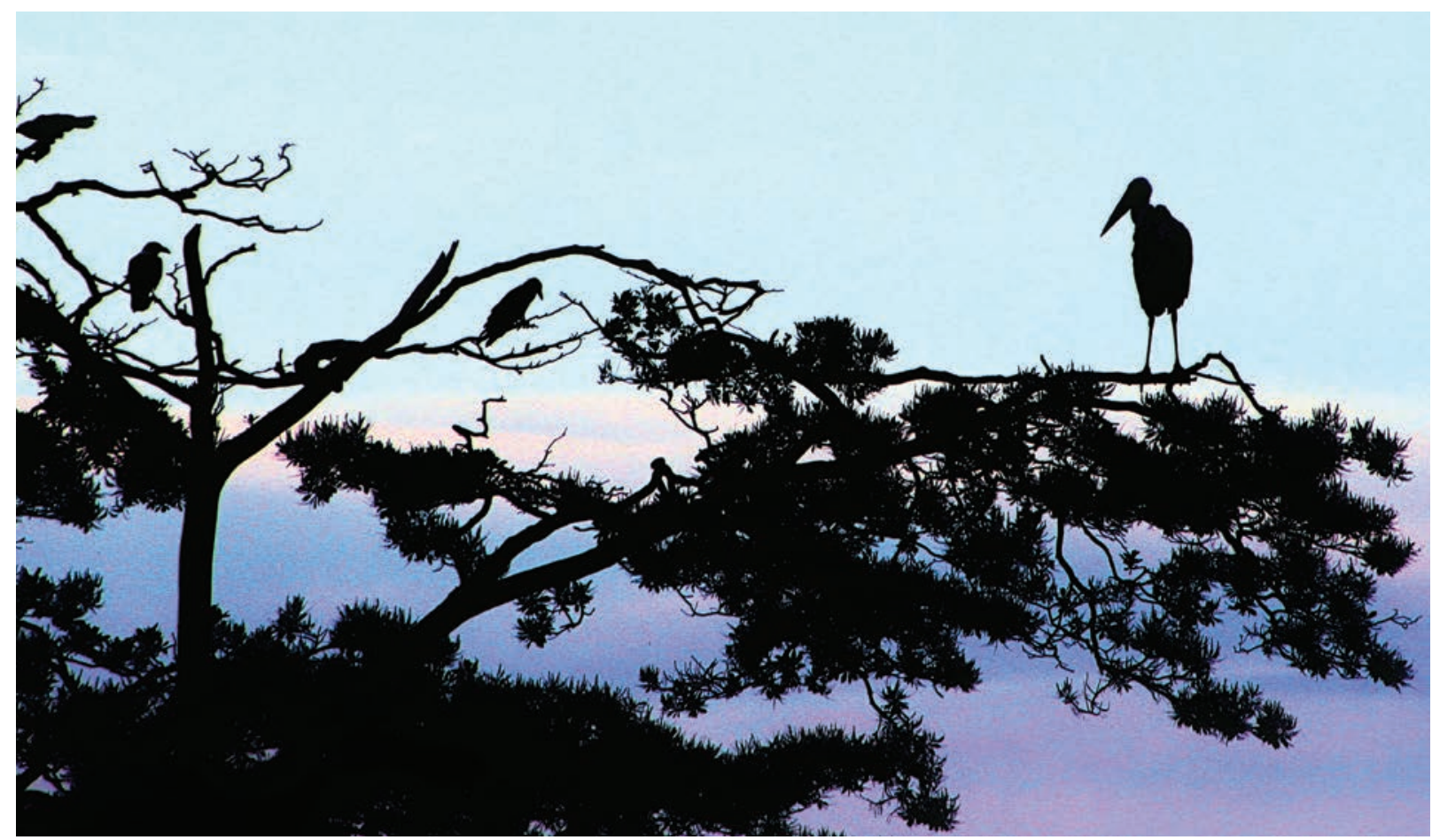

Marabú africano (Leptoptilos crumeniferus) y cuervos blancos (Corvus albus) en Jinja, Uganda. Fotografía utilizada por cortesía de Craig Beatty/UICN. 


\section{¿Existen especies concretas (por ejemplo, especies amenazadas} o endémicas), combinaciones de especies u otras unidades de conservación que requieran una consideración especial y un acomodo potencial en el proceso de planificación?

Los beneficios asociados a la inclusión directa de información relativa a la conservación de la biodiversidad y de las partes interesadas en el proceso de planificación compensan con creces los costes, siempre que quede claro desde el comienzo que no se pretende utilizar la FLR como un mecanismo de restauración plenamente ecológica. Pese a que es posible que la FLR no logre todos los objetivos de la restauración íntegramente ecológica, las personas involucradas en la conservación de la biodiversidad y la FLR dispondrán de una gran oportunidad para cooperar de cara a la mejora de la productividad ecológica y el fomento de los medios de vida. Para los profesionales expertos en biodiversidad, la FLR ofrece una ocasión para mejorar ampliamente el estado de las especies y de los ecosistemas, así como para reducir las amenazas y las presiones a las que se ve sometida la biodiversidad a una escala de cientos de millones de hectáreas en todo el mundo. Por otra parte, los profesionales implicados en la FLR pueden adquirir valiosos conocimientos sobre las especies y los ecosistemas presentes en los paisajes beneficiarios de las intervenciones, de manera que las acciones de restauración se puedan evaluar y planificar dentro de un contexto ecosistémico; y esto aumenta las posibilidades de éxito del proceso de restauración del paisaje.

Tanto la conservación como la restauración tienen el potencial de supervisar y comunicar los beneficios de un enfoque con respecto a las evaluaciones de la FLR que integre la biodiversidad. Estas pueden incluir la elaboración de informes en los que se analice el progreso de los objetivos y metas de desarrollo nacionales e internacionales, pero sobre todo, pueden permitir obtener los beneficios que puede ofrecer este tipo de enfoque con respecto a la FLR para el bienestar y los medios de vida humanos a corto y largo plazo.

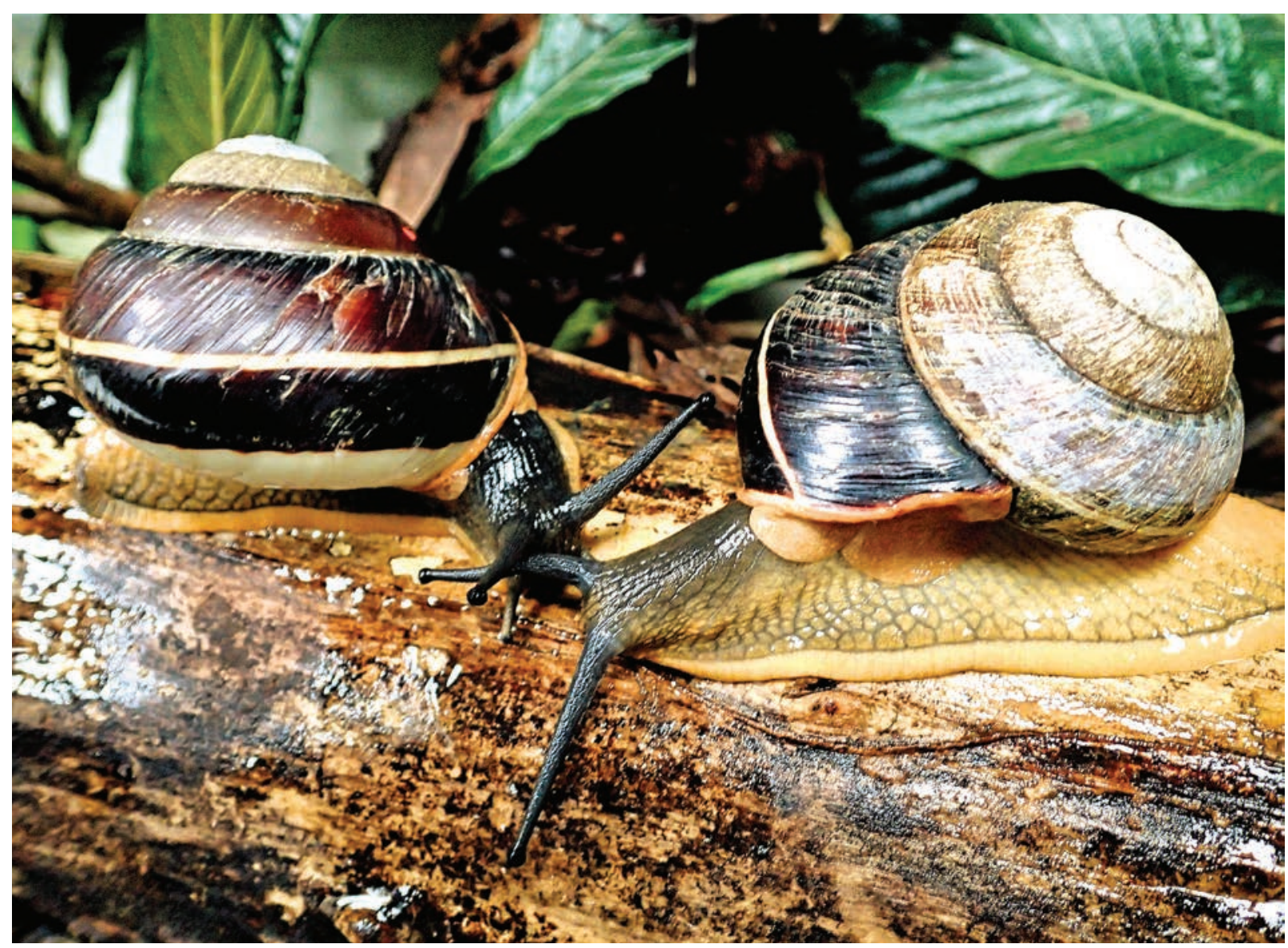

El caracol gigante vietnamita (Bertia cambojiensis) solo puede encontrarse en una pequeña zona del sur de Vietnam. Debido al gran tamaño de su concha y a su singularidad, se ve sometido a fuertes presiones derivadas de la colección y del declive del tamaño y la calidad del hábitat en el que vive. Fotografía utilizada por cortesía de Paul Pearce-Kelly. 


\section{Comunicación eficaz sobre la biodiversidad}

Cabe esperar que la identificación y evaluación de oportunidades de restauración de paisajes forestales, la interacción con las partes interesadas pertinentes, el análisis de políticas y el análisis de datos espaciales y de los beneficios económicos de la biodiversidad expuestos en la sección anterior y en el manual sobre la ROAM hayan dado lugar a la creación de una red de contactos nacionales e internacionales dedicados a la biodiversidad y a la generación de información pertinente sobre la FLR y la biodiversidad. Además, los datos espaciales y el análisis económico deberían haber generado datos empíricos sobre la ubicación y prioridad de áreas con biodiversidad dentro de la zona evaluada. Cuando se sometan a restauración, esas áreas pueden ayudar a aliviar las presiones y las amenazas a las que esté expuesta la biodiversidad, a incrementar la biodiversidad global del paisaje que se vaya a restaurar y a restaurar zonas con alto valor desde el punto de vista de la biodiversidad que se encuentren actualmente degradadas.

Aunque el trabajo se haya completado para cuando se llegue a esta fase, los resultados deben articularse con claridad y comunicarse tanto en el seno del equipo de evaluación como a las audiencias externas. La comunicación dentro del equipo garantiza que los beneficios que ofrezcan las consideraciones relativas a la biodiversidad para la FLR se incluyan explícitamente en la evaluación de oportunidades de restauración de paisajes forestales y la estrategia correspondiente. La comunicación de cara al exterior asegura que la información recabada o sintetizada a partir del proceso de evaluación sea tenida en cuenta en las políticas y planes pertinentes, y que se incorpore a la ejecución de la FLR.

La evaluación de la biodiversidad de cara a las evaluaciones de la restauración de paisajes forestales es un componente de un proceso mucho más amplio. Aunque se tenga en cuenta la biodiversidad en todas sus fases, existe una serie de hitos importantes dentro del proceso de evaluación en los que la información relativa a la biodiversidad se puede comunicar y/o integrar de manera especialmente eficaz.

La identificación de los beneficios de la biodiversidad como componente clave de cualquier evaluación de la FLR debe comunicarse al comienzo de cada proceso. Puede ocurrir que la conservación de la biodiversidad no figure entre los principales objetivos de una intervención de restauración de paisajes forestales, y es posible que esto se deba a razones comprensibles y prácticas. No obstante, con independencia de si la biodiversidad y el fomento de ecosistemas productivos es o no un objetivo explícito de la intervención, los procesos subyacentes que garantizan el éxito de la FLR están arraigados en la restauración de los procesos biológicos y ecológicos que tienen lugar a través de la interacción entre las especies que conviven en un paisaje. La biodiversidad es un componente de cualquier iniciativa de restauración del paisaje, y tan importante es incluir conocimientos específicos en materia de biodiversidad en el proceso de evaluación como trasladar el reconocimiento de todos los agentes implicados en torno a la dependencia crucial de la FLR con respecto a la biodiversidad. La restauración de paisajes puede seguir numerosos caminos por razones diferentes y, en ocasiones, contrapuestas; algunos de ellos pueden verse perjudicados por una dependencia excesiva de la integración de los aspectos específicos relacionados con la biodiversidad. A modo de ejemplo, la selección de especies agrosilvícolas puede verse gravemente limitada por la tolerancia de los mercados y las condiciones de crecimiento; esto puede provocar, a su vez, una reducción de la viabilidad de introducir la perspectiva referente a la biodiversidad en lo que atañe a las especies agrosilvícolas.

A la hora de integrar sus conocimientos sobre biodiversidad en el proceso de evaluación, el profesional encargado de la FLR debería reconocer cuándo un debate sobre la biodiversidad contribuye a facilitar el proceso y cuándo desvirtúa los objetivos de la FLR. En el caso de la agrosilvicultura, a pesar de que puede que la biodiversidad no siempre tenga un peso significativo en la elección de especies agrosilvícolas, el itinerario seguido para la ejecución de la restauración ofrece un punto de partida adecuado para un debate sobre la biodiversidad. Tratándose de una estrategia diversa aplicada a escala paisajística, la restauración de la biodiversidad del paisaje puede ayudar a respaldar el éxito de las intervenciones agrosilvícolas y, en lugar de centrarse únicamente en la elección de especies, el profesional experto en restauración también puede prestar atención a aquellos lugares en los que las intervenciones agrosilvícolas podrían interactuar con $y / o$ favorecer la biodiversidad del paisaje. Y a la inversa: quizá también sea posible evaluar el modo en que la restauración de la función ecológica en una zona puede favorecer la prestación de servicios ecosistémicos en otras zonas.

Durante el propio proceso, se puede recabar y comunicar información y conocimientos sobre la biodiversidad en la fase de diseño del proyecto, incluyendo para ello a las partes interesadas en (y preocupadas por) la conservación y restauración de la biodiversidad. Durante la parte analítica de la evaluación del paisaje, la información y los datos relativos a la biodiversidad pueden constituir un punto de partida para el análisis 
normativo e institucional a través de un examen de las estrategias nacionales sobre la biodiversidad y planes de acción, las fuentes de datos nacionales e internacionales sobre biodiversidad, así como mediante la evaluación de los servicios ecosistémicos y de las conexiones entre especies y mercados económicos. La fase analítica del proceso de evaluación representa un momento oportuno para garantizar que la biodiversidad desempeñe un papel claro en el logro de los objetivos de la FLR y que dicho papel esté respaldado por los datos, los conocimientos científicos y las políticas existentes. Una vez que la biodiversidad se haya incluido de forma explícita en el análisis, resulta mucho más sencillo comunicar los resultados de una evaluación de la FLR en términos de beneficios y ganancias desde el punto de vista de la biodiversidad.

Es fundamental comunicar de manera comprensible los conocimientos sobre la biodiversidad obtenidos mediante el proceso de evaluación del paisaje. Esto significa que la información acerca de la importancia de la biodiversidad no debe presentarse como un factor que se puede tomar en consideración o no; es la condición última que determinará el éxito o el fracaso de la restauración. Las intervenciones de restauración, sobre todo las que se llevan a cabo en paisajes productivos con escasas especies y que no consiguen fomentar la biodiversidad ni la diversidad genética en la restauración de la productividad del ecosistema, corren el riesgo de fracasar, puesto que las intervenciones pueden no resultar adecuadas a los sistemas ecológicos y los procesos paisajísticos predominantes (Lindenmayer et al., 2002; Reynolds et al., 2012).

Esto no quiere decir que los mapas y análisis que muestran los lugares en los que es especialmente importante tener en cuenta la biodiversidad no sean por sí mismos componentes valiosos del proceso de evaluación. Los productos de datos, los conocimientos generados y las conexiones institucionales entre la biodiversidad y los procesos de FLR ayudan a integrar tanto la biodiversidad como la restauración de paisajes forestales. El resultado de la comunicación de esta información sobre la biodiversidad en el seno del equipo evaluador y de manera externa a audiencias más amplias será un reconocimiento del crucial papel que desempeña la biodiversidad en el éxito a largo plazo de la restauración de paisajes forestales, así como una integración más profunda de los conocimientos, herramientas y capacidades relacionados con la biodiversidad en un proceso ya de por sí muy eficaz y útil.

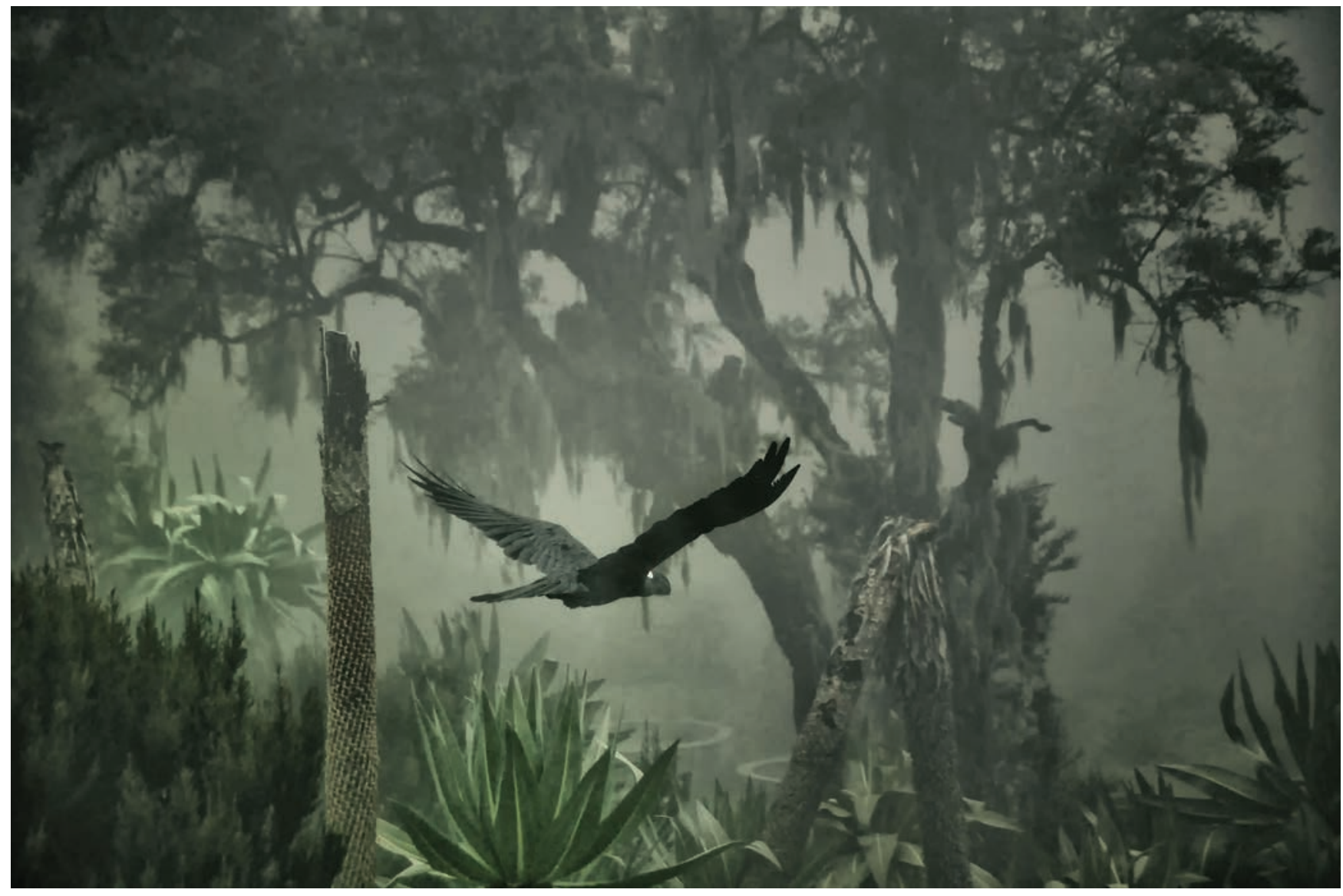

Un cuervo picogordo (Corvus crassirostris) en las montañas Simen (Etiopía). Fotografía utilizada por cortesía de Rod Waddington 


\section{Conclusión}

En la práctica, la FLR consiste en gran medida de intervenciones que tienen lugar en paisajes agrícolas dominados por el ser humano. Esto significa que depende poderosamente de actividades de restauración como la agrosilvicultura, la agricultura de conservación y otros métodos de restauración basados en la agricultura para mejorar la fertilidad del suelo y aumentar la producción de alimentos. Sin embargo, la integración de la biodiversidad autóctona y nueva en esas intervenciones representa un punto de partida único y muy importante para una consideración más sustancial de los procesos ecológicos involucrados en la FLR.

La restauración de paisajes forestales continúa emergiendo como una herramienta clave para mejorar las condiciones ambientales para la población y la naturaleza, tanto a escala local como mundial. Se espera que, en muchas circunstancias, una consideración más amplia y una utilización cuidadosa de los datos sobre la biodiversidad en el proceso de FLR conduzcan a lograr los objetivos socioeconómicos y ambientales deseados de las modernas actividades de restauración y conservación de paisajes, que además son beneficiosos para todas las partes.

Una correcta restauración de paisajes forestales, que integre las consideraciones y los beneficios asociados a la biodiversidad, será crucial para restaurar la productividad ecológica de un paisaje. Estas mejoras de la productividad ecológica son producto de unas prácticas paisajísticas saludables y sostenibles que favorecen la resiliencia y la productividad de los alimentos y respaldan la biodiversidad. Una de las fortalezas de la restauración de paisajes forestales es, quizá, el hecho de que aparentemente no se centra en la conservación y restauración de la biodiversidad; a menudo las cuestiones relativas a las especies y la biodiversidad pueden ignorarse en los procesos decisorios que rodean a la planificación, el diseño y la financiación del paisaje, sobre todo cuando la conservación pueda entrar en conflicto con otros objetivos de carácter económico o industrial.

La biodiversidad es inherente al proceso de FLR; no es posible incrementar la productividad ecológica de manera sostenible sin mejorar la diversidad de las especies y los beneficios paisajísticos que proporciona esta diversidad. No obstante, dado que la mayoría de las intervenciones de FLR tiene lugar en terrenos degradados y deforestados, se centra en detener y revertir la degradación de paisajes que en la actualidad son cultivados y utilizados por la población. La superficie terrestre disponible en todo el mundo para la restauración de tierras deforestadas o degradadas es enorme, y sin lugar a dudas mayor que la superficie de suelo disponible para la restauración ecológica tradicional.
En este documento de orientación se ha expuesto la importancia de tener en consideración los genes, las especies y los ecosistemas en las evaluaciones de la FLR y en las estrategias de ejecución resultantes. También se ha proporcionado una gran cantidad de recursos para obtener información sobre la biodiversidad y entrar en contacto con profesionales expertos en esta materia, y se han descrito algunas de las perspectivas cruciales para estudiar y supervisar el efecto de la FLR sobre la biodiversidad y los servicios ecosistémicos. También es muy importante la descripción detallada de las fuentes de información sobre biodiversidad, que tienen tanto una conexión explícita con la biodiversidad (como la Lista Roja de Especies Amenazadas de la UICN o la Lista Roja de Ecosistemas Amenazados de la UICN) como conexiones implícitas con las políticas de desarrollo económico. En este documento se articulan también los procedimientos propuestos para identificar las prioridades en lo que atañe a la biodiversidad dentro de un proceso de evaluación, junto con las fuentes de datos espaciales y no espaciales sobre la biodiversidad que respaldan dicho proceso de identificación. Por último, estas directrices ofrecen sugerencias y recursos para los profesionales dedicados a la FLR sobre el modo en que un proceso de evaluación de la FLR puede incluir procedimientos de protección de la biodiversidad para contribuir a garantizar que la FLR no provoque involuntariamente reducciones de la biodiversidad a través de intervenciones que, en determinadas circunstancias, pueden ser beneficiosas para la biodiversidad, pero en otras pueden resultar perjudiciales para esta.

Estas directrices pretenden facilitar una integración y consideración más amplias de los conocimientos disponibles sobre la biodiversidad en el proceso de evaluación de la FLR. El aumento de la biodiversidad en un paisaje sigue siendo un resultado fundamental de una restauración adecuada del paisaje forestal, si bien no es la razón de ser de este tipo de iniciativas conseguir grandes mejoras en términos de biodiversidad y conservación de especies. Las ganancias en términos de biodiversidad deberían ser incrementales y favorecer a los habitantes de esos paisajes. Esto no equivale a negar las increíbles oportunidades que existen para lograr importantes ganancias a través de la restauración de la biodiversidad y de los ecosistemas a través de las actividades de FLR, pero estos objetivos deben atemperarse mediante un enfoque intersectorial que restaure de manera iterativa el funcionamiento de los ecosistemas para crear paisajes funcionales.

LaUICN, que es una de las autoridades más importantes y respetadas en el ámbito de la biodiversidad y los ecosistemas, reconoce los efectos que pueden tener los cambios paisajísticos a gran escala sobre la biodiversidad y los ecosistemas. La restauración de 
paisajes forestales tiene un potencial enorme para apoyar los medios de subsistencia humanos, aumentar la biodiversidad y mejorar los servicios ecosistémicos y la productividad ecológica en los paisajes degradados. No deberían llevarse a cabo actuaciones de restauración de paisajes forestales en zonas que no se encuentren degradadas, y esto debería excluir las zonas prioritarias o que susciten preocupación desde el punto de vista de la conservación. En los casos en que exista ambigüedad en las definiciones o el alcance de la degradación, corresponderá a los profesionales expertos en restauración utilizar estas directrices para garantizar que los ecosistemas autóctonos no se clasifiquen erróneamente como "degradados" y apoyar enfoques de FLR que no causen daño a la biodiversidad autóctona, pero también adoptar enfoques diversificados con respecto a la restauración a fin de aumentar la biodiversidad, especialmente en zonas que revistan importancia para especies y ecosistemas amenazados. 


\section{Referencias}

Anderson, M.G. y Ferree, C.E. (2010). "Conserving the Stage: Climate Change and the Geophysical Underpinnings of Species Diversity". PLOS ONE. 5: e11554. doi: 10.1371/journal.pone.0011554.

Arrow, K., Bolin, B., Costanza, R., Dasgupta, P., Folke, C., Holling, C.S., Levin, S., Maler, K.-G., Perrings, C. y Pimentel, D. (1995). "Economic Growth, Carrying Capacity and the Environment". Science 268:520-521. https://doi.org/10.1126/ science.268.5210.520

Cardinale, B.J., Duffy, J.E., Gonzalez, A., Hooper, D.U., Perrings, C., Venail, P., Narwani, A., Mace, G.M., Tilman, D., Wardle, D.A., Kinzig, A.P., Daily, G.C., Loreau, M., Grace, J.B., Larigauderie, A., Srivastava, D. y Naeem, S. (2012). "Biodiversity Loss and its Impact on Humanity". Nature 486: 59-67. https://doi.org/10.1038/nature11148

Centro Mundial de Vigilancia de la Conservación (1992). Global Biodiversity: Status of the Earth's Living Resources. Londres: Chapman \& Hall.

De Vitis, M., Abbandonato, H., Dixon, K.W., Laverack, G., Bonomi, C. y Pedrini, S. (2017). "The European Native Seed Industry: Characterization and Perspectives in Grassland Restoration". Sustainability 9(10): 1682. https:// doi. org/10.3390/su9101682

FAO (2016). El estado de los bosques del mundo (2016). Roma, Italia: FAO.

Griscom, B.W., Adams, J., Ellis, P.W., Houghton, R.A., Lomax, G., Miteva, D.A., Schlesinger, W.H., Schoch, D., Siikamaki, J.V., Smith, P., Woodbury, P., Zganjar, C., Blackman, A., Campari, J., Conant, R.T., Delgado, C., Elias, P., Gopalakrishna T., Hamsik, M.R., Herrero, M., Kiesecker, J., Landis, E., Laestadius, L, Leavitt, S.M., Minnemeyer, S., Polasky, S., Potapov, P., Putz, F.E., Sandermann, J. Silvius, M., Wollenberg, E. y Fargione, J. (2017). "Natural Climate Solutions". Proceedings of the National Academy of Sciences of the United States of America 114(44): 11645-11650.

Haase, D.L. y Davis, A.S. (2017). "Developing and Supporting Quality Nursery Facilities and Staff are Necessary to Meet Global Forest and Landscape Restoration Needs". Reforesta 4: 69-93.

Hatton, T.J. y Nulsen, R.A. (1999). "Towards Achieving Functional Ecosystem Mimicry with respect to Water Cycling in Southern Australian Agriculture". Agroforestry Systems 45(1-3): 203-214. https://doi.org/10.1023/A:1006215620243

Herrera, D., Ellis, E., Fisher, B., Golden, C.D., Johnson, K., Mulligan, M., Pfaff, A., Treuer, T. y Ricketts, T.H. (2018). "Upstream Watershed Condition Predicts Rural Children's Health Across 35 Developing
Countries". Nature Communications 8:811. https://doi.org/10.1038/s41467-017- 00775-2

Hooper, D.U., Adair, E.C., Cardinale, B.J., Byrnes, J.E.K., Hungate, B.A., Matulich, K.L., Gonzalez, A., Duffy, J.E., Gamfeldt, L. y O'Connor, M.I. (2012). "A Global Synthesis Reveals Biodiversity Loss as a Major Driver of Ecosystem Change". Nature 486: 105.

Hooper, D.U., Chapin, F.S., Ewel, J.J., Hector, A., Inchausti, P., Lavorel S., Lawton, J.H., Lodge, D.M., Loreau, M., Naeem, S., Schmid, B., Setala, H., Symstad, A.J., Vandermeer, J. y Wardle, D.A. (2005). "Effects of Biodiversity on Ecosystem Functioning: A Consensus of Current Knowledge". Ecological Monographs 75(1): 3-35. https://doi.org/10.1890/04-0922

Jalonen, R., Valette, M., Boshier, D., Duminil, J., Thomas, E. (2017). "Forest and Landscape Restoration Severely Constrained by a Lack of Attention to the Quantity and Quality of Tree Seed: Insights from a Global Survey". Conservation Letters e12424. https://doi.org/10.1111/ conl.12424

Kumar, P., Brondizio, E., Gatzweiler, F., Gowdy, J., de Groot, D., Pascual, U., Reyers, B. y Sukhdev, P. (2013). "The Economics of Ecosystem Services: From Local Analysis to National Policies". Current Opinions on Environment Sustainability 5: 78-86. https://doi.org/10.1016/j.cosust.2013.02.001

Lamb, D. (2014). Large Scale Forest Restoration. Londres: Routledge.

Larsen, F.W., Turner, W.R. y Brooks, T.M. (2012). "Conserving Critical Sites for Biodiversity Provides Disproportionate Benefits to People". PLOS ONE 7(5): e36971. https://doi.org/10.1371/ journal.pone.0036971

Lindenmayer, D.B., Manning, A.D., Smith, P.L., Possingham, H.P., Fischer, J., Oliver, I. y McCarthy, M.A. (2002). "The Focal-Species Approach and Landscape Restoration: ACritique". Conservation Biology 16(2): 338-345. https://doi. org/10.1046/j.1523-1739.2002.00450.x

Mace, G.M., Baillie, J., Masundire, H., Ricketts, T.H., Brooks, T.M., Hoffmann, M., Stuart, S.N., Balmford, A., Purvis, A., Reyers, B., Wang, J., Revenga, C., Kennedy, E.T., Naeem, S., Alkemade, R., Allnutt, T., Bakarr, M., Bond, W., Chanson, J., Cox, N., Fonseca, G., Hilton- Taylor, C., Loucks, C., Rodrigues, A., Sechrest, W., Stattersfield, A.J., van Rensburg, B. y Whiteman, C. (2005). "Biodiversity". En: Millennium Ecosystem Assessment: Current State and Trends: Findings of the Condition and Trends Working Group. Ecosystems and Human Well-Being. Washington DC: Island Press. 
Maginnis, S. y Jackson, W. (2002). Restoring Forest Landscapes: Forest Landscape Restoration Aims to Re-Establish Ecological Integrity and Enhanced Human Well-Being in Degraded Forest Landscapes. Gland, Suiza: UICN.

Naumann, S., Kaphengst, T., McFarland, K. y Stadler, J. (2014). Nature-Based Approaches for Climate Change Mitigation and Adaptation. Bonn, Alemania: Agencia Federal Alemana para la Conservación de la Naturaleza.

Objetivos de Desarrollo Sostenible (2015). Temas 15 y 116 del programa del septuagésimo período de sesiones de la Asamblea General de las Naciones Unidas: Transformar nuestro mundo: la Agenda 2030 para el Desarrollo Sostenible. A/RES/70/1.

Oliver, T.H., Heard, M.S, Isaac, N.J.B., Roy, D.B., Procter, D., Eigenbrod, F., Freckleton, R., Hector, A., Orme, D.L., Petchey, O.L., Proença, V., Raffaelli, D., Suttle, K.B., Mace, G.M., Martín- López, B., Woodcock, B.A. y Bullock, J.M. (2015a.) Biodiversity and Resilience of Ecosystem Functions. Trends in Ecology \& Evolution 30(11): 673-684. https://doi. org/10.1016/j. tree.2015.08.009

Oliver, T.H., Isaac, N.J.B., August, T.A., Woodcock, B.A., Roy, D.B. y Bullock, J.M. (2015b). "Declining Resilience of Ecosystem Functions under Biodiversity Loss". Nature Communications 6: 10122. https://doi. org/10.1038/ncomms 10122

Orgiazzi, A., Bardgett, R.D., Barrios, E., BehanPelletier, V., Briones, M.J.I., Chotte, J.-L., De Deyn, G.B., Eggleton, P., Fierer, N., Fraser, T., Hedlund, K., Jeffery, S., Johnson, N.C., Kandler, E., Kaneko, N., Lavelle, P., Lomanceau, P., Miko, L., Montanarella, L., Moreira, F.M.S., Ramirez, K.S., Scheu, S., Singh, B.K., Six, J., Van der Putton, W.H. y Wall, D.H. (2016). Global Soil Biodiversity Atlas. Luxemburgo: publicaciones de la Comisión Europea, Oficina de la Unión Europea.

Pressey, R.L., Cabeza, M., Watts, M.E., Cowling, R.M. y Wilson, K.A. (2007). "Conservation planning in a changing world". Trends in Ecology \& Evolution. 22: 583-592. doi: 10.1016/j.tree.2007.10.001

Pringle, C.M. (2001). "Hydrological Connectivity and the Management of Biological Reserves: A Global Perspective". Ecological Applications. 11(4): 981-998. https://doi.org/10.1890/10510761(2001)011[0981:HCATMO]2.0.CO;2

Reusch, T.B.H., Ehlers, A., Hammerli, A. y Worm, B. (2005). "Ecosystem Recovery after Climatic Extremes Enhanced by Genotypic Diversity". Proceedings of the National Academy of Sciences of the United States of America 102: 2826. https:// doi.org/10.1073/pnas.0500008102

Reynolds, L.K., McGlathery, K.J. y Waycott, M. (2012). "Genetic Diversity Enhances Restoration Success by Augmenting Ecosystem Services". PLOS ONE 7(6): e38897. https://doi.org/10.1371/ journal.pone.0038397
Rietbergen-McCracken, J., Maginnis, S. y Sarre, A. (eds.) (2007). The Forest Landscape Restoration Handbook. Londres: Earthscan.

Secretaría del Convenio sobre la Diversidad Biológica (2010). Linking Biodiversity Conservation and Poverty Alleviation: A State of Knowledge Review. CBD Technical Series No. 55.

Secretaría del Convenio sobre la Diversidad Biológica (2013). Water and Biodiversity: Natural Solutions for Water Security. Montreal, Canadá.

Sunderland, T.C.H. (2011). "Food Security: Why is Biodiversity Important?" International Forestry Review 13(3): 265-274. https://doi. org/10.1505/146554811798293908

Tanveer, M., Anjum, S.A., Hussain, S., Cerda, A. y Ashraf, U. (2017). "Relay Cropping as a Sustainable Approach: Problems and Opportunities for Sustainable Crop Production". Environmental Science and Pollution Research 24(8): 6973-6988. https://doi.org/10.1007/s11356-017-8371-4

The KBA Partnership (2018). Guidelines on Business and KBAs: Managing Risk to Biodiversity. Gland: UICN. 24 pp., 2018. https://doi.org/10.2305/ IUCN. CH.2018.05.en

Thomas, C.D., Cameron, A., Green, R.E., Bakkenes, M., Beaumont, L.J., Collingham, Y.C., Erasmus, B.F., De Sigueira, M.F., Grainger, A., Hannah, L., Hughes, L., Huntley, B., Van Jaarsveld, A.S., Midgley, G.F., Miles, L, Ortega-Huerta, M.A., Peterson, A.T., Phillips, O.L. y Williams, S.E. (2004). "Extinction Risk from Climate Change". Nature 427(6970): 145-148. https://doi. org/10.1038/nature02121

UICN (2017). Lista Roja de Especies Amenazadas de la UICN. Versión 2017-1. http://www.iucnredlist.org. Consultada el 12 de mayo de 2017.

UICN y WRI (2014). Guía sobre la metodología de evaluación de oportunidades de restauración: evaluación de las oportunidades de restauración del paisaje forestal a nivel nacional o subnacional. Documento de trabajo. Gland, Suiza: UICN.

UICN/CSE (2013). Guidelines for Reintroductions and Other Conservation Translocations. Version 1.0. Gland, Suiza: UICN.

Urzedo, D., Vidal, E., Sills, E., Pina-Rodrigues, F. y Junqueira, R. (2016). "Tropical Forest Seeds in the Household Economy:" "Effects of Market Participation among Three Sociocultural Groups in the Upper Xingu Region of the Brazilian Amazon". Environmental Conservation 43(1): 13-23. https://doi.org/10.1017/S0376892915000247

Vayreda, J., Martinez-Vilalta, J., Gracia, M. y Rotana, J. (2012). "Recent Climate Changes Interact with Stand Structure and Management to Determine Changes in Tree Carbon Stocks in Spanish Forests". Global Change Biology 18: 1028-1041. https://doi.org/10.1111/j.13652486.2011.02606.x 
Vernooy, R., Bessette, G., Rudebjer, P. y Otieno, G. (eds.) (2016). "Resource box for resilient seed systems: handbook". Bioversity International, Roma, Italia.

Walker, B., Salt, D. y Reid, W. (2006). Resilience Thinking: Sustaining People and Ecosystems in a Changing World. Washington DC: Island Press.

Waller, N.L., Gynther, I.C., Freeman, A.B., Lavery, T.H. y Leung, L.K.-P. (2013). "The Bramble Cay Melomys Melomys rubicola (Rodentia: Muridae): A First Mammalian Extinction Caused by HumanInduced Climate Change?" Wildlife Research 44(1): 9-21. https://doi.org/10.1071/WR16157
Wetzel, F.T., Boissmann, H., Penn, D.J. y Jotz, W. (2013). "Vulnerability of Terrestrial Island Vertebrates to Projected Sea Level Rise". Global Change Biology 19: 2058-2070. https://doi. org/10.1111/gcb.12185

Wunder, S., Angelsen, A. y Belcher, B. (2014). "Forests, Livelihoods, and Conservation: Broadening the Empirical Base". World Development 64 (Supplement 1): S1-S11. https:// doi.org/10.1016/j.worlddev.2014.03.007

Young, T.P. (2000). "Restoration Ecology and Conservation Biology". Biological Conservation 92: 73-83. https://doi.org/10.1016/S00063207(99)00057-9 


\section{Anexo 1 Elementos de una ENBPA}

Las estrategias nacionales sobre la biodiversidad y planes de acción están repletos de información muy útil para las evaluaciones de las oportunidades de restauración de paisajes forestales, y contienen buena parte de la información necesaria para garantizar una correcta alineación de la FLR con los compromisos nacionales contraídos en el marco del Convenio sobre la Diversidad Biológica. Es importante destacar que las estrategias nacionales sobre la biodiversidad y planes de acción tienen una estructura coherente, que permite localizar con relativa facilidad esta información; la mayoría de los países ha utilizado esta estructura para definir metas nacionales representativas que les ayuden a lograr los objetivos de biodiversidad definidos en el CDB.

Las estrategias nacionales sobre la biodiversidad y planes de acción suelen incluir auditorías del estado y la tendencia de la biodiversidad nacional. Por lo general, dichas auditorías van dirigidas a conocer el estado de conservación de las especies que suscitan preocupación (según se define en la Lista Roja de Especies Amenazadas de la UICN o en las Listas Rojas Nacionales) y las tendencias en la cobertura geográfica de las zonas protegidas. Las descripciones de estos parámetros relacionados con la biodiversidad constituyen la base de referencia para evaluar las estrategias de conservación de la biodiversidad, y también el fundamento de buena parte de la información que presentan los países al CDB.

Además, las estrategias nacionales sobre la biodiversidad y planes de acción contienen una gran cantidad de información sobre la legislación nacional que regula la biodiversidad. En muchos casos, esta legislación pertenece al ámbito del establecimiento y mantenimiento de las zonas protegidas y de las actividades de conservación de la fauna y flora silvestres, aunque cada vez más incluye aplicaciones legislativas más amplias de la biodiversidad en sectores en los que esta puede no constituir un objetivo primordial, pero que dependan de ella (por ejemplo, la agricultura).

Junto con la información sobre estrategias para financiar la ejecución de estos planes de acción, las estrategias nacionales sobre la biodiversidad y planes de acción proporcionan la información que se necesita para traducir las evaluaciones de la biodiversidad a escala nacional en estrategias cuantificables y viables para la conservación de la biodiversidad en apoyo a la misión del CDB.

\section{Alianza Sobre Indicadores de Biodiversidad https://www.bipindicators.net/}

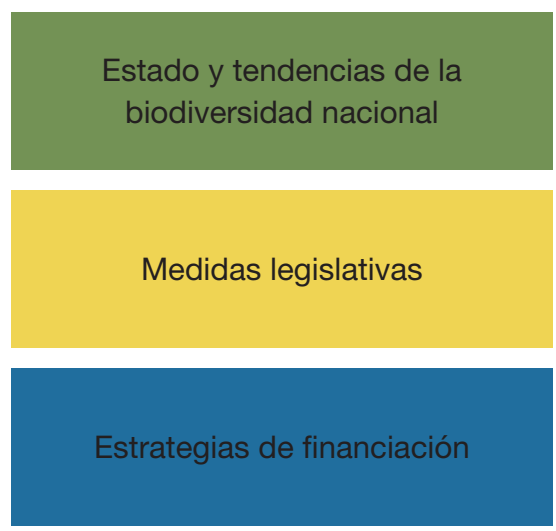

CDB, estrategias nacionales sobre la biodiversidad y planes de acción https://www.cbd.int/nbsap/

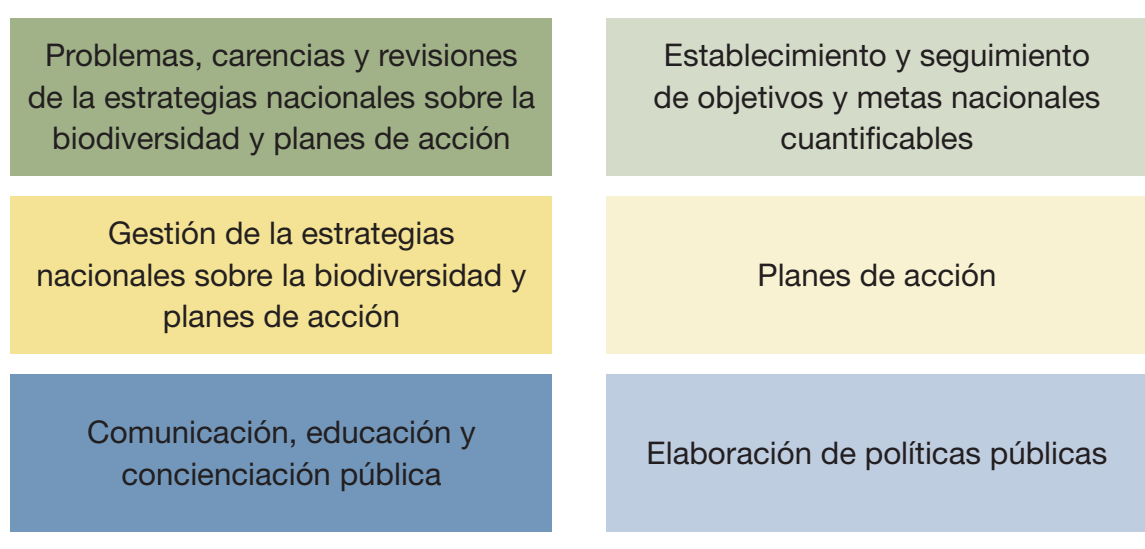

Adaptado de: The Biodiversity Planning Process: How to Prepare and Update a National Biodiversity Strategy and Action Plan (CDB, 2007) 


\section{Descripción indicativa de una estrategia nacional sobre la}

\section{biodiversidad y plan de acción}

I. INTRODUCCIÓN

1. Valores de la biodiversidad y de los servicios ecosistémicos presentes en el país y su contribución al bienestar humano

2. Causas y consecuencias de la pérdida de biodiversidad

3. Marco constitucional, jurídico e institucional

4. Lecciones extraídas de anteriores estrategias estrategia nacional sobre la biodiversidad y plan de acción y proceso de elaboración de una estrategia o plan de acción actualizado

II. ESTRATEGIA NACIONAL DE FOMENTO DE LA BIODIVERSIDAD:

PRINCIPIOS, PRIORIDADES Y METAS

5. Visión a largo plazo

6. Principios rectores de la estrategia

7. Principales objetivos o áreas prioritarias

8. Metas nacionales

III. PLAN DE ACCIÓN NACIONAL

9. Actuaciones nacionales dirigidas a aplicar la estrategia (incluyendo hitos)

10. Aplicación de la estrategia nacionalesobre la biodiversidad y plan de acción a entidades subnacionales

11. Intervención sectorial

IV. PLANES DE EJECUCIÓN

12. Plan de desarrollo de capacidades para la ejecución de la estrategia nacionalesobre la biodiversidad y plan de acción, incluida una evaluación de necesidades tecnológicas

13. Estrategia de comunicación y difusión para la estrategia o plan de acción nacional en materia de biodiversidad

14. Plan de movilización de recursos para la ejecución de la estrategia nacionalesobre la biodiversidad y plan de acción

15. Aspectos institucionales, seguimiento y presentación de informes

16. Estructuras de coordinación nacionales

17. Mecanismo de intercambio de información

V. SEGUIMIENTO Y EVALUACIÓN

*Adaptado de CBD. NBSAP, paquete de recursos de capacitación, versión 2.1 . 



\section{UICN}

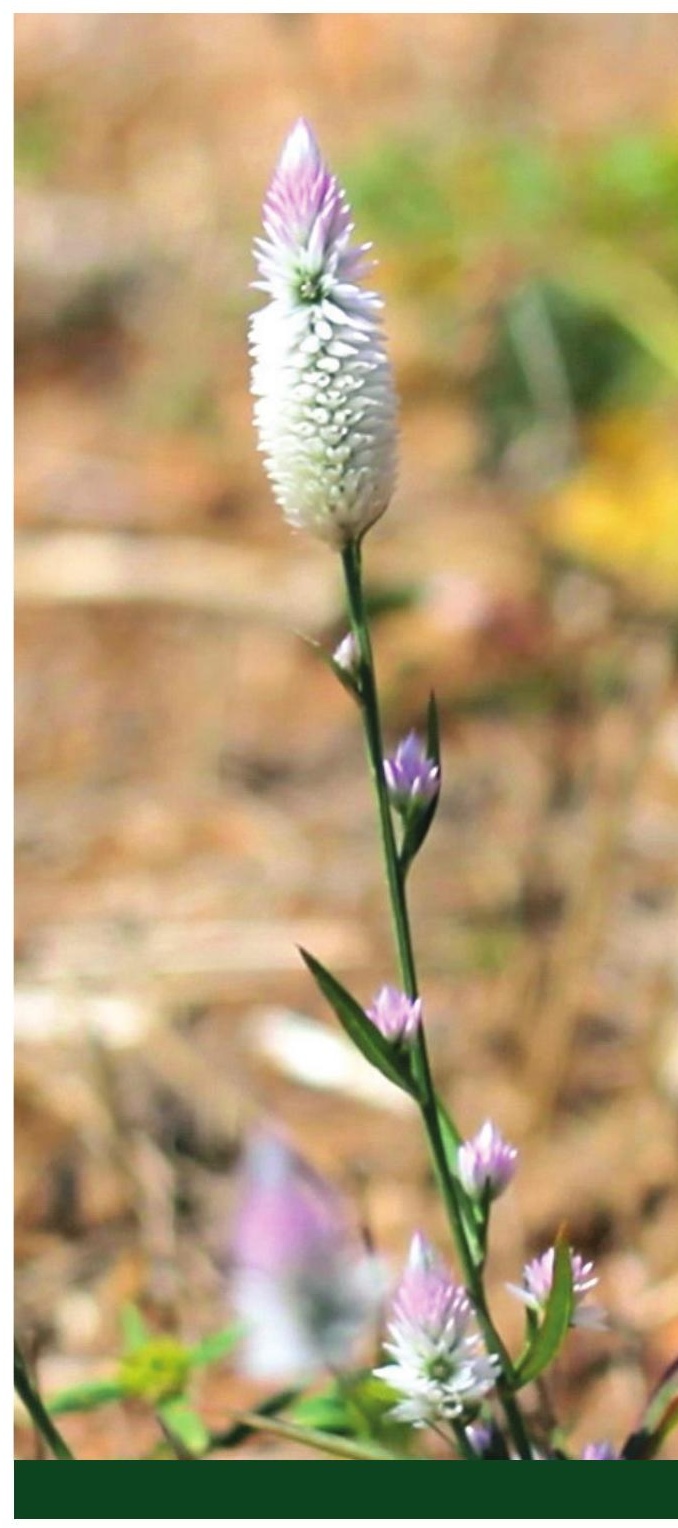

UNIÓN INTERNACIONAL

PARA LA CONSERVACIÓN DE LA NATURALEZA

SEDE MUNDIAL

Rue Mauverney 28

1196 Gland, Suiza

Tel.: +41 229990000

Fax: +41229990002

https://www.iucn.org/es 